\title{
EUROPA XXI
}

\author{
18 \\ TERRITORIAL DILEMMAS OF SOCIO-ECONOMIC \\ DEVELOPMENT IN EUROPE
}


VOLUME REVIEWED BY:

Annegret Haase and Mirosław Grochowski

VOLUME CO-FINANCED BY:

Ministry of Science and Higher Education

\author{
EDITORIAL OFFICE: \\ Insitute of Geography and Spatial Organization, PAS \\ 00-818 Warszawa \\ ul. Twarda $51 / 55$ \\ tel. (48-22) 6978851 \\ fax (48-22) 6202221 \\ www.igipz.pan.pl \\ e-mail: t.komorn@twarda.pan.pl
}

\title{
PREPARED FOR PRINT BY:
}

GEDGRAFIKA.PL

Sebastian Borkowski Jacek Majerczak

PRINTED IN:

Drukarnia Klimiuk

ul. Foksal 11

00-372 Warszawa

(C) Copyright by Stanisław Leszczycki Institute of Geography and Spatial Organization, PAS

Warszawa 2008

ISSN 1429-7132 


\section{CONTENTS}

TOMASZ KOMORNICKI — Editorial

MICHAEL MURRAY, DAVID HOUSTON, STEPHEN MCKAY, VALÉRY MICHAUX, CATHERINE NIARCHOS, FABRICE THURIOT — Rescaling territorial development: The 'pays' in France and Belgium

MICHAEL WEGENER - Competitiveness or cohesion? A phase strategy of European spatial development

PIOTR KORCELLI - Scenarios on the territorial future of Europe: a commentary and further implications

EWA KORCELLI-OLEJNICZAK - Research on metropolitan functions: jdentification and definitions according to the ESPON and alternative approaches

TOMASZ KOMORNICKI - ESPON 1.2.1 results and the future of Polish transport infrastructure

MARIUSZ KOWALSKI, JERZY SOLON — Ethnical diversity and regional development of eastern borderland regions in Poland, Lithuania and Latvia

GÁBOR NAGY - Regional inequalities in a transitioning country (Hungary) - Does HDI a useful tool for measuring?

SVITLANA PYSARENKO - Report on Ukrainian regional policy.

The main trends of regional policy formation in conditions of realization Ukrainian Euro-integration strategy 
BCl@PAN http://bibliotekacyfrowa.pan.pl 


\section{EDITORIAL}

Since the time of drawing up the European Spatial Development Perspective (ESDP) in 1999, a territorial dimension of the EU's cohesion policy has been systematically gaining in importance. This resulted, inter alia, in establishing the ESPON Program, within the framework of which a number of thematic projects were carried out, depicting regional diversification of Europe in respect of spatial development, as well as of assumptions and effects of territorial policy. A particular intensification of political efforts and research studies coincided with the time of accession of the new member states into the European Union. Then the socio-economic cohesion of the integrated Europe, as understood traditionally, abruptly decreased, and the territorial dilemmas of socio-economic development became more evident. These very problems are addressed in the current, now eighteenth, issue of Europe XXI.

Prospects of reconciling the goals of cohesion and competitiveness, in the context of the EU enlargement are dealt with by M. Wegener. The author puts forward a thesis that pursuing the cohesion goals should lead to a greater internal polarization within the new EU member states. He asserts also that cohesion-oriented efforts must inevitably bring on reducing the competitiveness of accession states at the EU level. An empirical illustration of these considerations is a paper by G. Nagy, who made use of Human Development Index to assess the dynamics of spatial diversifications to be observed in Hungary. A conclusion arrived at in the article is worthy of mention: namely that diversifications in terms of HDI are much lower than these measured by purely economic indexes (GDP).

A sizeable part of the featured articles touches on the research studies carried out within the framework of the first edition of ESPON Program that offered a critical evaluation of the conclusions and policy recommendation presented in the reports referring to the new EU member states. The article by P. Korcelli directly deals with ESPON 3.2 project dedicated to possible scenarios of Europe development. It provides a critical evaluation of the presented base scenarios (competitiveness and cohesion). Subsequent papers tackle the actual final reports and concern themselves with research studies on metropolitan functions (E. Korcelli-Olejniczak, ESPON 1.1.1 and ESPON 1.4.3) as well as with the future of Polish transport infrastructure (T. Komornicki, ESPON 1.2.1). Results of a number of ESPON projects also refer to a discussion over the future of territorial governance and spatial planning in Europe. These underscore, inter alia, the significance of multi-level governance. The issue of the new levels of spatial governance is a subject of the paper by M. Murray et al, who provided an example of new alliances for territorial development at the meso-spatial scale of the 'Pays' in France and Belgium.

Dilemmas concerning spatial policy are directly linked to the future of the European Union eastern border. According to all scenarios drawn up in the ESPON 3.2 Project (see the paper by P. Korcelli), Polish eastern border is to remain also the eastern border 
of the EU over the next 25 years. Even the scenario of competitiveness does not expect Ukraine to be integrated into the European Union. For that reason, among other things, it was thought appropriate to include the paper by S. Pysarenko concerning the shaping of the Ukrainian regional policy in the context of European experience. It is a sort of report providing insight into the barriers hampering spatial development of Ukraine (among others, increasing considerable interregional disparities). The subject matter relating to eastern frontiers of the EU is also brought up by M. Kowalski and J. Solon in the paper dealing with ethnical diversification of the eastern borderland between Poland, Lithuania and Latvia. Inter alia, the authors point to the opportunities and threats associated with cultural diversification of these areas.

Debate over spatial development and territorial cohesion of Europe is now becoming increasingly widespread. It is the Europe XXI Editorial Team's intention for the opinions and the results of research studies presented in the current issue to contribute to that discussion. The theses worthy of particular highlighting in that context are these pointing to the need of preparing a document being a successor of the present ESDP, differentiating goals of regional policy within the old and new EU member states (M. Wegener). Also, it is important now to make more detailed ESPON studies, since, in the initial stage of the project, there was only a little participation of specialists from the accession countries. Thus, serious mistakes could be avoided, especially in the process of formulating scenarios (P. Korcelli) and policy recommendations (T. Komornicki). Undoubtedly, dilemmas relating to cohesion and competitiveness ought to be looked at from a broader geographical perspective, which would allow for a more appropriate evaluation of the scale of growing disparities (e.g. compared to the countries kept out from integration processes - cf. S. Pysarenko).

Tomasz Komornicki 


\title{
RESCALING TERRITORIAL DEVELOPMENT: THE 'PAYS' IN FRANCE AND BELGIUM
}

\author{
MICHAEL MURRAY DAVID HOUSTON STEPHEN MCKAY \\ Queen's University Belfast \\ University Road, Belfast, BT7, 1 NN, Northern Ireland, United Kingdom \\ e-mail: m.r.murray@qub.ac.uk d.houston@qub.ac.uk s.mckay@qub.ac.uk
}

\author{
VALÉRY MICHAUX \\ Reims Management School \\ 59 rue Pierre Taittinger B.P. 30251 061, Reims, France \\ e-mail: valery.michaux@reims-ms.fr \\ CATHERINE NIARCHOS \\ Université Libre de Bruxelles \\ Avenue Adolphe Buyl 87, 1050 Ixelles, Belgium \\ e-mail: catherine.niarchou@ulb.ac.be \\ FABRICE THURIOT \\ Université de Reims \\ 23, rue Clèment Ader, 51100 Reims, France \\ e-mail: fabrice.thuriot@univ-reims.fr
}

\begin{abstract}
This paper gives consideration to the formation and initial operation of new alliances for territorial development at the meso spatial scale of the 'Pays' in France and Belgium (case study experiences from the Champagne-Ardenne region and Wallonia). It explores the contribution of 'Pays' as new scale action spaces, in which to engage elected representatives, civil society, the private sector and public officials in a constructive planning dialogue around locally determined development trajectories. The paper concludes with a critical assessment of the 'Pays' approach as a meaningful contribution to rescaling territorial development at the meso scale with particular reference to concerns around the interaction between strategic planning and multiple governance stakeholders.
\end{abstract}

Key words: 'Pays', territorial development dynamics and cohesion, territorial and multi-level governance, civil society 


\section{INTRODUCTION}

Over the past decade, there has been considerable momentum in the re-framing of European space at multiple scales through a combination of supra-national policy integration, enlargement, devolution, and regionalisation. This paper gives consideration to the formation and initial operation of new alliances for territorial development at the meso-spatial scale of the 'Pays' in France and Belgium. It explores the contribution of 'Pays' as new scale action spaces in which to engage elected representatives, civil society, the private sector and public officials in a constructive planning dialogue around locally determined development trajectories. Following this introduction, the second section of the paper highlights the contribution of two important dynamics that are endeavouring to support scale formation: strategic territorial planning and multi level governance. We then deal with the emergence and governance arena of the 'Pays' in France and present two case study experiences from the Champagne-Ardenne region. In the next section of the paper we consider the 'Pays' approach to territorial development in Belgium by drawing on the insights gained from two case studies in Wallonia (Figure 1). The paper concludes with a critical assessment of the 'Pays' approach as a meaningful contribution to rescaling territorial development at the meso-scale with particular reference to concerns around the interaction between strategic planning and multiple governance stakeholders.

\section{TERRITORIAL DEVELOPMENT DYNAMICS}

The rescaling of territorial development brings into play two important dynamics that help shape spatial outcomes: (i) strategic territorial planning, which is concerned with the harnessing of economic, social, environmental and cultural assets for indigenous development; and (ii) multi-level governance which recognises the value of collaboration across different levels of institutional and organisational responsibility.

Strategic territorial planning, expressed simply, is a structured way to analyse a local situation and map the way forward. It is a process that looks forward over a number of years, and which seeks to incorporate economic, social, cultural and environmental challenges into a coherent framework. It is a response to the frequent occurrence that treats decisions independently regarding different types of land use (e.g. housing, business, recreation), infrastructure (e.g. transportation, energy), and natural environments (e.g. areas of scientific value, coastal zones, areas of landscape excellence). Traditionally each of these themes has its particular objectives, policies and action plan. In contrast, strategic territorial planning is a collective and participatory process that seeks, through shared processes of reflection, to move towards closer integration.

But strategic territorial planning is also strongly related to different multi-level governance challenges. There are two axes of engagement here. First, there 
is a vertical governance challenge which must deal with the cooperation, coordination and collaboration activities between local, sub-regional, regional and national actors and which require a mix of top-down and bottom-up approaches in order to get close to citizen needs. Second, there is a double horizontal governance challenge that must deal with the cross-over between sectors (e.g. social inclusion, accessibility, spatial planning and economic development), and the cross-over between different types of actors (i.e. public bodies, the associational sector and the private sector). There are important research questions that revolve around how it is possible to break down the many vertical and horizontal barriers between sectors and actors, to develop real capacities for mutual engagement among stakeholders, and to understand which type of governance arrangements work best under which conditions.

In this regard, strategic territorial planning and multi-level governance are inextricably linked to an overarching European quest for territorial cohesion. Again, this is a concept that plays out at multiple scales, from the transnational to the subregional. Its attributes have been succinctly outlined by Healey (2002):

- A concern with the way that spatial and environmental linkages (across both the rural and the urban), economic linkages, social linkages, and cultural linkages combine a capacity to support each other within a territory with a capacity to embrace external connections. In other words, there is attention given to internal and external relationships within spatial settings at different scales: local, regional, national and transnational.

- An emphasis which is, arguably, less on the amount of development in a place, but more on the overall web of relations within which institutions, enterprises and people in one place are linked to institutions, enterprises and people in other places. This emphasis is directly on governance.

- Attempts to make public policy, wherever it is formulated, more integrated as it plays out in particular territories. These efforts support the need for strategic interventions.

Davoudi (2005) has taken this synthesis further forward by linking an understanding of territorial cohesion with express support for social equity. The added geographical dimension here is that "the quality of places where people live and work can influence their access to economic and social opportunities and the quality of their life" (p. 436). In short, the concept of territorial cohesion has at its core the spatial dimensions of economic, social, cultural and environmental development; it confirms the importance of relationships associated with multi-level governance arenas in which to promote and manage change; and it underlines the need to think and plan strategically within a spatial context. This is a complex alchemy and when charged with combining efficiency and equality, territorial cohesion, as noted by Schön (2005), aims to strengthen endogenous potential in territories so as to overcome the imbalances (and the disconnections) between territories. The rescaling of territorial development in France and Belgium, through the creation of 'Pays', 
offers a useful lens through, which to explore the potential contribution of a new public administration arena to territorial cohesion.

The analysis below draws on the activities undertaken during a transnational and interdisciplinary research project titled Strategic Planning Action Network (SPAN). This involved four regions within four EU member states: Northern Ireland (United Kingdom), Greater Dublin (Ireland), Wallonia (Belgium) and Champagne-Ardenne (France). In each region a local development organisation joined with a university partner to explore the potential and limits of civil society participation in spatial planning and development at local, sub-regional and regional scales. Within Northern Ireland the partnership involved the Institute of Spatial and Environmental Planning at Queen's University Belfast and Rural Community Network. The partners in Ireland were National University of Ireland Maynooth and Southside Partnership, in Belgium they comprised Universite Libre de Bruxelles and Fondation Rurale de Wallonie, and in France they were Universite de Reims and Reims Management School. The project was funded under the EU INTERREG 111B North West Europe Programme with an overall budget over the period 2003-2008 of some €4.8million. This paper deals with part of the action research undertaken in Champagne-Ardenne and Wallonia and it draws on a combination of secondary data analysis of planning documentation and animation work in-the-field with 'Pays' stakeholders.

\section{THE 'PAYS' IN FRANCE}

\section{EMERGENCE}

France has a complex multi-layered system of public administration extending downwards from the state, the regions and departments, to the basic unit of the commune. There are 36,782 communes in the country, some 87 per cent of which have fewer than 2,000 people. Foundation legislation dating from 1992, that culminated in the Chevènement Act of 1999, has provided for new forms of municipality cooperation. In order to achieve economies of scale in service provision, communes have created formal alliances that are referred to as 'communities of communes' in rural areas and towns, and 'communities of agglomeration' in urban areas. As noted by Negrier (2006) these reforms stimulating cooperation amount to an expression of the political impossibility of securing municipal mergers. The capacity for ambitious politicians to accumulate elective offices in higher levels of authority from local power bases (cumul des mandats) linked to a belief in constituency proximity, democratic empowerment, citizenship, and local self reliance (Cole 2006) have contributed to this mix of institutional rigidity and interdependence.

The 'Pays' approach is designed to deepen the scope for local cooperation and followed on from primary legislation in February 1995 and the subsequent planning-related "Voynet" Act in June 1999 that re-introduced a framework for territorial cohesion. The 'Pays' approach actually dates back to the 1970s but it was for rural 
areas only. This more recent manifestation has facilitated a new and voluntary governance dynamic at the local level by replacing a sectoral and diffuse administrative configuration, with a customised, common and cross-sectoral territorial strategy at a coherent geographical scale. A key concern is sustainable development reflecting the high level political patronage of former Government Minister, Dominique Voynet, and her connection with Les Verts party. The 'Pays' are not, however, part of the formal national spatial planning system. They are unevenly adopted across France with progress having been most rapid in the west and within rural areas due to the presence of larger populations and a greater commitment from these mainly rural citizens to the community association values that are deeply rooted in their Catholicism tradition.

However, a 'Pays' is neither a local community, nor an authority, but rather an interface for inter-municipal and inter-territorial cooperation between urban and rural areas. It works through a forward-looking dialogue-based planning process that is concerned with long-range development and seeks to involve public bodies, elected representatives and civil society in reaching agreement. In each 'Pays', a broad based civil society makes up an advisory Development Council with (or without) elected representatives to assist with 'Pays' planning and implementation activities. This is a deliberative forum and it does not have authority to make policy decisions. Within France, in 2007 there are some 320 'Pays' with an average population in each instance of 70,000 people (ETD 2005).

The 'Pays' manifests itself by two key outputs: a 'Pays Charter' setting out a 10 year spatial development strategy shared by the partners involved in its preparation; and a 'Pays Contract' comprising a maximum, but possibly renewed, 3-year action programme to implement that Charter (Cluniat et al, 2006). What is important is that the 'Pays', in the main, is not a delivery organisation, but rather a mechanism to foster coherent territorial development. Operational responsibilities remain for the most part with the local public administration bodies of the communes, communities of communes and communities of agglomeration. This sweep of activity is in line with observations on French rural policy making by Buller (2003) that "include a new emphasis upon horizontal rural territories, upon political decentralization, upon développement local rather than aménagement du territoire, upon new contractual forms of spatial management and upon agricultural multi-functionality rather than the primacy of productivisme" (p.324). In this regard, the budget of each 'Pays' comes from the State, the Region, and on occasion from the Département or the EU and while the local tax base is exclusively for the constituent communes and groups of communes, each 'Pays' can take advantage of the revenue creation potential of its public entities in order to facilitate the negotiation of project-related synergies.

Across France, 'Pays' territories adopt widely differing methods of organization. There is no single model, but rather an individual approach for each territory that is contingent on its history, its spatial configuration, and the legitimacy and spiritedness 
of the local stakeholders. The flexibility of the legislative provisions has enabled each territory to apply the 'Pays' process in its own way and thus to establish customized forms of territorial governance. Nonetheless, it is possible to identify some crosscutting key characteristics:

- Each 'Pays' is not an additional local authority structure and does not deprive any public body of its competences. This is why the different local entities wishing to collaborate with each other are obliged to set up a specific collective mechanism to enable them to discuss, negotiate and manage complex bargaining processes that will realize a consensus or at least acceptable compromises on the way forward. These trans-municipal governance dimensions are manifested in the 'Pays' Charter and Contract.

- Local entities involved in a 'Pays' are legally obliged to form a Development Council, but are given considerable flexibility regarding its composition. Accordingly, Development Councils differ widely in their size and make-up. They may involve, for example, the general public, people from official representation structures, economic — social—cultural stakeholders, associations and local elected representatives. The legislation requires that a Development Council must take part in the drawing up of the 'Pays' Charter and that it must be involved in examining and choosing the main strategic directions for the decade ahead. However, apart from these obligations, the role and influence of Development Councils does vary, not least

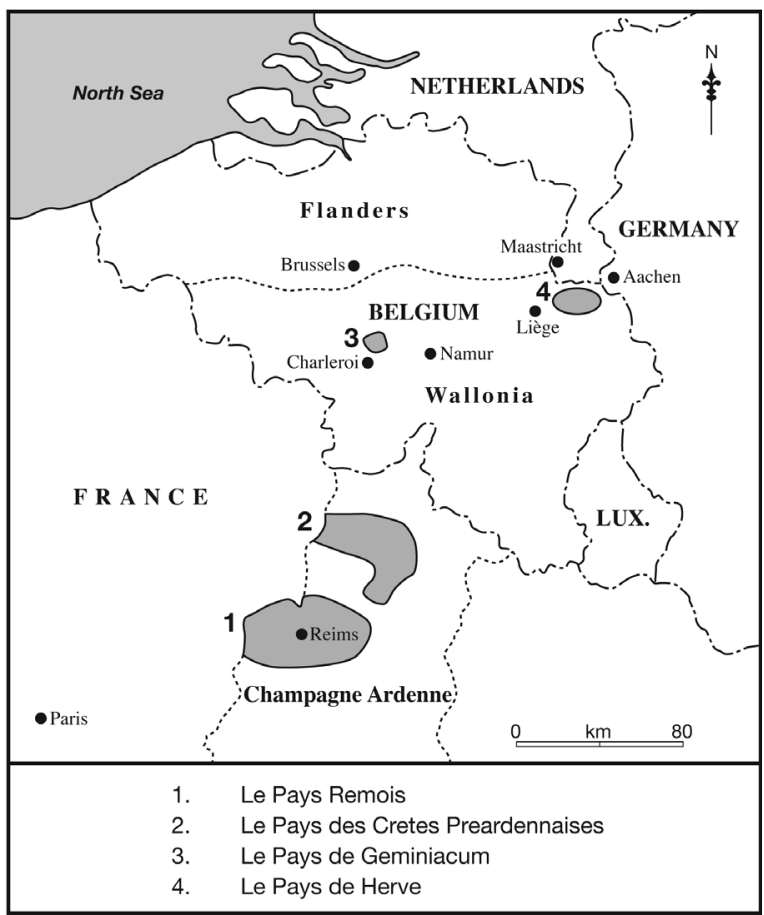

Figure 1. The 'Pays' case studies in France and Belgium 
because civil society involvement in territorial development and in the affairs of political decision-making is not a traditional feature of public administration in France.

\section{LE PAYS RÉMOIS}

The Pays Rémois within the Champagne-Ardenne region in north-east France contains 134 communes in the rural areas surrounding Reims that make up 16 'communities of communes' comprising 74,000 people ${ }^{1}$. The six urban communes of the 'community of agglomeration' of Reims total 214,000 people ${ }^{2}$ and are situated within the core of the 'pays'. A major development issue is that the physical expansion of the city of Reims is constrained because of the surrounding high quality agricultural and vine growing land. A sharp urban-rural land use divide translates in turn into a distinct cultural, and often tension filled, separation between urban and rural elected representatives ${ }^{3}$.

The 'Pays' approach was initially promoted in 2001 by city politicians, but secured a consensus with rural representatives on the need for collaboration at the end of 2002. The drawing-up of the Pays Charter gathered pace in 2003 with the establishment by the Syndicat Intercommunal d'Etudes et de Programmation de la Région Urbaine de Reims (SIEPRUR) of a 'Commission on Rurality' to give expression to local identity through high quality debates. SIEPRUR is the coordinating support association for the Pays Rémois territory in Champagne-Ardenne. Over a period of 18 months over 60 meetings were convened attended by more than 1,000 people to discuss 19 key topics of local concern including land management, housing construction, and physical infrastructure, not least the impact of an imminent high speed train link with Paris. This process of collective discussion resulted in the completion of the Pays Rémois Charter in 2004 and the agreement to go forward with a Pays Contract, which was co-signed by the intermunicipal structures in April 2005. These projects concern the rural area, while the urban area is covered by a complementary Agglomeration Contract. Each is co-financed by the Department and / or the Region and by the State, with the bulk of funding coming from the communes or groups of communes.

What makes this case study especially interesting was the need to get urban and rural elected representatives working together before engaging more fully with civil society. That early period denoted a successful phase of apprenticeship to mutual understanding and a subsequent rapprochement. SIEPRUR provided a necessary structuring role to galvanise that new urban-rural relationship within the territorial space of the 'Pays'. Thus was created an arena for collective decision-making that was independent of political tendencies as a replacement for competitive individual entity power and decision-making. But an underlying pragmatism to secure early funding for a project driven contract period was not an insignificant factor at play.

\footnotetext{
$<$ http://www.sieprur.fr/pays remois/index.php>

$2<$ http://www.reimsmetropole.fr/article.php?id article $=80>$

3 <http://www.aurr.asso.fr/DEVEL/AGENCE/territoires.php>
} 


\section{LE PAYS DES CRÊTES PRÉ-ARDENNAISES ${ }^{4}$}

Le Pays des Crętes Pré-ardennaises is centrally positioned within the Ardenne department and comprises 93 communes with a total population of just over 20,500 people. This is a contrasting territory of low population density, whose rurality is marked by declining agricultural employment and an increasing reliance on heritage and landscape quality to stimulate tourism development.

In this instance an intercommune association can be traced back to 1985 followed by the creation of the Communauté de Communes des Crętes Pré-ardennaises in 1996. The 'Pays' initiative for this equivalent territory was set in place by the Communauté de Communes in 2000 and again has involved a combination of politicians, representatives of economic sectors, and local citizens working together over an 18 months period to agree a 'Pays Charter'. A follow on action programme was defined by the civil society-led Development Council and subsequently validated by elected representatives.

Within this 'Pays' the securing of progress depended on working through the tensions between the Community Council of the Communauté de Communes and the Development Council for the 'Pays'. Each is concerned with initiating actions, with the shaping of strategic programming made more difficult by the often different priorities and interests of elected representatives and civil society. The fact that some elected representatives sat on both bodies provided a useful mediation link. But there cannot be complete power-sharing within this arena, not least because of differences in legal status. The Communauté de Communes is a public institution for cooperation across communes, while the Development Council has the status of a non profit organization. This horizontal organisational challenge was also configured against a vertical governance tension between individual communes and these supra community dimensions, with the legitimacy of the latter only accepted on the basis that local interests had been served.

In short, there is a power game being played out between the Communauté de Communes and the Development Council aimed, on the one hand, at moderating the requests of the latter and, on the other hand, at pushing the former to support initiatives that seem to be fair in the minds of the civil society participants. For example, major economic development investment and, more specifically, tourism related projects are being favoured by the Communauté de Communes, while the Development Council is predominantly concerned with advancing cultural, heritage and sustainable development. In this regard the Development Council has been extending its reach into local associations and informal groups to bring forward within the 'Pays' contract process a 'Pays' café festival, a 'Pays' days and heritage exhibition, and a plan for the interpretation of natural and cultural heritages

$4<$ http://www.cc-cretes-preardennaises.com > 


\section{THE 'PAYS' IN BELGIUM}

\section{EMERGENCE}

Belgium comprises a federal structure made up of the Federal state, the Language Communities, the Regions (Wallonia, Flanders, and the Brussels Capital Region), and the Provinces. Over the period since 1977 there has taken place the top down-directed merging of 2,739 municipalities into 589 larger scale municipalities or communes. Today there are 262 communes within Wallonia, 308 communes in Flanders, and 19 communes in Brussels. These exercise a strong municipal autonomy that is supervised by higher level authorities and hold responsibility for a wide range of public services that include community infrastructure, economic development, tourism, housing and cultural activities, as well as heritage management and town planning.

Although the Walloon Regional Spatial Development Plan (RSDP) recommends the creation of intercommunal areas of cooperation and development plans, and despite the fact, that many cities and communes voluntarily engaged in this process by creating 'Pays' and Urban Communities, the Walloon legislation in the field of Spatial Planning, Urban affairs and Heritage (Code Wallon de l'Aménagement du Territoire, de l'Ubanisme et du Patrimoine) makes no provision for such cooperation; in Article 2, it is stated that "Spatial Planning is organized using RSDP and Communal Structural Schemes".

In Wallonia citizen participation in public affairs and quality of life are stated policy goals of the regional government. This is underlined by the initiation of Wallonie 2020 in 2000 as a large scale participatory visioning process by the Walloon Government and the French-speaking Community and the subsequent adoption of a Contract by the Walloon Government in 2002 supporting the involvement of all Walloon citizens in the development of their region. It is within that context of local government reform and citizen engagement that the 'Pays' as a form of territorial experimentalism has emerged within Wallonia. Unlike the situation in France, there is no enabling legislation in Belgium for this form of governance and its emergence has been dependent on localised cooperation initiatives between communes, partnership between communes and civil society, or territorial alliances whereby civil society itself takes the lead.

\section{LE PAYS DE GEMINIACUM ${ }^{5}$}

Le Pays de Geminiacum is situated to the north of Charleroi on the east-west axis between Mons and Liège and emerged out of an EU LEADER 2 rural development project that created a non profit partnership organisation between two neighbouring communes concerned with tourism, local products and environment. The 'Pays' contains 12 villages with a population of some 25,000 people. The LEADER 2 local action group was, therefore, a significant catalyst in bridging the historic independence of this large number of pre-1977 municipalities, and also in engaging two new

$5<$ http://www.geminiacum.be> 
communes in cooperative action. During that period significant outputs included the completion of a local development plan and agreement on a local biodiversity contract. In the post LEADER 2 period the two communes agreed to constitute their areas as a 'Pays' to exploit a quality rural tourism resource within the area, not least a notable archaeology from Roman times when the Pays de Geminiacum was very much a 'land of passage'. A new strategic development plan was prepared and submitted under Leader+ but this was not selected for funding. The 'Pays' then gave emphasis to cultural identities and language (two key issues in its strategic plan) and a Pays Contract (Le Contrat de Culture) was subsequently agreed for implementation by the partnership with funding over the period 2002-2008 from the French Speaking Community and the two communes.

Essentially, therefore, the 'Pays' provides a territorial space in Wallonia for municipal cooperation and draws in private sector participation, including local producers, in a limited number of local development and quality of life activities through the operation of the non-profit organisation. Within only a few years, the 'Pays' has managed to bring together these different stakeholders who had never cooperated in the past and to involve them in a series of common projects. At the same time, the 'Pays' has forged a local identity to which the resident population subscribes.

Nonetheless, there are apparent political disconnections in the form of governance. For example, the 'Pays' emerged out of a LEADER 2 programme that was managed by the Walloon Region. Its current activities are focused on language and culture, but these are not regional government responsibilities. These rest with the French Speaking Community and thus the embeddeness of its activities in the spheres of local and environmental development, new information and communication technologies and tourism within the more powerful patronage of the Region is, at best, weak. There are also issues of development capacity in that the Pays de Geminiacum is probably too small in scale for strategic tourism promotion and investment and is constrained not only in this sphere, but also in other local development activities by the absence of any mandate to link with adjacent communes on common issues except on policing matters. The fact that the Pays de Geminiacum does not have a strategic alliance with its neighbouring inter-communal structures, such as Communauté de Charleroi, is further evidence of this territorial isolation. Finally, the Pays de Geminiacum, is caught in that relational space between two autonomous and relatively new municipalities, which raises issues of who decides on development priorities at the 'Pays' scale, how these decisions are arrived at, and put more bluntly, what is the precise role of the 'Pays' itself-a 'think tank', a strategic opportunity, a support structure for public and private sector stakeholders, or just another development tool. In short, key questions can be identified as to whether the current status of the Pays de Geminiacum represents a workable model of governance associated with a common territorial project at the intercommunal scale or is merely a grant grabbing artificial construct with short term legitimacy. 


\section{LE PAYS DE HERVE ${ }^{6}$}

Le Pays de Herve is recognised as 'the garden' of the three cities of Maastricht, Aachen, and Liège and commands a border location in Wallonia relative to the Netherlands and Germany. With a current and fast growing population of some 145,000 people, this is an accessible rural area in regard to business and housing development with inward investment from neighbouring countries being able to take advantage of lower land prices and excellent transportation corridors. It is a landscape of rolling hills, small towns and villages, but where the land use break between the built environment and the countryside is increasingly threatened in many places by ribbon development.

In late 1999 a citizen-led discussion commenced on the future of this territory leading to a formal colloquium in 2000 , that adopted a manifesto to manage change. The momentum continued into 2002 with the creation of 'Le Pays de Herve au Futur'-a non profit organisation with citizen membership. Over the intervening period it has sought to secure funding, without success, from the Walloon Region, the French Speaking Community, and local communes, but has been pressing on with its work to produce a Charter that will champion landscape conservation and lead to the establishment of a transjurisdictional natural park. Quite clearly, the 'Pays' organisation represents itself as an issues coalition concerned with moderating the perceived intense development pressures within this territory.

In this instance the key driver of the 'Pays' project is civil society with its efforts marked by no small amount of enthusiasm, sense of urgency and recognition of the need to link participatory democracy with elected representation. The language may therefore, be of trans-commune cooperation, but it is appreciated that the conservation objectives of 'Le Pays de Herve au Futur' may not coincide with the politically more prominent economic development priorities of the municipalities. Landscape has been appropriated as the single cross-cutting theme to engage the governance arena and a well attended event, that attracted local and regional politicians as well as senior officials, was convened in November 2006. However, while attempts have been made to expand the citizen initiative into a widely supported project, there is mounting appreciation that reflection and mobilisation are not sustainable without committed political patronage around funding, not least for the appointment of a local development agent to coordinate and sustain the dynamics of this landscape policy project.

\section{DISCUSSION}

Notwithstanding significant differences in the overarching institutional environment that the four 'Pays' discussed above find themselves in, there emerges a broadly comparable commitment to strategic territorial planning as these 'Pays' seek to rescale

$6<$ http://www.intelliterwal.net/Experiences/PaysDeHerve Questions-transversales.pdf> 
territorial development within the context of their multi-level governance arenas. The involvement of civil society to help define development issues and set policy trajectories is contingent, however, on a willingness for political experimentalism. Thus, the formal procedures in France provide for the establishment of Development Councils to work alongside local government structures within the territorial context of 'Pays' charters and contracts. In Belgium, the preferred model is a more loose thematic cooperation that is seeking to find a locus of activity within the interstices of political control at municipal, language community and regional levels.

Nonetheless, this re-scaling of the state through the creation of an additional territorial layer of public management in both jurisdictions raises the spectre of an even more complex institutional landscape that poses challenges for the effective delivery of strategic territorial planning and the operation of multi-level governance. In France, for example, it is possible to speculate about the permanency of the 'Pays' given that the existing institutional structure of the State is already extraordinarily dense (Departments, regions, communes, cantons, arondissements, communities of communes and communities of agglomeration). Sceptics may condemn 'Pays' to being nothing more than glorified talking-shops which can do little that is additional to what could be achieved within the pre-existing public administration framework. Indeed, as part of a wider process of decentralized public policy, without adequate funding, the impact of the 'Pays' may be more illusory than real. Moreover, their claim to advance the interests and participation of civil society could be perceived as sitting alongside the existing and adequate involvement and voice of civil society in numerous associations and Chambers of Commerce. And there are issues related to the maintaining of momentum whereby after an initial burst of formation and strategic planning activity the mechanism runs the risk of becoming relatively inactive and the territory of the 'Pays' remains a constellation of autonomous entities linked by a mainly financial interest. These are valid concerns and when situated beside the difficulties attached to concluding development contracts the lack of visibility of the 'Pays, at national and regional levels, their perceived remoteness from the private sector and an absence of wider recognition for their innovative methods of collective engagement at the local level (Lecamp 2005), they pose a powerful set of pressing issues for political leaders and civil society to address.

But in their defence, the intercommunality that is apparent from our four case studies highlights scope to develop new horizontal and vertical relationships that can enrich meso-scale planning and action above the individual commune and below the regional scales. The linkage with territory, environment and culture is noteworthy and in this regard the 'Pays' approaches to territorial development in both France and in the Wallonia region of Belgium are, at the very least, at an early stage in contributing to the full blown attributes of meso-scale territorial cohesion as outlined at the start of this paper. The Pays de Geminiacum, for example, is seeking to address difficulties in organizing its consultation process with institutions, enterprises and people because of its status as a non-profit body, obtaining steady, multi-annual 
funding for implementation of its development plan, and avoiding duplication by the communes in the fields of culture and tourism. In Le Pays des Crętes Pré-ardennaises, the linkages that are necessary for territorial development have been assembled with the longer term view in mind: agricultural producers and consumers have been brought together by the creation of "Goûts et Couleurs" (Tastes and Colours) in a monthly farmers' market; and new associations have been formed to nurture consultation among social partners, for example, by the "Pôle bois" (wood centre) and by the "Centre d'éveil au patrimoine" (heritage learning centre) (Lecamp 2005). From all this it can be concluded that giving attention to creating and maintaining a web of relations around participatory citizenry and elected representatives is crucial if the 'Pays' in France and Belgium are to become an established approach for framing territorial development. In this regard it becomes important that there is a willingness from a few participants from the civil society sector to take the participatory process of the 'Pays' to other players from civil society and to elected representatives and that theme based working groups continue to convene discussions on the implementation of practical projects.

The emphasis placed on bringing forward new configurations of territorial planning that seek to integrate the place based implications of environmental, social and economic development at the meso-scale is also significant because this effort extends beyond traditional commune boundaries. In Belgium the alignment of the 'Pays' to strong geographies of rural cultural and place-based identity provides a robust rationale for a form of territorial planning and development that seeks to complement municipal action. As such, the 'Pays' can be conceived as having a capacity to forge deeper connections to the region in Belgium (or to the state in France), by fostering and celebrating the relationship of citizens to their local cultural traditions and preferences (Moentmann 2003). The work of the Pays de Geminiacum in promoting its shared heritage product across the two municipalities with funding initially from the region and more latterly the French Speaking Community evidences that reality.

The 'Pays' experience described above thus hints at its boundary spanning potential to move beyond a narrow parochialism and to engage in more strategic spatial analyses. Geography, for example, has a significant contribution to make in this regard and as argued by Roche and Humeau (1999) the implementation of partnership geographic information systems projects can contribute to inter-municipal cooperation in regional governance. The scale of the 'Pays' can help overcome the financial inability to invest in geomatic systems at individual municipal levels and provide momentum towards more strategic dataset preparation and analysis. In the Pays Rémois the effort placed on facilitating closer urban-rural interdependence through the preparation of its Pays Charter signals a welcome recognition that the rural and the urban cannot be separately planned for. The experience evidences urban-rural interaction within a new urban-rural relationship that is facilitating win-win development outcomes. Similarly the 'Pays de Herve Futur' initiative has embraced a varying geometry for territorial planning that simultaneously recognizes its rela- 
tionship with firstly only four communes, secondly a much larger 17 communes area and thirdly its position at the heart of Euregio as the "Park of Three Boundaries".

It is also possible to speculate about the integration of this more global approach of the 'Pays', that is centered on meso-scale strategic planning and participative territorial governance, with a top-down territorial strategy for targeted projects within France and Wallonia, dealing, for example, in the case of the former with the promotion of des pôles d'excellence rurale (centres of rural excellence) or des pôles de compétitivité (centres of competitiveness) (Faure 2005; Epstein 2005, 2006; Némery 2006). There is a tension here between the operation of sustainable development processes across this level of territorial governance, and a territorial competitiveness agenda that facilitates selective economic development in only some areas to the detriment of others. While this form of territorial specialization into particular economic niches for immediate gain runs, the risk of obsolescence within a period of time it is more worrying that, in this pursuit of greater competitiveness and profit maximization, there is a disregard for local citizens and civil society associations being at the heart of the development process. The creative tensions that operate between Communities of Communes and Development Councils in France are a microcosm of this dilemma between pursuit of a dominant sectoral development approach and a more participatory and gradualist sustainable development approach. But at the very least the 'Pays' approach offers a relational space for mediation based on knowledge and dialogue.

In conclusion, it is this flexibility of inclusive spatial engagement that perhaps represents the single greatest asset of the 'Pays' model. Accordingly the public administration challenge, offered by the 'Pays', is more in line with the general comment by Smith (1997) on the matter of multi-level governance, which suggests that we need to temper our thoughts of political systems dominated by solely vertical or horizontal axes with concentric models of territorial governance that overlap and are connected to other concentric patterns with local, regional, national and transnational expressions of scale.

\section{REFERENCES}

Buller, H. (2003), De la terre au territoire: the reinvention of French rural space. Modern and Contemporary France, 11, 3, 323-334.

Cluniat, R., Roubaud, J-P., Roux, A. (2006), Evaluation des démarches contractuelles de pays, Conseil général du génie rural, des eaux et des forêts, février, No 2391.

Cole, A. (2006), Decentralization in France: central steering, capacity building and identity construction, French Politics, 4, 31-57.

Davoudi, S. (2005), Understanding territorial cohesion. Planning practice and research, 20, 4, 433-441.

Entreprises territoires et développement (ETD) (2005), Conseils de développement, 
enjeux et perspectives, Les Notes de l'Observatoire, <www.projetdeterritoire.com, cf. also www.datar.gouv.fr, www.etd.asso.fr.>

Epstein, R. (2005), Gouverner à distance. Quand l'Etat se retire des territoires, Revue Esprit, novembre, 96-111.

Epstein, R. (2006), Point de vue sur les politiques (post) contractuelles, Conférencedébat sur leur remplacement par les appels à projets au Forum des territoires 2006, Pays et Quartiers d'Aquitaine, <www.forum-des-territoires.org, janvier>.

Faure, A., Douillet, A-C., (eds.) (2005), Laction publique et la question territoriale, Compte rendu de Renaud Epstein, Politiques publiques: un panorama des recompositions à l'oeuvre. Pouvoirs Locaux, 67, décembre 2005, Presses universitaires de Grenoble, reproduit le 20/01/2006 dans < http://espacestemps.net/document1805.html> Healey, P. (2002), Key phrase: territorial cohesion, University of Newcastle upon Tyne. Lecamp, G. (2005), Ex ante evaluation: SPAN_Interreg IIIB North West Europe: final report, Université Libre de Bruxelles, Brussels.

Moentmann, E. M. (2003), The search for French identity in the regions: national versus local visions of France in the 1930s, French History, 17, 3, 307-327.

Negrier, E. (2006), Rescaling French urban territories: state, local power and regional configurations in the building of new metropolitan institutions, European Planning Studies, 14, 7, 939-958.

Nemery, J-C., (ed.) (2005), Le rôle des pays dans le développement local en France, communication à la conférence SPAN de Dublin le 27-28 octobre 2005, <http:// www.iclrd.org/documents/JeanClaudeNemery-FrenchVersionPaper-Parallel Session.pdf.>

Nemery, J-C., (ed.) (2006), Les pôles de compétitivité dans le système français et européen. Approches sur les partenariats institutionnels, Actes du colloque sur les pôles de compétitivité des 1-2 juin 2006, Université de Reims Champagne-Ardenne, L'Harmattan.

Roche, S. and Humeau, J-B. (1999), GIS development and planning collaboration: a few examples from France, URISA Journal, 11, 1, 5-14.

Schön, P. (2005), Territorial cohesion in Europe? Planning Theory and Practice, 3, 389-399.

Smith, A. (1997), Studying multi-level governance: examples from French translations of the Structural Funds, Public Administration, 75, Winter, 711-729. 
BCl@PAN http://bibliotekacyfrowa.pan.pl 


\title{
COMPETITIVENESS OR COHESION? A PHASE STRATEGY OF EUROPEAN SPATIAL DEVELOPMENT
}

\author{
MICHAEL WEGENER \\ Spiekermann \& Wegener, Urban and Regional Research \\ Lindemannstrasse 10, D-44137 Dortmund, Germany \\ e-mail: mw@spiekermann-wegener.de
}

\begin{abstract}
The European Union is committed to three overarching political objectives: competitiveness (economic growth), cohesion (equity) and environmental sustainability. The three goals are in conflict. The paper looks into the spatial implications of this goal conflict for European policy making using the enlargement of the European Union and European transport policy as example. Based on results of project 1.1.3 of the European Spatial Planning Observation Network ESPON, a phase strategy of spatial development is proposed in, which in early stages of economic development of a country the promotion of growth poles is appropriate, in later stages, however, the development of a polycentric spatial structure.
\end{abstract}

Key words: European Union, spatial policy, competitiveness, cohesion

\section{INTRODUCTION}

The European Union is committed to three overarching political objectives: competitiveness (economic growth), cohesion (equity) and environmental sustainability. The competitiveness objective was prioritised at the meeting of the European Council in Lisbon in 2000. The sustainability objective was confirmed at the Council meeting in Gothenburg in 2001. The three goals are in conflict. In the face of growing global competition and under the dominant neoliberal economic doctrine, the goal conflict is obscured by political rhetoric ("equitable and sustainable growth").

This paper looks into the spatial implications of this goal conflict for national and European policy making, using the enlargement of the European Union and European transport policy as example. Competitiveness is interpreted as growth in gross domestic product (GDP) despite its obvious limitations as indicator of human well-being. Cohesion is represented by two concepts, territorial cohesion, i.e. the reduction 
of disparities in GDP per capita between regions, and polycentricity, i.e. the reduction of disparities between cities at different levels in the urban hierarchy both at the national and European scale.

The paper starts by presenting past and current trends in regional economic development in the old and new EU Member States and their likely continuation in different scenarios of transport infrastructure improvements and their impacts on cohesion and polycentricity both at the national and European level. It shows that over time territorial cohesion improves in relative terms but declines in absolute terms, whereas polycentricity declines at the national and improves at the European level. Based on these findings, a phase strategy of spatial development is proposed in, which in early stages of economic development of a country the promotion of growth poles is appropriate, in later stages, however, the development of a polycentric spatial structure.

\section{EU ENLARGEMENT AND COHESION}

The term cohesion stands for a wide range of concepts including social justice and solidarity and co-operation between the countries and regions in Europe. The objectives of economic and social cohesion date back to the Treaty of Rome (1957) and became official goals of the European Union in the Maastricht Treaty (1992). The Treaty of Lisbon of 2007 added territorial cohesion to the objectives of economic and social cohesion. Territorial cohesion addresses the spatial dimension of cohesion. It aims at reducing disparities between the regions and a balanced and polycentric spatial structure of the Union's territory. With the enlargement of the European Union by twelve new Member States in 2004 and 2007, territorial cohesion has obtained a new dimension: The population of the European Union has increased by $28 \%$ but its wealth by only $7 \%$. Regional disparities have doubled; the gap in wealth between the poorest and the richest regions has grown from 1:10 to 1:20; and even the poorest regions in Europe are affluent compared to the poorest regions in the world.

This dramatic increase in disparities presents a new challenge to European policy making. How much inequality in wealth, accessibility and quality of live between the regions in the European Union is acceptable? Perfect equality in living conditions in all parts of the Union's territory would be an illusive goal. Peripheral regions will remain peripheral because of their geographical location, and no government will be able to change this. But how much inequality is politically feasible? The new Member States point to their disadvantage after sixty years of planned economies and demand continued transfers to catch up with the prosperity of the old Member States. But how much equality would be sustainable? For the new Member States, merely replicating the growth path of the old Member States would have severe ecological implications. Should the wasteful life styles of the old Member States be the model for all countries, just at a time when these become under pressure to 
reduce their energy consumption and greenhouse gas emissions? And finally, how much inequality is desirable? According to the Lisbon strategy, global competition requires the promotion of the most innovative and efficient central regions, and these may for some time to come continue to be the metropolitan regions in western Europe.

There are no easy answers to these questions. They involve values, interests and different beliefs about the likely effects of available policy options. While the followers of the neoliberal economic doctrine hold that in the face of growing global competition, only the promotion of the economically strongest metropolitan regions will create the wealth needed to generate the spill-over effects for the economic recovery of the new Member States, critics fear that such a strategy would deepen the existing gap in affluence between the old and new Member States and would run counter to the stated environmental objectives of the Community. Obscuring the goal conflicts between competitiveness, cohesion and sustainability by political rhetoric using oxymoron terms such as "equitable and sustainable growth" is, of course, no way out. What is needed is a rational discourse based on the best available scientific evidence, which explores the likely impacts of available policies in terms of economic growth, territorial cohesion and environmental sustainability.

To contribute to such a rational discourse about European spatial policy after the enlargement of the EU by twelve new Member States in 2004 and 2007 was the aim of the research project 1.1.3 Enlargement of the European Union and the Wider European Perspective as Regards its Polycentric Structure of the European Spatial Planning Observation Network ESPON. Established in 2006, the ESPON programme conducts applied research and studies on spatial development and planning seen from a European perspective in support of policy development in trans-national research groups part-financed by the European Regional Development Fund (ESPON 2008; Faludi 2002).

In ESPON 1.1.3 (ESPON 1.1.3 2006) simulation models were used to forecast the impacts of different scenarios of employment, migration and transport policies in conjunction with and after the EU enlargement. The SASI model was used to model the impacts of the EU enlargement as such and of related transport infrastructure investments.

The SASI model is a recursive simulation model of socio-economic development of regions in Europe subject to exogenous assumptions about the economic and demographic development of the European Union as a whole and transport infrastructure investments, in particular of the trans-European transport networks, and other transport policies. The SASI model differs from other regional economic models by modelling not only production (the demand side of regional labour markets) but also population (the supply side of regional labour markets). The impacts of transport infrastructure investments and transport system improvements on regional production and other transport policies is modelled by regional production functions in which, besides non-transport regional endowment factors, spatially disaggregate 
accessibility indicators are included. The model does not only represent spatial redistribution effects of transport policies but also generative effects on the European economy as a whole. The study area of the model are 1,330 NUTS-3 or equivalent regions in the 27 countries of the European Union plus Norway and Switzerland and the Western Balkan countries (see Figure 1). The remaining European countries, including the European part of Russia, are used as additional destinations when calculating accessibility indicators. Descriptions of the SASI model are contained in Wegener and Bökemann (1998), Bröcker et al. (2004), Wegener et al. (2005) and Wegener (2008).

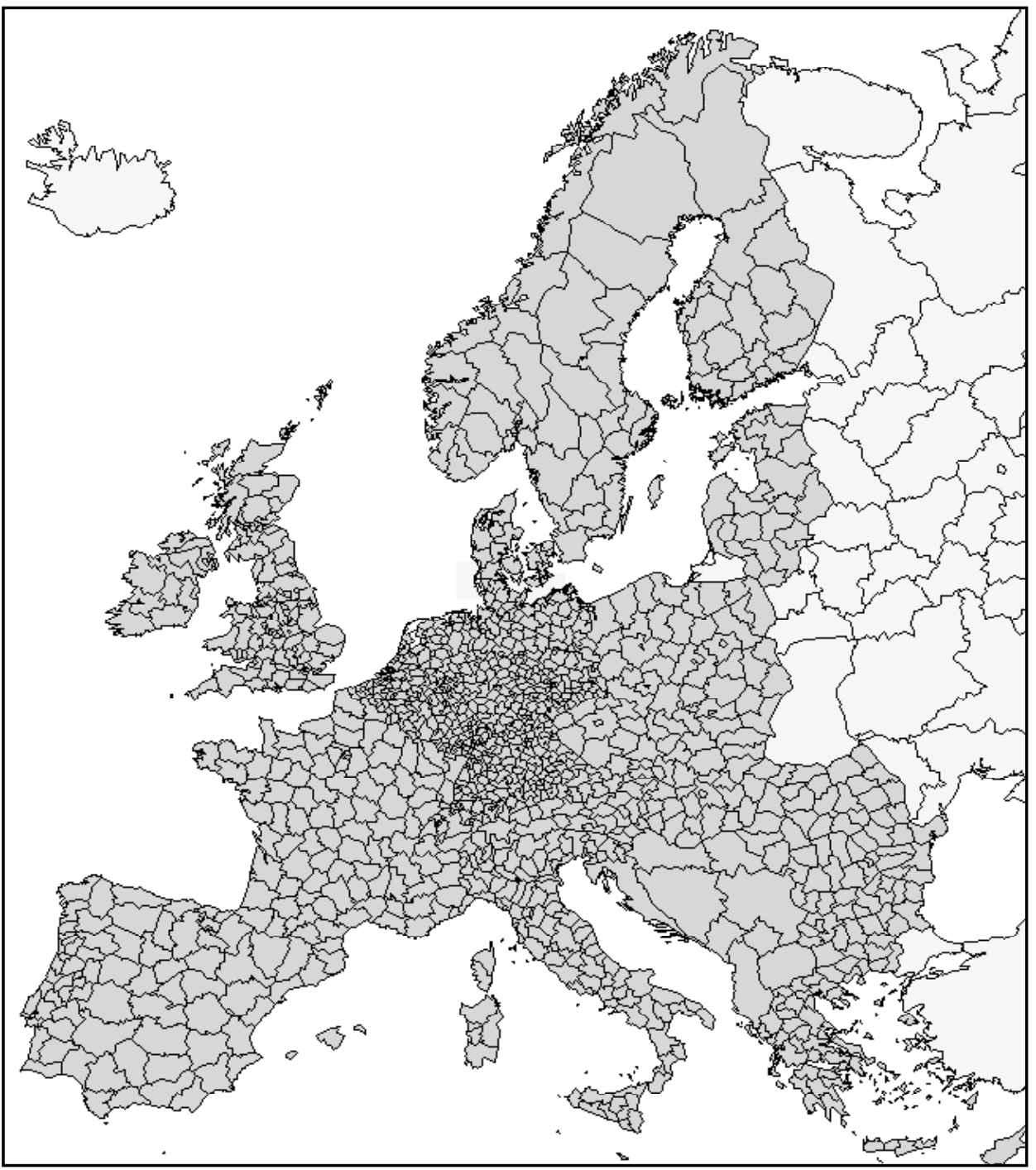

Figure 1. The SASI system of regions 
In ESPON 1.1.3 the SASI model was used to forecast the spatial impacts of one reference scenario and six policy scenarios (ESPON 1.1.3 2006, p. 200-201):

00 Reference Scenario: no EU enlargement, no projects in new Member States

A1 EU enlargement, no projects in new Member States

B1 A1 + all TEN priority projects

B2 $\mathrm{A} 1+\mathrm{B} 1+\mathrm{TEN} / \mathrm{TINA}$ projects in new Member States

B3 A1 + all TEN/TINA projects

B4 A1 + B3 + additional TINA projects in new Member States

B5 $\mathrm{A} 1+\mathrm{B} 3+$ maximum TINA projects in new Member States

The Reference Scenario (Scenario 00) is defined as the fictitious development that would have taken place if there had been no EU enlargement and only the transport projects of the "old" (Essen) priority list of TEN projects, which included only projects in the old Member States, would be implemented. The Reference Scenario serves as the benchmark against, which all policy scenarios are evaluated.

Scenario A1 is a scenario to examine the impacts of the EU enlargement itself on transport and hence accessibility and economic development. In the enlargement scenario no transport infrastructure projects beyond the projects already contained in the Reference Scenario are implemented. However, it is assumed that the process of enlargement started in 2004 gradually reduces the barriers to economic exchange and travel as well as waiting times and costs at border crossings between the old and new Member States and between the new Member States themselves.

All remaining policy scenarios include Scenario A1, i.e. assume the same integration effects as Scenario A1. Scenario B1 to B3 assume different combinations of the transport infrastructure projects of the "new" TEN priority list (HLG 2003) and the Transport Infrastructure Needs Assessment (TINA) projects in the new Member States (European Union 2004; TINA 2002). Scenario B4 and B5 assume that, in addition to the projects included in Scenario B3, further transport infrastructure projects in the new Member States defined for the EU 5th Framework project IASON (Bröcker et al. 2004, Wegener et al. 2005) will be implemented.

The results of the simulation of the six policy scenarios until 2031 and their policy implications are discussed in the Final Report of ESPON 1.1.3 (2006, p. 201-218). Here only one aspect relevant for the topic of this paper will be highlighted: the difference between relative and absolute growth.

Figure 2 shows the impacts of Scenario B3 (EU enlargement + all TEN/TINA projects) on GDP per capita as the difference between GDP per capita in the policy scenario and in the Scenario 00 (no EU enlargement, no projects in the new Member States) in the year 2031. Both maps show only winners: Because of reduced waiting times at borders and the reduction of other barriers to travel and trade and because of the substantial reductions in travel time and cost through the TEN and TINA transport infrastructure investments, all regions are better off.

However, there are significant differences in degree. The left-hand map shows relative differences in percent. It appears as if the regions in the new Member States, 

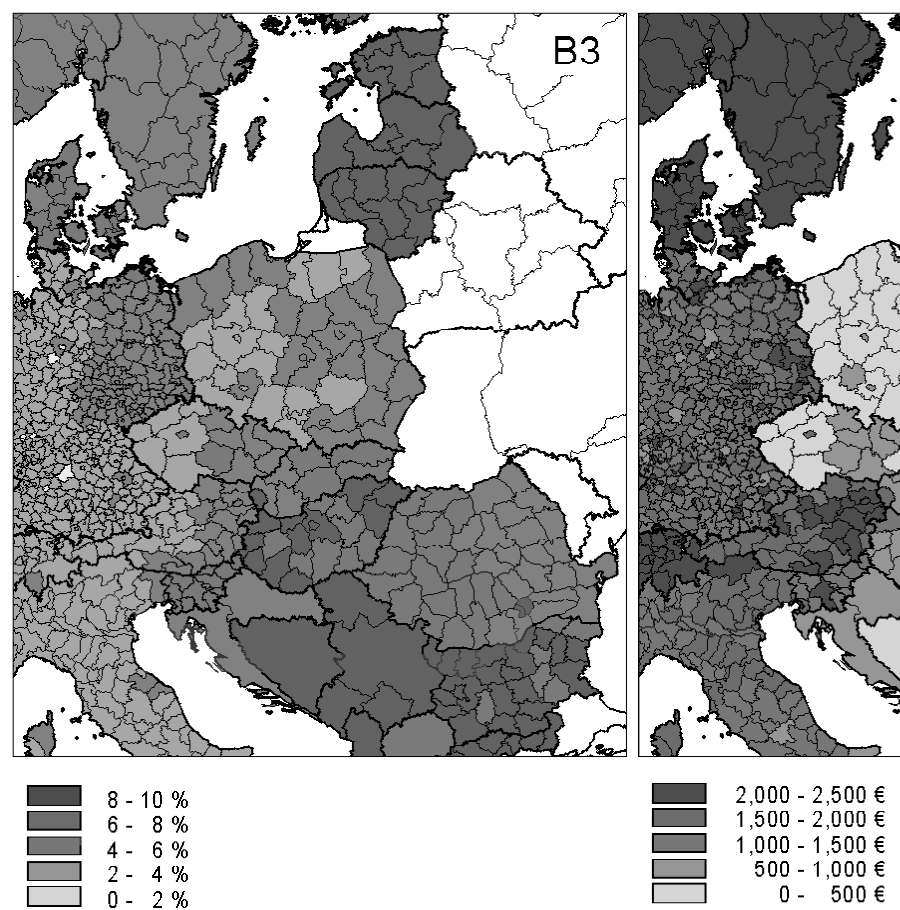

Figure 2. Scenario B3 (EU enlargement + all TEN/TINA projects): relative (left) and absolute (right) difference in GDP per capita to Reference Scenario 00 in 2031
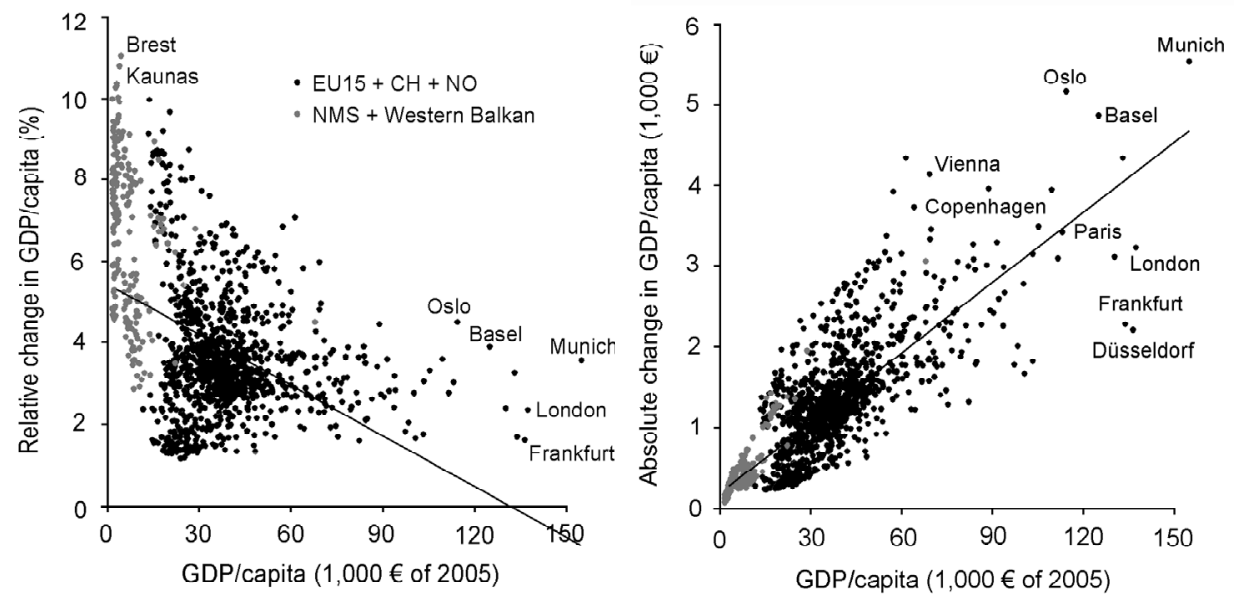

Figure 3. Scenario B3 (EU enlargement + all TEN/TINA projects): relative (left) and absolute (right) difference in GDP per capita to Reference Scenario 00 in $2031 \mathrm{v}$. level of GDP per capita in 2031.

in particular the Baltic states, Slovakia, Slovenia, Hungary, Romania and Bulgaria gain most, but also the Western Balkan countries, because they benefit from the improved accessibility of their EU neighbours. A look at the right-hand map, however, 
gives a different picture. The map shows absolute differences in GDP per capita in Euro (of 2005 to exclude inflation). Now it becomes clear that the higher percentage gains of the new Member States are in absolute terms much smaller than the gains of the old Member States because of their still much lower income levels.

The distinction between relative and absolute growth has implications for the debate about cohesion. Is Scenario B3 successful in terms of territorial cohesion? At first sight it seems so because in relative terms the differences in regional income between the rich and the poor Member States decrease. But can this be called convergence if in absolute terms the gap in income between the rich and poor regions becomes larger?

The SASI model calculates a range of cohesion indicators to measure the convergence or divergence effects of different scenarios. It was demonstrated in the IASON project (Bröcker et al. 2004, Wegener et al. 2005, p. 36-38) and in ESPON 2.1.1 (2005, p. 96-100) that different cohesion indicators give different results. The most important distinction is whether the indicator measures relative or absolute convergence or divergence. If, for instance, all regions gain in relative terms by the same percentage, the richer regions gain more in absolute terms as shown above. Some commonly used indicators, such as the coefficient of variation or the Gini coefficient, may indicate relative convergence where in absolute terms divergence may occur.

Figure 3 illustrates this by two scatter diagrams showing the correlation between change and level of GDP per capita in Scenario B3. The left-hand diagram shows relative, the right-hand one absolute change plotted against the level of GDP per capita. In the left-hand diagram the regression line points downward, indicating that in relative terms the gains in GDP per capita are larger in the poorer regions. However, in the right-hand diagram the regression line points upward, indicating that the richer regions gain more in absolute terms. Whether one calls this convergence or divergence is a matter of political preference, but it is important to clearly state, which type of indicator is used.

\section{EU ENLARGEMENT AND POLYCENTRICITY}

The objective of balanced polycentric urban systems was first introduced by the European Spatial Development Perspective (ESDP) (European Union 1999). The interest in polycentric development was fuelled by the hypothesis put forward in the ESDP that polycentric urban systems are more efficient, more sustainable and more equitable than both monocentric urban systems and dispersed small settlements.

Until today, the concept of polycentricity has remained largely at the level of rhetoric without a precise operational definition (which puts it into a class with similarly vague concepts such as "city networks" or "industrial clusters"). There exist no generally accepted methods to identify or measure polycentricity at different spatial scales or to assess the impacts of polycentricity (or the lack of it) with respect 
to policy goals such as efficiency (competitiveness), equity (cohesion) and sustainability. It is therefore impossible to determine an optimum degree of polycentricity between centralisation and decentralisation or, in other words, between the extremes of monocentricity and dispersal. How much polycentricity is most efficient? Large centres offer economies of scale but risk negative effects of over-agglomeration. Dispersed settlements are too small to support major infrastructure facilities. Furthermore, how much polycentricity is equitable? Spatial polarisation may lead to social and spatial segregation. Spatial dispersal is egalitarian but denies the opportunities for social mobility. And finally, how much polycentricity is sustainable? Large cities use less energy for transport but more for high-rise buildings and heating, whereas dispersed settlements are wasteful in terms of energy for transport. These open questions make it difficult to formulate well-founded policy recommendations as to which cities should be developed with priority.

It is therefore necessary to develop an operational concept of polycentricity and operational methods for identifying and measuring the polycentricity of European urban systems. The methodology should allow:

- to measure the degree of polycentricity of the urban system of a region, a country or Europe at large,

- to evaluate it with respect to policy objectives, such as competitiveness, cohesion and environmental sustainability,

- to forecast the impacts of European policies on the degree of polycentricity and its impacts on major policy goals.

Table 1 . The index of polycentricity

\begin{tabular}{|c|l|l|}
\hline Index & \multicolumn{1}{|c|}{ Sub-index } & \multicolumn{1}{c|}{ Indicator } \\
\hline \multirow{3}{*}{ Polycentricity } & Size (33\%) & $\begin{array}{l}\text { Slope of regression line of population (10\%) } \\
\text { Primacy rate of population (40\%) } \\
\text { Slope of regression line of GDP (10\%) } \\
\text { Primacy rate of GDP (40\%) }\end{array}$ \\
\cline { 2 - 3 } & Location (33\%) & Gini coefficient of service areas \\
\cline { 2 - 3 } & Connectivity (33\%) & $\begin{array}{l}\text { Slope of regression line of accessibility (50\%) } \\
\text { Gini coefficient of accessibility (50\%) }\end{array}$ \\
\hline
\end{tabular}

With this in mind, ESPON 1.1.1 (2004, 60-84 and 329-346) developed an index of polycentricity consisting of three components and seven sub-indicators (Table 1).

- The size indicator measures the distribution of population and GDP based on the notion that a flat rank-size distribution is more polycentric than an urban system dominated by one large city.

- The location indicator measures the spatial distribution of cities assuming that a uniform distribution of cities across a territory is better for a polycentric urban system than one where all cities are clustered in one part of the territory.

- The connectivity indicator measures the distribution of accessibility across cities 

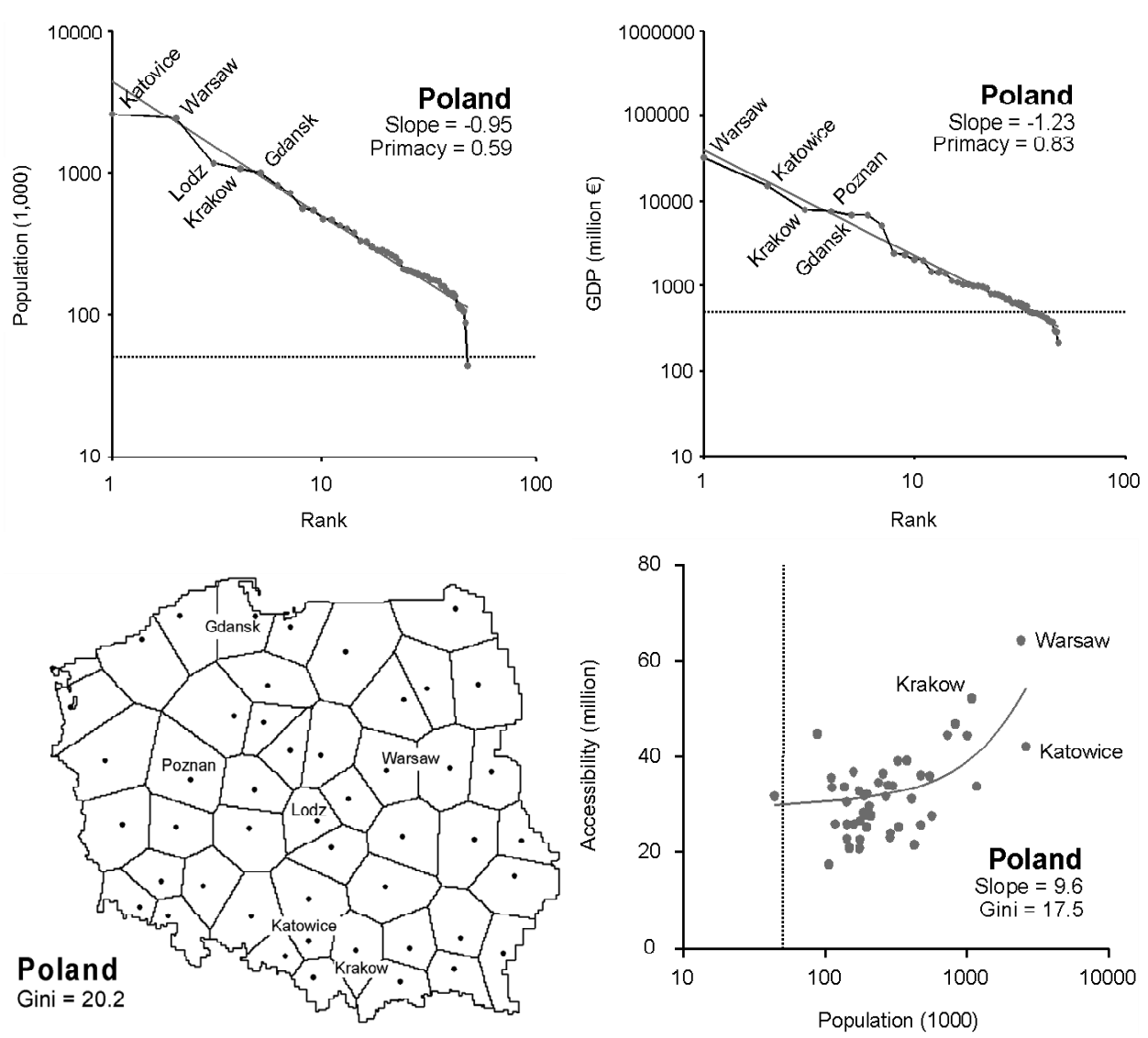

Figure 4. Components of polycentricity of Poland: size index population (top left), size index GDP (top right), location index (bottom left), connectivity index (bottom right)

assuming that an urban system with good connections between lower-level cities is more polycentric than one in which all connections are concentrated on the largest city.

The index of polycentricity was calculated for all countries of the European Union and Norway and Switzerland for the Functional Urban Areas (FUAs) identified in ESPON 1.1.1. Figure 4 shows the sub-indicators using Poland as an example.

The index of polycentricity was calculated in ESPON 1.1.3 (2006, p. 157-173) for the FUAs defined in ESPON 1.1.1 in the new Member States. Table 2 shows the results of the evaluation for the three component indices and the index of polycentricity for the new Member States on a 0-100 scale. The last two rows of the table show the weighted average scores of the new Member States (NMS) and, for comparison, the weighted average scores of the old Member States (EU-15).

Table 2 shows that the new Member States on average have urban systems that are more polycentric than those of the old Member States. This is mainly because their cities are more evenly distributed over space. With respect to connectivity, however, they are on average more polarised. Except for the special case of Cyprus, 
the most polycentric countries are Slovenia and Poland. Slovenia has high scores in all three polycentricity dimensions. Poland scores high in the size index and the location index but is weak in the connectivity index because all transport lines are oriented towards Warsaw. The Baltic states and Hungary are the least polycentric of the new Member States. Estonia and Lithuania suffer from the poor accessibility of their peripheral areas, Latvia from the dominance of Riga, and Hungary is weak in all three dimensions.

Table 2. Component indices and polycentricity index

\begin{tabular}{|l|c|c|c|c|c|}
\hline Country & FUAs & Size & Location & Connectivity & Polycentricity \\
\hline Bulgaria & 31 & 77.1 & 80.2 & 52.6 & 68.8 \\
Cyprus & 4 & 75.7 & 100.0 & 89.1 & 87.7 \\
Czech Republic & 25 & 79.2 & 51.7 & 63.5 & 63.8 \\
Estonia & 10 & 64.7 & 94.8 & 26.4 & 54.5 \\
Hungary & 77 & 61.6 & 57.7 & 50.4 & 56.3 \\
Lithuania & 8 & 76.5 & 83.5 & 18.5 & 49.0 \\
Latvia & 8 & 35.5 & 97.0 & 52.4 & 56.5 \\
Poland & 48 & 84.1 & 83.1 & 58.7 & 74.3 \\
Romania & 59 & 78.3 & 80.9 & 46.6 & 66.6 \\
Slovenia & 6 & 76.0 & 91.6 & 72.0 & 79.4 \\
Slovakia & 27 & 83.5 & 77.0 & 41.6 & 64.4 \\
\hline NMS average & 303 & 77.5 & 77.1 & 52.7 & 67.3 \\
EU15 average & 1,200 & 77.7 & 57.2 & 68.1 & 66.1 \\
\hline
\end{tabular}

A similar analysis was performed for the whole of Europe for the 76 Metropolitan Growth Areas (MEGAs) defined by ESPON 1.1.1. (ESPON 1.1.3 2006, p. 169-172). The system of MEGAs is even more balanced than if all FUAs were considered. The MEGAs in the new Member States are in the lower ranks of the urban hierarchy in Europe. In the rank-size distribution of GDP of MEGAs in Europe, mediumsized economic centres, such as Stuttgart, Frankfurt and Hamburg score higher than their population size would indicate. Even more than in the rank-size distribution of population, the MEGAs in the new Member States find themselves at the tail end of the distribution.

The location of MEGAs is, however, highly clustered in the curved shape between south-west England, the Benelux countries, the Rhine-Ruhr and Rhine-Main regions, Switzerland and northern Italy— the "Blue Banana" and not the "Pentagon". At the outer periphery, however, there are large areas served only by one MEGA.

Accessibility is relatively equally spread over large and small cities as it should be in a polycentric urban system. The MEGAs with the highest accessibility are all in the old EU Member States, whereas those in the new Member States are still less well linked to the major centres in western Europe. 
The polycentricity index can be used to forecast polycentricity trends and the impacts of EU policies on polycentricity. In ESPON 1.1.3 this was done with the SASI model for the six policy scenarios described above (ESPON 1.1.3 2006, p. 214-217). A methodological difficulty in forecasting polycentricity is that the SASI model deals with NUTS-3 regions and not cities. It was therefore assumed that population, GDP and accessibility of cities change like those of the NUTS-3 region in which they are located.

Figure 5 (left) shows the development of the polycentricity index between 1981 and 2031 for the old (EU15) and new (NMS) Member States. The diagram confirms that the urban systems of the new Member States are on average more polycentric than those of the old Member States. They were even more polycentric in the past because of their history as planned economies in which there was no market-driven spatial development. However, after the opening of the Iron Curtain in the early 1990s, their capital cities and major agglomerations attracted formerly suppressed rural-to-urban migration with the effect that these cities grew at the expense of smaller urban centres.
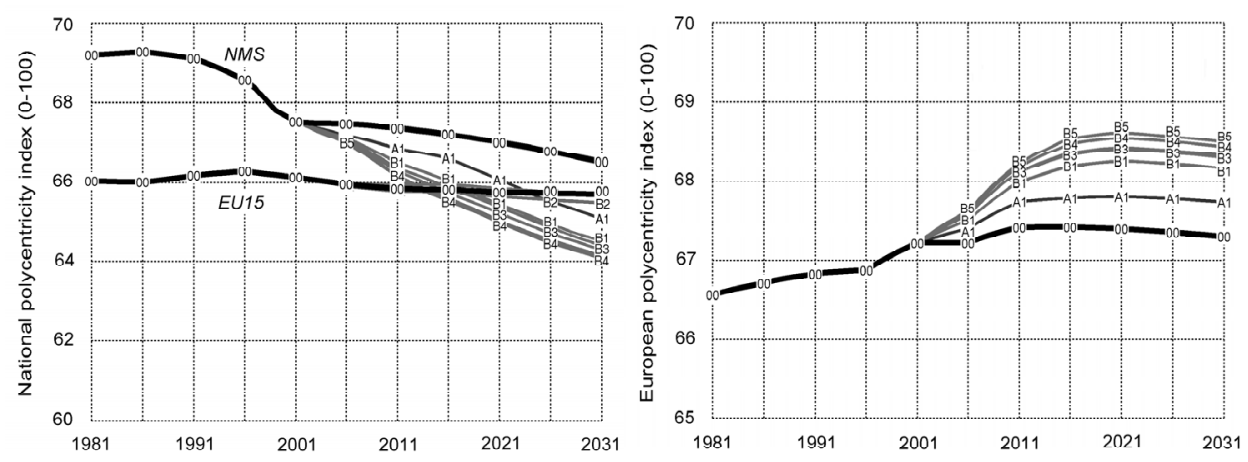

Figure 5. Development of polycentricity in the old and new Member States (left) and development of polycentricity of MEGAs in Europe (right) 1981-2031

Moreover, if the forecasts of the model are correct, polycentricity in the new Member States will further decline due to market forces and even become lower than that of the old Member States. Polycentricity in the old Member States declines, too, but much more slowly than in the new Member States because of their longer experience with market-driven spatial development. This is possibly also the reason why the infrastructure improvements in Scenarios B1 to B5 have only little effect on polycentricity in the old Member States. Another reason may be that the transport networks in the old Member States are already highly developed and can only marginally be improved. However, in the new Member States there is still a great demand for transport infrastructure and so infrastructure improvements have much larger effects.

Figure 5 (right) shows the development of the global index of polycentricity based on MEGAs between 1981 and 2031 in the Reference Scenarios and the six policy 
scenarios. Unlike the forecasts of national polycentricity, polycentricity at the highest level of the urban hierarchy in Europe has increased in the past and is likely to increase in the medium-term future. This is mainly due to the fast economic growth of the capital cities and other large cities in the new Member States. Already the opening of the Iron Curtain in the early 1990s and the integration effects of the EU enlargements in 2004 and 2007 (Scenario A1) have moved these cities up in the urban hierarchy.

The comparison of the two diagrams in Figure 5 confirms that the goals of European polycentricity and national polycentricity are in conflict and that the price for gains in polycentricity at the European level are more polarised national urban systems.

\section{A PHASE STRATEGY OF SPATIAL DEVELOPMENT}

Polycentricity is associated with major policy objectives of the European Union. Countries with a polycentric urban system are in general economically more successful and environmentally more sustainable than countries with a dominant capital city, but not necessarily spatially more equitable if also rural regions are included (ESPON 1.1.1 2004, p. 80-82). However, the polarisation of the urban systems in the new Member States has increased since their transition from planned to market economies in the 1990s and is likely to further increase in the future.

Table 3. Goal conflicts of polycentricity (Benz et.al. 2004)

\begin{tabular}{|l|l|l|}
\hline \multicolumn{1}{|c|}{ Goal } & \multicolumn{1}{|c|}{ Policy } & \multicolumn{1}{c|}{ Goal conflict } \\
\hline $\begin{array}{l}\text { Competitiveness } \\
\text { ("Lisbon') }\end{array}$ & Strengthen global cities & $\begin{array}{l}\text { Polarisation between old and new } \\
\text { Member States }\end{array}$ \\
\hline European cohesion & $\begin{array}{l}\text { Strengthen major cities in } \\
\text { new Member States }\end{array}$ & $\begin{array}{l}\text { Polarisation between cities in new } \\
\text { Member States }\end{array}$ \\
\hline National cohesion & $\begin{array}{l}\text { Strengthen medium-sized } \\
\text { cities in new Member States }\end{array}$ & $\begin{array}{l}\text { Competitiveness of new Member } \\
\text { States may decrease }\end{array}$ \\
\hline $\begin{array}{l}\text { Sustainability } \\
\text { ("Gothenburg") }\end{array}$ & $\begin{array}{l}\text { Strengthen small cities in } \\
\text { new Member States }\end{array}$ & $\begin{array}{l}\text { Competitiveness of new Member } \\
\text { States may decrease }\end{array}$ \\
\hline
\end{tabular}

This creates serious goal conflicts for future EU spatial policy oriented at a balanced polycentric territorial structure of Europe (see Table 3).

If, for instance, the goal is to strengthen major urban centres outside the "Pentagon", this will increase spatial disparities between the already too dominant capital cities and other large cities in countries such as the Baltic states, Hungary or the Czech Republic. However, if the promotion of balanced urban systems in these countries is a common goal, more Structural Funds and transport infrastructure 
would have to go into the peripheral regions of the new Member States, and this would go at the expense of their capitals.

It is the responsibility of the future spatial policy of the European Union to find a rational solution to these goal conflicts. This solution cannot be the one-sided pursuit of one of the conflicting goals at the expense of the others. Rather, the task is to develop a balanced strategy, which is differentiated in both space and time, and takes the specific needs of different regions into account.

Such a strategy starts from a phase model of spatial development according to which in early stages of economic development of a country the promotion of growth poles is appropriate, in later stages, however, the development of a polycentric spatial structure. This allows to set different priorities in the old and the new Member States: In the old Member States decentralised, polycentric spatial structures are promoted. In the new Member States for a limited transition period the capital cities and other major cities are be strengthened, until later also in these countries balanced polycentric spatial structures can be developed. The rationale behind this is that scientific and technical innovations are not restricted to large agglomerations but can also or even better, be achieved in well connected cities of medium size. Such a strategy is not in conflict with the competitiveness goal but achieves it in a more sophisticated way than by the one-sided promotion of large agglomerations.

From such a spatial strategy differentiated in space and time new challenges for European spatial policy arise: In a multi-level approach to policy formulation policies at the EU level (macro), at the national level (meso) and at the regional-local level (micro) need to be co-ordinated (vertical co-ordination). In a cross-sectional approach to policy making the stated EU goals competitiveness, cohesion and sustainability need to be reconciled (horizontal co-ordination). This requires co-ordinated multi-level and cross-sectoral policy combinations or integrated strategies (ESPON 1.1.3 2006, p. 219-233):

- Structural policy: In a transition phase subsidies from the Structural Funds should focus on major city regions in new Member States to facilitate convergence at the European level. In the following phase they should focus on second-tier cities and rural areas.

- Infrastructure policy: In a transition phase priority should be given to fast and efficient transport between the main cities in the new Member States and with the economic centres in the old Member States. Later the focus should shift to improving the accessibility of medium-sized cities and rural areas.

- Financial integration: In the near future the centralising effects of liberalisation should be accepted as condition for rapid economic growth. In the long run, however, decentralisation at the national and regional level should be supported to ensure that equity is not overshadowed by competition.

- Border region integration: In the short term successful forerunner regions should be promoted, but in the medium and long term the focus should be on the integration of disadvantaged and lagging regions. 
It is interesting to note that one of the new Member States, Poland, has already adopted a phasing strategy of spatial policy (Korcelli 2005). The National Concept of Spatial Development of 2001 in a first stage gives priority to offering advantages to private investors and accepts interregional and interurban disparities as a price to be paid for rapid economic growth, but for a later phase foresees spatial equalisation policies, after the development gap between Poland and the west European countries has become smaller.

\section{CONCLUSIONS}

The European Spatial Development Perspective (ESDP) of 1999 is still waiting to be updated to take account of the enlargement of the EU. Instead the ministers of the EU Member States responsible for spatial planning, at the Leipzig meeting of 25 May 2007, agreed on the Territorial Agenda of the EU, a declaration of intent that is to be reviewed in future negotiations (European Union 2007). The Territorial Agenda of the EU confirms the objectives of the ESDP, polycentric spatial development, equitable access to infrastructure and knowledge and protection of nature and cultural heritage, but it ignores the special needs of the new Member States, which differ from those of the old Member States, and it suggests that growth, cohesion and sustainability are not in conflict.

It is necessary to raise the awareness that Europe needs a common spatial policy to cope with the challenges of globalisation, climate change and energy scarcity. This requires a renewed European Spatial Development Perspective for the enlarged EU territory. The new ESDP must differentiate between different types of Member States, regions and cities taking account of their different stages of development and hence their different development needs.

The new ESDP must set different priorities in the old and new Member States: In the old Member States decentralised, polycentric spatial structures should be promoted. In the new Member States for a limited transition period the capital cities and other major cities should be strengthened. Later also in these countries balanced polycentric spatial structures are to be developed.

\section{ACKNOWLEDGEMENT}

The author is grateful to his project colleagues in ESPON 1.1.1 and ESPON 1.1.3 for their permission to report on common work. 


\section{REFERENCES}

Benz, A., Borchard, K., Eser, T. W., Kujath, H.J. et al. (2004), Why the EU needs a European spatial development policy, ARL Position Paper, 60, Honnover, $<$ http://www.arl-net.org/pdf/publications/PosPaper60_engl.pdf.>

Bröcker, J., Meyer, R., Schneekloth, N., Schürmann, C., Spiekermann, K., Wegener, M. (2004), Modelling the socio-economic and spatial impacts of EU transport policy. Deliver-able D6 of IASON (Integrated Appraisal of Spatial Economic and Network Effects of Transport Investments and Policies), Christian Albrechts University, Institute of Spatial Planning, Kiel-Dortmund.

ESPON (2008), European Spatial Planning Observation Network < http://www.espon.eu.>

ESPON 1.1.1 (2004), Potentials for polycentric development in Europe. Final Report. Nor-dic Centre for Spatial Development, Stockholm <http://www.espon.eu/ $\mathrm{mmp} /$ online/web-site/content/projects/259/648/file_1174/fr-1.1.1_revised-full.pdf.>

ESPON 1.1.3 (2006), Enlargement of the European Union and the wider European per-spective as regards its polycentric spatial structure. Final Report. Royal Institute of Tech-nology, Stockholm <http://www.espon.eu/mmp/online/website/content/ projects/259/650/file_1190/full_revised_version_113.pdf.>

ESPON 2.1.1 (2005), Territorial impact of EU transport and TEN policies. Final Report. Institute of Regional Research, Christian Albrechts University, Kiel $<$ http://www.espon.eu/ mmp/online/website/content/projects/243/239/file_374/ fr-2.1.1_revised.pdf.>

European Union (1999), ESDP_European Spatial Development Perspective: Towards balanced and sustainable development of the territory of the European Union, Office for Official Publications of the European Communities, Luxembourg $<$ http://ec.europa.eu/ regional_policy/sources/docoffic/official/reports/pdf/sum _ en.pdf.>

European Union (2004), Decision No 884/2004/EC of the European Parliament and of the Council of 29 April 2004 amending Decision No 1692/96/EC on Community guidelines for the development of the trans-European transport network, Official Journal of the European Union, L 167, 1-38.

European Union (2007), Territorial agenda of the European Union: towards a more competitive and sustainable Europe of diverse regions. Agreed on the occasion of the Informal Ministerial Meeting on Urban Development and Territorial Cohesion in Leipzig on 24-25 May $2007<$ http://www.bmvbs.de/Anlage/original_1005295/Territorial-Agenda-of-the-European-Union-Agreed-on-25-May-2007-accessible.pdf.>

Faludi, A. (Ed.), (2002) European spatial research and planning, MA, Lincoln Institute of Land Policy, Cambridge, 115-140.

HLG-High Level Group on the Trans-European Transport Network (2003), Report. Euro-pean Commission, Brussels <http://ec.europa.eu/ten/transport/ revision/hlg/2003_report_kvm_en.pdf.> 
Korcelli, P. (2005), The urban system of Poland, Built Environment, 31, 2, 133-142. TINA (2002), Status of the pan-European transport corridors and transport areas. Developments and activities in 2000 and 2001. Final Report, TINA Secretariat, Vienna.

Wegener, M. (2008), SASI Model Description, Working Paper, 08/01, Spiekermann $\&$ Wegener Urban and Regional Research, Dortmund <http://www.spiekermannwegener.de/mod/pdf/AP_0801.pdf.>

Wegener, M., Bökemann, D, (1998), The SASI Model: Model Structure. SASI Deliverable D8, Berichte aus dem Institut für Raumplanung, 40, Institut für Raumplanung, Universität Dortmund <http://www.raumplanung.uni-dortmund. de/irpud/pro/sasi/ber40.pdf.>

Wegener, M., Komornicki, T., Korcelli, P. (2005), Spatial impacts of the trans-European networks for the new EU Member States, EUROPA XXI, 13, 27-43. 


\title{
SCENARIOS ON THE TERRITORIAL FUTURE OF EUROPE: A COMMENTARY AND FURTHER IMPLICATIONS
}

\author{
PIOTR KORCELLI \\ Institute of Geography and Spatial Organization \\ Polish Academy of Sciences \\ Twarda 51/55, 00-818 Warszawa, Poland \\ e-mail: igipzpan@twarda.pan.pl
}

\begin{abstract}
The ESPON 3.2 Project on Spatial Scenarios for Europe, 2003, which presents future-oriented studies on spatial development of the EU has received a notable resonance in scientific analyses and disputes. The aim of the study concerns the elaboration of conceptual bases for spatial policy at the European level discussing the development according to two contrasting hypothetical paths - following a competitiveness-driven and a cohesion-oriented policy. In the course of the project an attempt is made to design "an optimal", so-called "Proactive Scenario", as an alternative to the two "boundary situations", which treats competitiveness, cohesion and sustainability as complementarities. It is claimed that the scenario may be fulfilled, when the development focuses on two sectors, namely education and innovation.
\end{abstract}

Key words: spatial scenarios, competitiveness, cohesion, sustainability

\section{INTRODUCTION}

The ESPON 3.2 project on: Spatial Scenarios for Europe, 2030, the last one within the ESPON I programme, has received a notable resonance. During a short time span since its completion in 2006, the project results have become a standard reference in studies and discussions focusing on spatial policy, both at the European and a national level. Its impact matches that of the ESPON 1.1.1 project on: the Role, Specific Situation and Potentials of Urban Areas, with its identification and classification of Functional Urban Areas (FUA) and Metropolitan European Growth Areas (MEGA) that have been widely quoted and adopted in the current professional sources.

A part of the success of the scenarios project is due to the nature of future-oriented studies that put the readers' imagination in motion, and, by providing informa- 
tion to prospective private and public actors, may generate self-fulfilling predictions. Another reason for the wide reception of the project results consists in its substantive characteristics - an in-depth analysis based on rich arrays of data and the application of novel modelling tools.

Still, a perusal of the project reports (ESPON 3.22007 ) leads to some questioning of the results, in particular in relation to the consistency of the underlying assumptions used, as well as to interpretation and evaluation of spatial patterns generated in the form of individual scenarios. These two aspects will be more specifically looked at below. According to the authors of the report, the aim of using the scenario approach was "to identify positive as well as negative trends and driving forces in order to shape a more desirable future and to.... understand the limitations of public policies" (ibid., p.7). To be viable, such policies need to be framed within sets of more or less realistic assumptions concerning the driving forces, i.e. the external factors. It is recognized that, as a consequences of the recent (2004-2007) enlargement of the EU, the importance of different external conditions, including the geopolitical relations with the rest of the world, will have an increasing impact on the European territory.

\section{THE SCENARIOS ASSUMPTIONS: DRIVING FORCES AND RESPONSE FUNCTIONS}

Among eight categories of scenario assumptions, those related to climate change, demography and energy cost represent autonomous factors, i.e. external driving forces, with adjustment (response) functions varying among the three scenarios: the baseline (trend), the competitiveness-oriented and the cohesion-oriented development paths. The remaining categories that pertain to economy, transportation, rural development, governance, as well as future EU enlargement contain substantial, in some cases dominant policy ingredients, and may be interpreted as internal drivers. Missing from the list are assumptions concerning the pace of globalization and technological change, though they are hidden under headings such as economy, rural development and transportation, and accounted for de facto in the analysis.

The nature of the external driving forces is kept constant across the three scenarios. As to climate change, a temperature rise of one degree Celsius is assumed throughout the projection period (till 2030), with an increasing frequency of extreme nature events. With respect to the energy factor, it is a steady increase of energy prices. The main characteristics of population change include zero demographic growth accompanied by significant rates of population ageing. These trends, however, have different impact upon general, as well as territorial development owing to the alternative policy approaches adopted.

When compared to the trend scenario, the competitiveness-oriented policy mix brings increased climate-related risks, caused, among others, by higher emission 
and pollution levels, owing to subordination of environmental measures to market efficiency. Such policies tend also to produce steeper increases of energy cost through greater demand on energy and by neglecting the development of renewable energy resources. With respect to demographic change, the competitiveness-oriented policies bring an overall increase of population size as a consequence of EU enlargement, as well as of some liberalization of immigration from third countries. Conversely, in the cohesion-oriented scenario climate change has less damaging effects upon the environment due to several factors: lower emission levels and better environmental protection, a slower rise of energy cost as a result of lower rates of economic growth, a wider use of renewable energy resources, as well as a negative overall of rate population change- a consequences of the break on further EU enlargement combined with restrictive immigration policies.

The internal coherence of the individual sets of scenario assumptions is somewhat disputable. Thus, for example, in the competitiveness-oriented scenario the admission of Turkey and Ukraine by the year 2020 is combined with elimination of all barriers to internal migration within the EU. There is an obvious contradiction between the two assumptions, taking into account their broader social, economic and political context. Conversely, the assumed abolishment of market barriers between the EU member countries is the fact of life rather than a projected future event. On the other hand, supporting fertility growth through fiscal incentives seems to run counter to the general assumption of policy liberalization and the withdrawal from public intervention in social matters. Interestingly enough, in the cohesion-oriented scenario an increase of fertility rates is also found among policy objectives, to be achieved via improvements of child care systems. The latter scenario assumes a sustenance of the EU budget and reinforcement of structural funds (with a focus on the weakest regions) under lower economic growth—a politically nonviable solution.

In general, the assumptions guiding the cohesion-oriented scenario seem to be somewhat less realistic then those based upon the competitiveness-oriented policies. It should be noted again at this point, that all the assumptions are formulated in terms of deviations from current trends and policies. These, however, as the authors of the project emphasize, are rather poorly adjusted so as to address the emerging global challenges facing the European Union.

\section{THE ALTERNATIVE PATTERNS OF TERRITORIAL DEVELOPMENT}

According to the baseline scenario, spatial concentration forces will prevail over the projection period, while the Pentagon, as defined in the European Spatial Development Perspective (ESDP 1999), i.e. the area extending between London, Paris, Milan, Munich and Hamburg, will strengthen its dominant position in the European urban system. This zone of intense concentration of flows and high-ranking economic activities is expected to expand along the main transport corridors and to 
absorb a number of important MEGAs, including Barcelona and Madrid, Rome and Naples, Copenhagen and Stockholm, as well as Berlin, Warsaw, Prague, Vienna and Budapest. Such a development, with respect to East-Central Europe, has been in fact anticipated earlier by A. Kukliński, in his concept of Berlin-Warsaw Trajectory (Domański 1999), and by J. Kołodziejski (Koncepcja 2001). In the trend scenario spatial concentration and expansion of metropolitan areas is accompanied by marginalization of peripheral and other predominantly rural regions.

In comparison to the trend scenario, the pattern generated in the competitiveness-oriented policies exhibits an even stronger concentration and spatial polarization. The sphere of intense flows and advanced economic activities is much more limited, basically restricted to the Pentagon proper, or even its central zones, with just a few of its new extensions reaching out to encompass Marseille, Vienna and Copenhagen. Numerous regions are plagued by deindustrialization, while the peripheral and rural regions face large scale out migration and overall socioeconomic marginalization. The impact of natural hazards becomes particularly strong. A question arises, however, whether such spatial pattern, with all its negative features, would be an unavoidable consequence of the competitiveness-oriented future development trajectory of the European Union. This calls for an examination of some of the main assumptions underlying the particular scenario.

One of its crucial initial conditions is a reduction of the EU budget and reorientation of the expenditures towards research and development, education, information and computer technology, as well as strategic external accessibility, mainly at the cost of structural funds and Common Agricultural Policy. Such a shift would indeed strengthen spatial concentration forces, although additional growth impulses would most likely be also experienced by major metropolitan areas situated beyond the Pentagon. Rapid technological progress in a number of fields, including biotechnology and energy sources would be conditioned upon the development of EU—wide networks of university and research centres. A major retreat from Common Agricultural Policy, while detrimental to some peripheral regions, might also hit hard some of the EU core regions which have been the main beneficiaries of this policy for a long time.

Another important assumption that underlies the competitiveness-oriented scenario concerns the labour markets, which are to be "regulated in a more flexible way". This involves elimination of all restrictions on the free circulation of workers, as well as service providers and other entrepreneurs (the still remaining partial restrictions pertaining to new member states expire in 2011), between the EU member countries. When combined with the assumption of admission of Western Balcans countries by 2015 , and of Turkey and Ukraine by 2020 , this would create a very powerful mechanism fuelling international labour migration in Europe. Such a policy would amplify spatial concentration forces, but, at the same time, would accelerate the process of economic convergence, which is conditioned upon free transfer of production factors. In a long run, it would therefore lead to more decentralized, polycentric development. 
Under such a regime of economic growth and policy, the spatial evolution of the European urban system might considerably deviate from the one presented in the respective project scenario. The European Union would become too large and populous, and too much diversified to be controlled, in terms of flows and economic activities, by a single core area, i.e. the Pentagon. The extension of the Union far to the east would probably result in the formation of several second-order zones (areas) of advanced economic integration in Central Europe, focusing on Vienna-Budapest and Warsaw, and subsequently, in Eastern Europe, around Kiev and Istanbul. This tendency would be supported by the growing openness of the EU to the outer world.

Such a future development pattern is also suggested by another crucial assumption of the competitiveness-oriented scenario, namely a significant increase of infrastructural investments to be put into extension of existing road, motorway and railway systems, especially geared to reinforce the links between major metropolitan areas. These policies would benefit both the EU core regions and a number of large cities in Central and Eastern Europe, "...favoured by the strengthening of the TransEuropean corridors and of broad bend networks" (ESPON Project 3.2, p. 38).

These sets of policies (and some others, for example on the diversification of energy supply systems), as outlined in the competitiveness-oriented scenario, would undoubtedly work so as to strengthen the process of concentration of population and economic activity in Europe's metropolitan areas. They would lead, as claimed by the authors of the project, to less polycentric urban systems, i.e. a further development of their upper level at the cost of medium-sized and small cities, and to territorial expansion of metropolitan areas involving, along with the accumulation of social problems in central cities, a gradual transfer of important, high-ranking functions and related jobs in advanced economic actives from cores to metropolitan ring zones. It is not convincing, however, that such a development would involve a sort of implosion of the EU economic heartland-the Pentagon i.e., a relative, compared to the baseline scenario shrinking of the area of intense flows and activities. It seems rather that the competitiveness-oriented pattern, including a major enlargement of the European Union to the east, would be accompanied by a territorial extension of the main frame of the European urban system formed by a set of strongly interconnected large urban centres and of clusters of metropolitan areas. The West-East economic divide within the EU might indeed grow in the initial period, but prospects for a faster convergence in a more distant future would also increase.

The cohesion-oriented scenario is grounded on the presumption that in case of incompatibility between cohesion and competitiveness priority will be given to the former criterion. Although some measures related to competitiveness are still integrated into the scenario, an important role is ascribed to social policies, focusing on a broad spectrum of issues, including education, employment, integration, support to families, with children etc. However, the deepening of the European integration (together with the brake on future enlargement of the EU), implies 
the introduction of a number of new regulations at the EU level, which may in fact have anti-cohesion consequences. Such effects may have standardization of measures and standards concerning environmental and consumer protection, unification of taxation policies which would not only lead to growing costs for public budgets, but would also eliminate preferences now enjoyed by firms and regions in the EU new member countries. More control may simply be not in the interest of economically less developed parts of the Union.

The assumed reallocation of infrastructural funds towards the cohesion countries and peripheral regions may turn out to be their dubious gain in face of the overall substantial reduction of the EU budget, including transportation investments. Such reduced outlays would be by far insufficient to meet all the numerous goals of transportation policy as identified in the scenario: the development of efficient transport infrastructure along main corridors in the new member countries and linking them with EU-15, building of a number of regional transportation axes connecting medium-sized and small towns to the trunk networks, promoting (requiring very high expenditures) revival and modernization of railway and inland waterway systems.

Shrinking EU budgets (compared to the trend scenario), together with higher transaction costs for businesses, particularly in the new member countries, and lower rates of overall economic growth might seriously slacken the economic convergence process at the EU level. On the other hand, promises of the cohesion-oriented scenario include demographic revival, socio-cultural integration, lower environmental damages and less negative impacts on rural regions-a rather imposing catalogue of positive directions of change. Spatial concentration forces would be resisted and a certain balance achieved between the development of metropolitan and nonmetropolitan areas.

It is by far uncertain, however, whether all these changes would lead, as shown in the territorial image of the cohesion scenario, to a rightful extension of the Pentagon in all directions, the emergence of new zones of economic integration in the periphery, and the rise of major cities of Central and Eastern Europe in the European urban hierarchy. Could such a spatial development pattern be achieved under lower economic growth, smaller interregional and international flows of people and goods, and the elimination of many incentives for firms from Western Europe to relocate their production and service provision to the new member countries? Even though such a pattern is generated by econometric models used for the purposes of the project, the results should be approached with a dose of scepticism.

\section{TOWARDS A RECONCILIATION BETWEEN COMPETITIVENESS AND COHESION-ORIENTED OBJECTIVES}

In the project report, the competitiveness—oriented and the cohesion—oriented scenarios are treated as rather extreme, "boundary situations". Their sub-optimal and, at the same time largely irrealistic character is clearly exposed by the authors. This 
is corroborated by the following concluding statements: "As environmental damages, social tension and violence are each time higher and unacceptable by the populations, it can be questioned whether a strict, sustained competitiveness policy is realistic in the long run (ESPON 3.2 Project 2007, p. 44). And: "The long-term continuation of a strong cohesion policy very much depends upon the resources that are to be allocated to it. As the global growth rate generated by the cohesion-oriented scenario is rather modest, it can thus be questioned whether a sustained cohesion policy is realistic for the long term (ibid., p. 50).

As a consequence of these evaluations, an attempt is made in the project to design "an optimal", a Proactive Scenario, in which competitiveness, cohesion and sustainability are not treated as trade-offs, but rather as complementarities. In order to meet such a strategic goal ways must be find to combine the policies of substantial public spending with significant increases in productivity. This, it is claimed, can be achieved by focusing on two sectors: education and innovation (building science parks, enlarging university departments) and public services, notably heath care and child care.

With respect to spatial dimension, it is taken into account that objectives and policies may differ at different scale. This approach is in a way alternative, and perhaps complementary to the diachronic "phase-policy model" elaborated at the Academy for Spatial Research and Planning in Hannover (Benz et al. 2004). The large metropolitan areas are regarded as one of Europe's assets, and their position in global networks should be maintained. At the same time, policy of resource transfer from the richest to the poorest regions would continue, so that certain economic and social standards are met across space. Also a balance would be found between protection of cultural diversity and heritage and the policies of competitiveness and cohesion which may tend to undermine traditional structures and lead towards a cultural homogeneity.

The territorial pattern that emerges from the Proactive Scenario is fairly close to, though less deconcentrated than in the case of the cohesion-oriented scenario. It provides for the development of the so-called economic integration zones outside the Pentagon (rather than a territorial expansion of the Pentagon proper), the areas characterized by high levels of investments, innovation and agglomeration effects. Such areas would include the core of the Baltic Sea Region, and the "Eastern Square" of Central and Eastern Europe, formed by Berlin, Vienna, Budapest in Warsaw; the South of France and Catalonia. Between individual zones of economic integration strategic links would develop, such as, in the case of Poland, between Gdańsk and Łódź, and between Warsaw and Riga.

A constellation of mutually interlinked zones of economic integration (following the terminology introduced in the ESDP), stretching across large parts of Europe, constitutes a somewhat novel idea when compared to the concept of territorial extension of the Pentagon area. It reflects a spatial development pattern that could be found attractive enough, and sufficiently general to be accepted and assimilated by spatial policy both at the EU and a national level. When looking from the Polish perspective two modifications of the idea can be put forward. Firstly, zones of economic 
integration should be considered as clusters of major metropolitan areas comprising functionally integrated networks, rather than continuous territorial units. Secondly, when delimiting those zones, the actual as well as potential interaction between cities should be used as the basic criterion. This has not always been the case of the Proactive Scenario, in which, for example, the interdependence between metropolitan areas, in particular the capital cities of the new EU member countries is generally overestimated.

\section{CONCLUSIONS}

Several objectives have been fulfilled by the ESPON Scenarios project that comprise important steps in the elaboration of conceptual bases for spatial policy at the European level. Sets of assumptions were formulated referring to two hypothetical policy approaches-the competitiveness and the cohesion-oriented policies. These assumptions were employed in building mutually contrasting, boundary development scenarios, including their territorial images. Even though the correspondence between the assumptions and the ensuing spatial patterns leaves the reader with a number of doubts, the usefulness of the exercise for further work is clearly undisputable. The main result of the study, however, is the attempt to construct a framework for the reconciliation between competitiveness and cohesion-oriented development goals. This is the area, in which a lot of subsequent, spatial policy focused research will certainly be conducted.

\section{REFERENCES}

Benz, A., Borchard, K., Eser, T. W., Kujath, H.J. et. al. (2004), Why the EU needs a European spatial development policy, ARL Position Paper, 60, Honnover.

Domański, R. (ed.) (1999), The Changing Map of Europe. The Trajectory BerlinPoznań-Warszawa. A tribute to Antoni Kukliński, Friedrich Ebert Stiftung, Warszawa.

ESDP, (1999), European Spatial Development Perspective. Towards balanced and sustained development of the territory of the European Union, European Commission, Luxembourg.

ESPON Project 1.1.1, (2004), The role, specific situation and potentials of urban areas as nodes in polycentric development, Final Report, European Communities, Luxembourg.

ESPON Project 3.2, (2007), Scenarios on the territorial future of Europe, Final Report, European Communities, Luxembourg.

Koncepcja polityki przestrzennego zagospodarowania kraju [Poland's spatial development perspective], (2001), Monitor Polski, 26, 503-595. 


\title{
RESEARCH ON METROPOLITAN FUNCTIONS: IDENTIFICATION AND DEFINITIONS ACCORDING TO THE ESPON AND ALTERNATIVE APPROACHES
}

\author{
EWA KORCELLI-OLEJNICZAK \\ Institute of Geography and Spatial Organization \\ Polish Academy of Science \\ Twarda 51/55, 00-818 Warszawa, Poland
}

\begin{abstract}
In the course of the project ESPON 1.1.1, on polycentricism of the European urban space, three categories of Functional Urban Areas-spatial units identified earlier in the study-were distinguished. The indicators chosen for this analysis were population, transport, tourism, industry, knowledge, decision-making and public administration. This allowed to identify the functionally strongest FUAs, i.e. the Metropolitan European Growth Areas (MEGAs), which were then qualified according to a set of eight further variables. The ESPON 1.4.3, which directly concerned urban functions, has slightly modified the indicators of FUA and MEGA typology, which was proceeded by a thorough analysis of the assessment criteria of the classification. The significant contribution, which the effects of the two projects present with regard to the discussion on what are 'metropolitan functions' may only be questioned in the respect, whether the practical limitations to the analysis, such as data availability have an impact on the complexity and completeness of the applied factors. On the basis of some classic and newer identifications and definitions of metropolitan functions, the present paper raises the questions, whether and how empirical studies change theoretical concepts. Is the term 'metropolitan functions' and are the variables described as 'metropolitan functions' composed a priori or a posteriori. In the light of these ideas, the Author explores the findings of the two ESPON projects.
\end{abstract}

Key words: metropolitan functions, functional specialization, identification, definitions, perceptual studies, theoretical models

\section{INTRODUCTION}

The ESPON projects 1.1.1 (2004) and 1.4.3 (2007) have analyzed European urban space in its functional dimension. The first project, on "the role, specific situation and potentials of urban areas as nodes in a polycentric development" was to research the conditions for a more polycentric urban development of the European urban 
system, following, with some restrictions, the idea of policentricity manifested by the European Spatial Development Perspective. The main idea was the assertion that a polycentric urban development of the EU27+2 requires a counterweight to the Pentagon, which constitutes a too much concentrated space of European urban power. This had led to an investigation of the state of the urban system with respect to its functional specialization and the degree of its polycentricity. The ESPON 1.4.3., in reference to the postulate of polycentricism has continued the study of functional specialization of urban units, identified earlier in the course of the studies as the FUAs (Functional Urban Areas). Trying to answer the question whether "more polycentric national and European structures could lead simultaneously to more equity and effective regional development, (...), to a more effective, competitive and better integrated European economy, favouring also the sustainable development" (Draft Final Report, Executive Summary, p.8-9). An indirect result of the two studies, serving further investigations, was an identification of a set of variables corresponding with the metropolitan functions of the FUAs. After the ESPON 1.1.1. had developed the FUA typology and distinguished 76 strongest units, the so called FUAs of Excellence (MEGAs) were again tested according to selected factors. This had led to a MEGA qualification, and established a ranking of these functionally strongest FUAs. The ESPON 1.4.3. had then developed the applied criteria of FUA and MEGA qualification by modifying the functional measures of the spatial units.

The indicators selected by 1.1.1. were modified by the second project in line with the aims of urban competition, cohesion and the Lisbon criteria. The comparison and evaluation of the selected variables in the two studies is the starting point and precondition for the primary and direct aim of the present paper, which is to show whether and to what extent the ESPON projects 1.1.1. and 1.4.3. have contributed to the development in defining and identifying metropolitan functions. It has to be stressed at this point that the identification of functions, which arose from the proceedings undertaken by the projects cannot be treated as complete, due to the practical fact that the selection of factors was more on less dependent on the accessibility of data. The research questions, which seem significant to put at this place are: how the practical aims and the limitations to the study influence the theoretical identifications of metropolitan functions. Are definitions and selections of metropolitan functions restricted by their measures in practice. And therefore, to what extent can an empirical project be faithful to its theoretical assumptions. Are scientific generalizations considering the notion of metropolitan functions and their distinction formulated a priori or a posteriori?

\section{“METROPOLITAN FUNCTIONS" AS A RESEARCH OUESTION}

In his studies on the transformation of urban systems Bourne (1997, p.7) identifies five most basic urban features, so called logics: communication, circulation, produc- 
tion, consumption and reproduction, as well as control and regulation. As the author puts it, the existing "classic" theories referring to urban systems, such as "the economic base" and the central-place theory, accentuate the special importance of production and distribution. On the contrary, newer theories describing globalization, financial flows and the world city phenomenon, stress the significance of the other three logics, control and regulation in particular. As in the conditions of the early XX century, trade and transportation (Gras 1922), and then communication, finances and management (McKenzie 1933; Bogue 1949) were those activities the specialization and range of which distinguished a central place and a metropolitan city. P.S. Florence (1955) has distinguished metropolitan cities within an "urban hierarchy, which were characterized by such functions as: financial and entrepreneurial services, editorial and printing activities, science, arts and entertainment. Another hierarchical concept was introduced by Vance and Smith (1954) were the metropolis was categorized according to its position as a recipient of the world economy. This had lain only a step behind the definition of world city functions provided by Hall (1966) in The World Cities, were next to the position in the global economy the variety, the multiplex character of a global metropolis was accentuated. A world city performs simultaneously the roles: of centres of national and international political power and trade, as centres of banking, insurance and other related services, but also in law, medicine, higher education, knowledge-based technology, information, mass media, production of luxury and mass-quality goods, as centres of culture, arts and entertainment. The "world city hypothesis' (Friedmann 1986), developed only a few years later identified corporate control and regulation, international finances, global transportation and communication and specialized business services, such as insurance, law, commercials, and additionally ideological penetration and control (dissemination of information, news and entertainment) as functions distinguishing world cities. These indicators were then often used when describing the functional structure of large cities, not necessarily those of global importance. Drawing from the concept of the "world city", metropolitan functions are usually defined as "highly specialized functions of mostly international, but not less than national importance" (Korcelli-Olejniczak 2004). Some authors however perceive this question less rigorously. A city can for example, perform only some of the functions, and/or have a smaller spatial range (e.g. more than regional) and still count as metropolitan. This leads, on the one hand, to an excessive multiplication of metropolises, on the other, to a development of a hierarchy of metropolitan cities, all performing metropolitan functions of various range, importance and specialization.

At this point it is useful to recall the question put by Maik (2003), whether metropolises and their functions should be analyzed in a traditional way, basing on the fundamental concepts and using traditional measures, such as the employment indicators, and if this leads to the achievement of the intended goals. Maik stresses the importance of combining various approaches and methods. Metropolitan functions should be researched on the basis of the existing theories and measured by 
the help of employment indicators, this procedure should however be complemented by the analysis of institutions, urban organizations and the reach of their activity. The Author seeks the identification of metropolitan functions in the semantic model of the "metropolis", i.e. the features characterizing a metropolitan city. The list of these features consists of the demographic potential of the city, its overall economic capacity, its spatial accessibility, economic and financial connectivity, advanced services, its intellectual and cultural potential (Maik 2003, p. 15). Following these ideas a further question should be put forth, namely how the actual studies of metropolitan functions, where the choice of method is dependent on the availability of data, corresponds with their identification reflected by the theories. Theories are seldom actualized, new concepts take place 'next to them' and seldom replace them, like the concept of the "innovative city" (Domański 2001) which builds upon classic urban theories and physical theories, placing them within contemporary conditions of requirements and possibilities. But are new concepts created as a result of empirical findings? And, putting a less ambitious question, how do the sets of indicators measuring metropolitan functions correspond with those identified in theoretical models, i.e. those created only for the sake of their existence as a theoretical basis?

Germany's spatial planning focuses in the last years on developing the concept of "metropolitan regions", which take the place of cities, as classic locations of innovation, development and competition. These new forms of concentration are a part of a currently arising system of international labour division within the global competition. The spatial delineation of these urban regions is not clear, as they are rather a compound of metropolitan equipment and institutions, a place of exchange of major regional actors, targets, strategies, projects and forms of organization. The concept of "metropolitan regions", their identification and description is subject to numerous projects, which function on the intersection of science and regional policy. A joint program of four leading German Institutes and Institutions ${ }^{1}$ has provided a theoretical background study aiming at a thorough description and understanding of "metropolitan regions"(Ergebnisse ... 2007). One of the results was an a priori identification of functions which the metropolitan regions were to perform in the globally networked flows of goods, capital, information and people. The study identified four major metropolitan functions:

- Function of Innovation and Competition;

- Decision-making and Control function;

- Gateway function;

- Symbolic function.

The above functions are key fields of activity, which aim at sustaining and development of the capability of metropolitan regions. Decision-making and control mean a good position of the urban region as a competitor for location, which provides im-

${ }^{1}$ Akademie für Raumforschung und Landesplanung (ARL, Hannover), Deutsches Institut für Urbanistik (difu, Berlin), Institut für Landes- und Stadtentwicklungsforschung und Bauwesen des Landes NRW (ILS, Dortmund), Leibniz-Institut für Regionalentwicklung und Strukturplanung (IRS, Erkner). 
portance and required interlinking in space. The larger the importance of the knowledge-based economy in the region, the lower the danger of 'brain drain'. The gateway function has various aspects; it concerns both the capability of infrastructure, in the first place the position of the region as a transportation node and the functioning as a 'gateway to the rest of the world' with respect to the access to and the exchange of services, information, knowledge, ideas and attitudes. To be metropolitan means also to be characteristic, unique in its medley of internationality and regionalism, tradition and cosmopolitan features, to produce 'spatial brands', which are then vitalized and disseminated by people.

A similar approach, as the one above was used in the study on metropolitan regions and metropolization by Markowski and Marszał (2006), which ordered the existing nomenclature, defined terms and introduced various identifications. The study distinguished two kinds of criteria, which decide about the metropolitan character of a city. Functional criteria, such as population size, economic and innovational potential, connectivity and the performance of metropolitan functions are described here as primary in relation to morphological features, that is the existence of well developed metropolitan spatial systems, the uniqueness and special character of the place, historical or cultural values. The authors provided also a definition and identification of metropolitan functions, which are "functions directed towards the outside, of a more than regional importance, which base on highly specialized service activities belonging to the IV sector of the economy" (Markowski, Marszał 2006, p. 13). The following activities are identified as metropolitan: of a political, religious and administrative centre, cultural, scientific and educational node, a tourist attraction, economic and financial centre, a place accumulating and radiating information and transportation flows. Especially decision-making and control functions of global importance are perceived here as superior.

Descriptive and systematizing assumptions are applied also in most monographs on metropolitan cities or urban systems. The works analyze metropolitan features, evaluate the criteria of their typologies, qualify metropolises according to chosen rules (e.g. Bassand 1993; Kunzmann, Wegener 1991; Dematteis 1997 or Jałowiecki 1999). Most often, the identification of metropolitan functions is a secondary procedure, a way of defining a metropolis. The performance of metropolitan functions is described as one of the criteria which decides about the metropolitan character of the city. Metropolitan activities are also treated as criteria of hierarchical (according to their range and variety) and non-hierarchical (estimating the dominance of a particular activity) classifications of metropolises. Parysek (2005, p.48) stresses the fact that there is a reciprocity and interdependence between morphological (the development of spatio-structural systems) and functional features (development of metropolitan functions) of a city. He also points to the fact that a precondition for classifying a city as metropolitan is the co-existence of a number of metropolitan functions of various character, e.g. cultural, scientific, political. A city performing one specialized activity cannot therefore qualify as metropolitan. 


\section{IDENTIFICATION VERSUS APPLICATION}

What happens when the variables identified as metropolitan functions have to be measured? How do we proceed when the study reaches beyond descriptive goals? Is there an interdependence between the choice of indicators defined as metropolitan functions, the availability of methods chosen for their quantitative or qualitative measurement and the accessibility of data? These questions, also relevant in studies analyzing only chosen metropolitan functions like control and regulation, air connectivity, network linkages or cultural institutions (e.g. Taylor et al. 2002; Śleszyński 2002; Lijewski 2003; Domański, Guzik, Gwosdz 2000; Roloff-Momin 1995) in this case are directed towards those research attempts which concern the general functional structure of the city. As on their basis, the relation between empirical studies and the $a$ priori identification of metropolitan functions can be evaluated.

Gawryszewski, Korcelli, Nowosielska (1998, p. 103) identify 14 following groups of metropolitan activities:

- Publishing and printing activities;

- Wholesale trade;

- Hotels and restaurants;

- Transportation;

- Postal activities and communication;

- Finances, stock exchange, insurances;

- Entrepreneurial services;

- Computer services, information, electronics;

- Science and R\&D;

- Political and administrative power (above local scale);

- Higher education;

- Entertainment, art, museums, expos;

- Diplomatic posts;

- Research institutions, offices, branch offices of foreign companies.

According to the authors, "metropolitan functions" are highly specialized functions of the III and IV sector of the economy. Their selection corresponds with some exceptions with the Standard Classification Index (SIC) which lists certain types of employment. The data from the Polish Index (PKD), collected by the Central Statistical Office are constantly accessible. The list, however, includes also those functions not present in the index. As the study aimed at estimating the number of persons employed in the respective metropolitan activity, the lacking statistical data was achieved via other methods. It seems therefore that the research methods and data accessibility were treated here as secondary in relation to the a priori composed list of metropolitan functions.

Basing the definition of metropolitan functions on the 'world city concept', and on the reworked identification of metropolitan activities (logics) by Bourne (1997) in a comparative study of Berlin and Warsaw (Korcelli-Olejniczak 2004), the present 
author has attempted at a possibly faithful analysis of all metropolitan functions identified.

Table 1. Metropolitan functions as components of urban activities

\begin{tabular}{|l|l|}
\hline Metropolitan function & Activity \\
\hline Transportation node & Distribution and circulation \\
\hline City of knowledge and innovation & Production and reproduction \\
\hline Cultural centre & Consumption and reproduction \\
\hline $\begin{array}{l}\text { Seat of government and parliament } \\
\text { Location of headquarters } \\
\text { Financial centre }\end{array}$ & Regulation and control \\
\hline
\end{tabular}

Source: E. Korcelli-Olejniczak 2004.

The methods chosen were mostly qualitative; a comprehensive in-depth interview with 30 experts was completed by a statistical analysis of employment data. The balanced relation between theory, concept and empirical studies, which was one of the aims of the work, could quite easily be sustained here.

\section{Theory $\longleftrightarrow$ Concept $\longleftrightarrow$ Perceptual Studies}

Figure 1. Relation between theoretical models, descriptive concepts and perceptual studies

This is the track, which the present author follows while exploring the findings of ESPON 1.1.1 and 1.4.3.

\section{METROPOLITAN FUNCTIONS AND THE ESPON APPROACH}

A primary goal of ESPON 1.1.1. was the identification of functionally strong urban nodes, which, dispersed throughout the continent, could potentially be treated as a possible counterweight to the Pentagon. The functions chosen for the sake of the analysis were:

- Mass function (population);

- Transportation;

- Tourism;

- Industry;

- Knowledge;

- Decision-making;

- Public administration.

The study failed to separately or jointly analyze the spatial range of the given functions. In some categories though, the way they were chosen allowed for an evalu- 
ation of the city's importance in the spatial dimension. This concerned for example the decision-making function, as measured by the location of the largest companies in Europe, or the administrative role of the FUA, where the importance of the city was identified as local, regional, national or transnational. When the FUA held European or other international institutions, the range was treated as transnational. Transportation was measured according to traffic levels at the main airports, which said nothing about the origin and destination of the passengers and therefore could not characterize the spatial importance of the airports investigated. By analogy, the measurement of the knowledge functions of the FUA provided good know-what on the degree of polycentricity of science and education in the respective country, and evaluated the national importance of the region with respect to this category, but no information whatsoever whether the range of the function was mainly regional, or national, or transnational. Such knowledge could be attained by in-depth survey studies.

The functions identified differ with respect to their scope; some carry more information and are more objective than the others (Korcelli-Olejniczak 2007). Some functions, identified by most other studies were clearly omitted. This concerns in particular culture and mass media. It seems that the reason for this lies beyond the conceptual level, that the lack of easily accessible data was decisive here. There is no ambiguous relation between the presence of a university and the performance of cultural functions, as some small university towns have limited cultural importance. The transportation measures (air connectivity) and the tourist function elevated some small summer resorts like Palma de Mallorca to high positions.

The 76 MEGAS (FUAs, which qualified as best in the study) were in the next step tested according to eight variables, components of metropolitan functions. Those were population, GDP in millions of EURO, GDP in Purchasing Power Parity per capita, location of Top 500 companies in Europe, number of passengers at airports, the multimodal accessibility indicator, education level and R\&D share of employment. The selected criteria were to measure the mass, competitiveness, connectivity and knowledge basis of the MEGAs. Here especially the results concerning urban competitiveness are questionable, as the chosen criteria (e.g. location of Top 500 companies in Europe) are rather positive consequences of the city's competitiveness than components of their development potential. As this is not the place for a further analysis of the MEGA qualification, it can only be stressed that the classification achieved corresponds, with some restrictions, but all in all, with other rankings of European metropolises.

Continuing the efforts of 1.1.1., ESPON 1.4.3. has attempted at deepening the studies of the functional structure of FUAs. In the course of the analysis five functions were selected which, on the one hand, were to evaluate the city regions, on the other, were easily measurable due to the accessibility of data. The chosen functions were:

- Administrative functions, both national and international;

- Decision functions; 
- Transport functions, measuring connectivity via air, rail, road and sea;

- Knowledge functions, including the localization of important universities, research centres and knowledge-based production;

- Tourism functions, encompassing potential conditions and factual usage of tourist facilities, when available also other cultural criteria, such as information on congresses, theaters, festivals and the like.

The results were presented on maps showing the spatial distribution of FUAs and their position according to each of the selected functions. The identification of functions was conditioned by data availability but considerably improved in comparison with the former project. The selection corresponded to a great extent with the functions present in most theoretical models, though the FUA classification was in some cases still distant from that presented in most existing rankings of cities and city regions.

\section{CONCLUSIONS}

The analysis of the functional structure of FUAs, carried out in the framework of ESPON 1.1.1 and 1.4.3. was severely restricted by practical limitations. The choice of indicators was in the first case more random, while strictly pre-conditioned by the availability of data, in the second example more theoretically based, although also restricted by measurement possibilities. This clearly shows that these limitations in some-though only immeasurable way-influence the results, but more directly shake the balanced relation theory-concept-empirical findings. This is a negative phenomenon, as this model constitutes the spine of scientific research. It is however positive that studies treading on the marks of their predecessors tend to improve; both as far as the overcoming of limitations and the balancing of the above relation are considered.

\section{REFERENCES}

Bassand, M. (1993), The metropolisation of the world, in: Gorzelak, G., Jałowiecki, B. (eds.) Regional questions in Europe, 10, University of Warsaw, Warsaw, 17-32.

Bogue, D.J., (1949), The structure of the Metropolitan Community, University of Michigan Press, Ann Arbor.

Bourne, L. S. (1997), Urban systems in an era of global restructuring: expanding the research agenda, in: Palomäki, M., Karunaratne, J.A. (eds.) Urban development and urban life, Universitas Wasaensis, Vaasa, 15-19.

Dematteis, G. (1997), Répresentation spatiale de l'urbanisation européenne, in: Villes en Europe, La Découverte, Paris.

Domański, R. (2001), The innovative city, The Academy of Economics, Poznań. 
Domański, B., Guzik, R. Gwosdz, K. (2000), Konkurencyjność i ranga wielkich miast Polski w świetle inwestycji zagranicznych firm produkcyjnych, Biuletyn KPZK PAN, 192, Warszawa, 99-122.

ESPON Project 1.1.1 (2004), The role, specific situation and potentials of urban areas as nodes in a polycentric development, Final Report. The ESPON Programme $<$ www.espon.lu>

ESPON project 1.4.3 (2007), Study on urban functions, Draft Final Report, The ESPON Programme <www.espon.lu>

Ergebnisse des gemeinsamen Arbeitskreises "Metropolregionen-Innovation, Wettbewerb, Handlungsfähigkeit” (2007), ARL, Hannover; difu, Berlin; ILS, Dortmund; IRS, Erkner, Hamburg.

Florence, P. S. (1955), Economic efficiency in the metropolis, in: Fisher, R.N. (ed.) The metropolis in modern life, Double Day, Garden City, New York, 86-88.

Friedmann, J. (1986), The world city hypothesis, Development and change, 17, 1, Institute of Social Studies, The Hague, 69-83.

Gawryszewski, A., Korcelli, P., Nowosielska, E. (1998), Funkcje metropolitalne Warszawy, Zeszyty IGiPZ, 53, PAN, Warszawa.

Gras, N. S. B. (1922), The development of metropolitan economy in Europe and America, American Historical Review, 27, 695-708.

Hall, P. (1966), The world cities, Weidenfeld and Nicolson, London.

Jałowiecki, B. (1999), Metropolie, Wyższa Szkoła Finansów i Zarządzania, Białystok. Korcelli-Olejniczak, E. (2004), Funkcje metropolitalne Berlina i Warszawy w latach 1990-2002. Współzależność pozycji w systemie miast Europy Środkowej, Prace Geograficzne, 198, IGiPZ PAN, Warszawa.

Korcelli-Olejniczak, E. (2007), Evaluation of MEGA identification and qualification, in: ESPON 1.4.3 Final Report, Comments on ESPON 1.1.1 Final Report.

Kunzmann, K., Wegener, M. (1991), The pattern of urbanisation in Western Europe 1960-1990, Berichte aus dem Institut für Raumplanung, 28. Fakultät Raumplanung, Institut für Raumplanung, Universität Dortmund, Dortmund.

Lijewski, T. (2003), Koncentracja ośrodków aktywności gospodarczej w Polsce w świetle list 500 firm, Przeglad Geograficzny, 75, 2, 433-447.

Maik, W. (2003), Pojęcie metropolii a problem badania funkcji metropolitalnych, in: Jażdżewska, I. (ed.) Funkcje metropolitalne i ich rola $w$ organizacji przestrzeni. XVI Konwersatorium Wiedzy o Mieście, Uniwersytet Łódzki, Łódź.

Markowski, T., Marszał, T. (2006), Metropolie, obszary metropolitalne, metropolizacja. Problemy i pojęcia podstawowe, KPZK, PAN, Warszawa.

McKenzie, R.D. (1933), The metropolitan community, McGraw-Hill, New York.

Parysek, J.J.(2005), Miasta polskie na przełomie XXiXXI wieku. Rozwój iprzekształcenia strukturalne, Bogucki Wydawnictwo Naukowe, Poznań.

Roloff-Momin, U. (1995), Kulturstandort Berlin, in: Süß, W., Rytlewski R. (eds.) Berlin. Die Hauptstadt. Vergangenheit und Zukunft einer europäischen Metropole, Nicolaische Verlagsbuchhandlung Beuermann GmbH, Berlin, 543-550. 
Śleszyński, P. (2002), Struktura i rozmieszczenie ośrodków zarządzania w polskiej gospodarce w 2000 roku, Przeglad Geograficzny, 74, 2,199-228.

Taylor, P.J., Walker, D.R.F., Catalano, G., Hoyler, M. (2002), Diversity and power in the world city network, Cities, 19, 4, Elsevier Science Ltd., 231-241.

Vance, R. B., Smith, S. (1954), Metropolitan dominance and integration, in: The urban South, University of North Carolina Press, Chapel Hill. 
BCl@PAN http://bibliotekacyfrowa.pan.pl 


\title{
ESPON 1.2.1 RESULTS AND THE FUTURE OF POLISH TRANSPORT INFRASTRUCTURE ${ }^{1}$
}

\author{
TOMASZ KOMORNICKI \\ Institute of Geography and Spatial Organization \\ Polish Academy of Sciences \\ Twarda 51/55, 00-818 Warszawa, Poland \\ e-mail: t.komorn@twarda.pan.pl
}

\begin{abstract}
This paper presented results from the ESPON 1.2.1 Project, contained the conclusions end recommendations the point of view of Poland, especially from the development of infrastructure in the coming twenty years. Thus, the paper presents: (a) a shorthand outline of the content of the Report; (b) the main problems associated with the applied methods, source data and indicators; (c) a general assessment of the policy recommendations; (d) conclusions valid for Poland, originating from the recommendations and (separately) from the entire material. The description of the methods, sources, and of the conclusions has partly a critical character.
\end{abstract}

Key words: transport infrastructure, ESPON, Poland

\section{INTRODUCTION}

At the end of 2006, the period of realisation of the projects in the framework of the first ESPON program (European Spatial Planning Observation Network, for more information see www.espon.eu $)^{2}$ terminated. The results from these projects became, in particular, the basis for the Territorial Agenda of the EU, adopted in May 2007. Hence, the results of these projects exert an influence on the present

\footnotetext{
1 The paper was elaborated on the basis of the expert report entitled: Transport networks and services: spatial trends of development of the infrastructural networks and basic services for the attainment of territorial cohesion (2002-2004) - recommendations for the National Development Plan for the years 2007-2013 and for the Concept of the Spatial Organisation of the Country, [in Polish], prepared by the author at the commission from the Ministry of Economy at the turn of the year 2005.

2 Launching the ESPON project in the financial period 2000-2006 was a direct consequence of European Spatial Development Perspective arrangements, and was related to an increasing significance of spatial issues. Within the framework of ESPON program a dozen or so large projects, concerned with spatial aspect of a great number of basic socio-economic issues, were carried out. A part of these were dedicated to giving assesment of the sector and EU policies from the perspective of territorial effects. As a result, Atlas and ESPON database containing spatial bits of information were created. In charge of these projects were transnational consortia of scientific institutions, every time at least from three different countries. The whole project encompassed 29 countries, including all the then current members of the European Union (as of 2000) and 12 candidate states, as well as Switzerland and Norway.
} 
and future (especially with respect to the period of financing 2007-2013) policies of the Union, both regional and sectoral. The broadly understood transport was in the focus of interest of a number of ESPON projects. The specialists from Poland could fully participate in the realisation of the Program only after May 1st, 2004. That is why the majority of the initial projects were prepared without their active participation $^{3}$. Limited participation concerned all the new member countries. In some cases, this resulted in lack of adequate knowledge, and also of the source data, concerning Central Europe, and so also not fully adequate conclusions and recommendations. This applies, in particular, to Project 1.2.1, concerning transport networks and services. A careful and critical assessment of the conclusions, contained in the results from the project, is, therefore, a highly important task for all the specialists associated with transport geography.

The purpose of the present paper is then to generally, characterise the Final Report from the ESPON 1.2.1 Project, entitled: Transport services and networks: territorial trends and basic supply of infrastructure for territorial cohesion, to assess the conclusions and recommendations contained therein from the point of view of Poland, and especially from the point of view of the development of infrastructure in the coming twenty years. Thus, the paper presents: (a) a shorthand outline of the content of the Report; (b) the main problems associated with the applied methods, source data and indicators; (c) a general assessment of the policy recommendations; (d) conclusions valid for Poland, originating from the recommendations and (separately) from the entire material. The description of the methods, sources, and also of the conclusions has partly a critical character. This does not imply the criticism with respect to the Report as a whole. It is merely the indication of these elements, which might lead to false generalisations, and first of all - to the inappropriate recommendations concerning the space of Poland.

Against this background the challenges will be presented, facing Polish transport policy in the context of the further development of infrastructure (including, first of all, its linear elements-roads and railways), and the necessary institutional solutions, supporting this development. In this part of the present paper the fragments of a previous paper, published before in the Bulletin of KPZK, are made use of. ${ }^{4}$

\section{EUROPEAN AND POLISH TRANSPORT POLICY CONTEXT}

An accurate assessment of the contents of the Report from ESPON Project 1.2.1 requires looking at the basics of a European and Polish transport policy. At the Eu-

3 Situation changed in the years 2005-2006, when the Institute of Geography and Spatial Organisation of the Polish Academy of Sciences and the Euroreg institute of the University of Warsaw participated in altogether some ten projects.

4 Komornicki, T., 2007, Rola infrastruktury transportowej w rozwoju kraju-wyzwania wobec kohezji przestrzennej [The role of transport infrastructure in the national development—challenges with respect to spatial cohesion; in Polish], in: Markowski, T., Stasiak, A., (eds.) Rola polskiej przestrzeni w integrującej się Europie, Biuletyn KPZK, 233, KPZK, Warszawa, 63-86. 
ropean community level, the transport policy has a relatively short history. Actually, it was originated in 1992 with publishing the White Paper on a Common Transport Policy. Its primary assumption was striving for goals related with competitiveness, cohesion (regional development) and environmental protection (Banister et al. 2000). In the initial period, that was predominantly based on developing transnational infrastructural projects. In 1994, 14 transeuropean transport investment projects were given high priority. Simultaneously, however, the transport investment projects consumed a huge part of structural funds provided for poorer regions within the EU (especially for Spain, Portugal, Greece and Ireland). A vast number of transportation projects were also financed by the European Investment Bank. However, the transport policy based on investments was criticized at that time by academic circles, emphasizing the need for change of the paradigm of unlimited growth in mobility of people and goods. It was contended that unlimited mobility is not desirable environmentally and socially (Banister et al. 2000). Irrespective of the fact that a great number of studies suggested reducing the mobility in the future, a large body of experts realized that there were limited chances of it happening (Nijkamp et al. 1998). That follows, inter alia, from the fact that taxes associated with vehicles and use of these constitute a highly significant part of budget income for European states-a part seen as a one of the basic sources for social expenditures (Forecasting car ownership and use 1982). In addition, the automotive industry is perceived as a driving force behing development. In this respect Poland, wherein the automotive industry proved to be one of the most dynamic businesses under conditions of political system transformation, may serve as a good example. As early as 2001, Menes (2001) estimated that, in Poland, total fiscal revenues from a broadly understood automotive industry totalled 20 billion PLN, accounting for 13-14\% of all the fiscal tax revenues. Chances of restricting mobility were questioned in light of the fact that there were much poorer than expected effects of telecommunication development (including the teleworking, Button 2005).

Nevertheless, the ongoing discussion had an impact on the European transport policy at the turn of the centuries, shaped under conditions of the already adopted Kyoto Protocol (1997). The European Union faced then a serious dilemma with the under-mentioned determinants:

- Growing role of environmental protection (including curbing carbon dioxide emissions) and associated with this the necessity of replacing the investment policy with the demand shaping policy (controlling the mobility), as well as with the policy of improving effectiveness of the already existing networks.

- The oncoming accession of 12 new member states, the majority of which (including Poland) were characterized by huge backwardness in development of modern transportation networks, both internal as well as external hampering the connection with the economic core of the EU.

That problem could be solved only by means of diversifying the EU regional transport policy. Adopting the system of pan-European corridors for Central-East Europe 
in 1992 by European Ministers of Transport was a manifestation of such diversification (while not being the intra-Union initiative). Also, the support provided for the accession countries within the framework of ISPA project was a move toward that direction.

Poland's transport policy in the pre-accession period did not refer practically to the aforementioned dilemmas. In fact, in the declarative sphere, it had an investment character. Also, in a fair number of cases that policy was even based on the assumptions made in the earlier period of centrally planned economy. In such approach, major significance was attached to transit linkages, perceiving transport as a potential source of income from external entities. Depreciation of railway transport, whose transformation went under dictate of a trade union, was allowed (as a result over 8 thousand $\mathrm{km}$ of railway lines were closed). At that point, unfortunately, the potential conflicts related with the EU environmental policy were overlooked. In addition, the dillmeas over transport policy, were not brought up as a matter for accession negotiations (what is more, no efforts were made to introduce transitory periods due to backwardednes in infrastructural development). At the same time, however, the mobility of the population was growing fast, exemplified by a rapid exponential motorization of Poland, not justified by the growth in GDP, which was frequently criticized by various leading specialists in different transport-related fields (inter alia, Suchorzewski 2000; Lijewski 2000; Taylor 2002).

\section{CONTENTS OF THE FINAL REPORT OF THE PROJECT 1.2.1}

The Project was executed by the consortium of six research institutions, with the lead partner being University of Tours (France). Besides, there were also two other French institutions involved (INRETRS from Lille and NESTEAR from Gentilly), one Italian (Polytechnic of Milan), one Spanish (MCRIT from Barcelona) and one German (S\&W from Dortmund). Project was realised in the years 2002-2004. By the assumption, made by the authors of the Report, it was meant to answer the three fundamental questions:

- To what extent the transport network of Europe plays the role of the key factor in the sustainable and polycentric spatial development of Europe?

- How to improve the accessibility to services and knowledge for purposes of increasing the territorial cohesion?

- What shall be the consequences of the enlargement of the European Union with respect to the two first questions?

Final Report is composed of four parts and the annexes. The first part (Summary) constitutes the outline of the whole and is complemented with selected maps. In the second part (Context and Method) the problems of the European transport policy are characterised (with reference made to the European Spatial Development Perspective, ESDP), as well as new technological and organisational solutions in 
road, railway and sea transport. Then, the methodology and the most important of the indicators used were presented. Special attention was paid to the methodological bases for the analysis of spatial accessibility and the principles of graph construction. Other indicators (most probably designed by the subcontractors to the Project) have not been characterised in detail.

The analytic basis of the Report is constituted by the amplest Part III (Transport Indicators and Maps), where, successively, all the indicators are commented upon, and where the maps and the diagrams have been placed. The following problems are consecutively presented in this part of the Report:

- the state of investment making into the transport infrastructure,

- the costs and the times of travel,

- the daily and the potential accessibility,

- the traffic intensity and the magnitude of cargo flows,

- the external costs of transport,

- the hazards to the transport system from the side of natural and anthropogenic factors.

The whole is summarised in Part IV (Interpretations and Recommendations), composed of three proposals concerning spatial typology, consideration of the most important regional differentiations, as well as the policy recommendations, presented in general and in the breakdown into five macro-regions. A set of complementary maps, concerning accessibility, is contained in the annex. The Report is illustrated by altogether 86 maps (excepting those in the annexes), 41 others, and 20 tables. They present the values of indicators, of which a part originates from the statistical data published, while the remaining ones are the effect of application of models.

\section{STUDY METHODS, SOURCE MATERIALS AND INDICATORS}

The project arose out of the rich theoretical and methodological foundations. Numerous research methods, of diverse degrees of advancement, have been applied in it. This allowed, on the one hand, for a comprehensive approach to the problems studied, but, on the other hand, resulted in a definite inconsistency of the Report. The research methods themselves (including the models applied) and their theoretical foundations do not give rise to doubts. Some methods of presentation, and at the same time chapters of the Report could, however, most probably be omitted, without any detriment to the quality of the Report as a whole. First of all, though critical assessment should be made of some of the assumptions adopted (network pattern, scale of investigation, etc.) and of the basic data used (especially with respect to the key issue of the commodity flows). This concerns in the first place the so-called new accession countries, including Poland.

Definite errors appeared already at the level of construction of graphs, being the basis for a large proportion of the further investigations. Two graphs were devel- 
oped, namely the CESA Graph 765 (765 nodes and 2265 edges, with nodes outside of EU-27 accounted for) and the CESA Graph 4172 (4172 nodes and 9350 edges). In the analysis these two graphs were referred to in an inconsistent manner. Of these two, Graph 4172 is characterised by bigger precision and provides a more complete image for the inside of the territory of EU-27. Simultaneously, though, it does not contain the nodes and edges from the outside of this area (the Balkans, the former USSR), which has a decidedly negative impact on the image obtained for the broadly conceived border regions of the EU. Thus, for the cases of Poland, Romania and the Baltic countries this brings about the deformation of the main directions of connections, excessive emphasis on the relations and potential traffic along the NorthSouth direction, with the reduction of their role on the East-West direction (Figure 1). In particular, in the case of Romania and partly also of Bulgaria the role of transit routes to Greece has been overestimated. In conditions of the advancing normalisation of relations of both Serbia and Macedonia with the EU, and the impending accession of Croatia, the transit routes through Belgrade and Skopje to Greece, as well as through Belgrade and Sofia to Turkey systematically regain their significance.

The data base, concerning the course of the existing infrastructure, contains errors, which are thereafter repeated and multiplied in the calculations and the more complicated cartograms. An example is provided by the high density of motorways in the north-eastern Poland (as shown on one of the maps). In reality, within the corresponding NUTS 3 units there is no single kilometre of the motorways (neither of the expressways). Some of the maps underline the connections (graph edges), crossing the outer boundary of the Union, as the routes of the internal Union transit. In the case of Poland this concerns the route Warsaw-Vilnius through Grodno and the route Gdańsk-Kaunas through Kaliningrad. In reality, transit traffic along these two directions is marginal and one can hardly expect its intensification in the coming years. The map of the railroad network shows essential gaps in the area of the eastern boundary of the EU (e.g. lack of the key Polish-Ukrainian connections). The considerations concerning the inland navigation in the accession countries do not account for the actual technical conditions and the capacities of the navigation routes. It also appears to be erroneous to assume a dense and stable railway network in the accession countries. Contrary to the statements contained in the Report, the railroad network in Poland is undergoing already now rapid shortening.

One does not find in the Report, neither, a more precise description of the sources of statistical data. Their critical assessment would certainly be useful for the correct interpretation of results. While the data, originating from the Eurostat, concerning population numbers and the GDP values, are definitely sufficient, the data on flows give rise to numerous reservations (for the accession countries already at the level of NUTS 2). The "SCENE database", constituting the basis for the analysis concerning commodity traffic, does not contain reliable and updated information for Central Europe. It can be supposed that a part of data were estimated, which found its reflection in the results of the downstream analysis. It should be remembered that on 


\section{Hierarchy of the european road network}

(evaluated through the relations between cities)

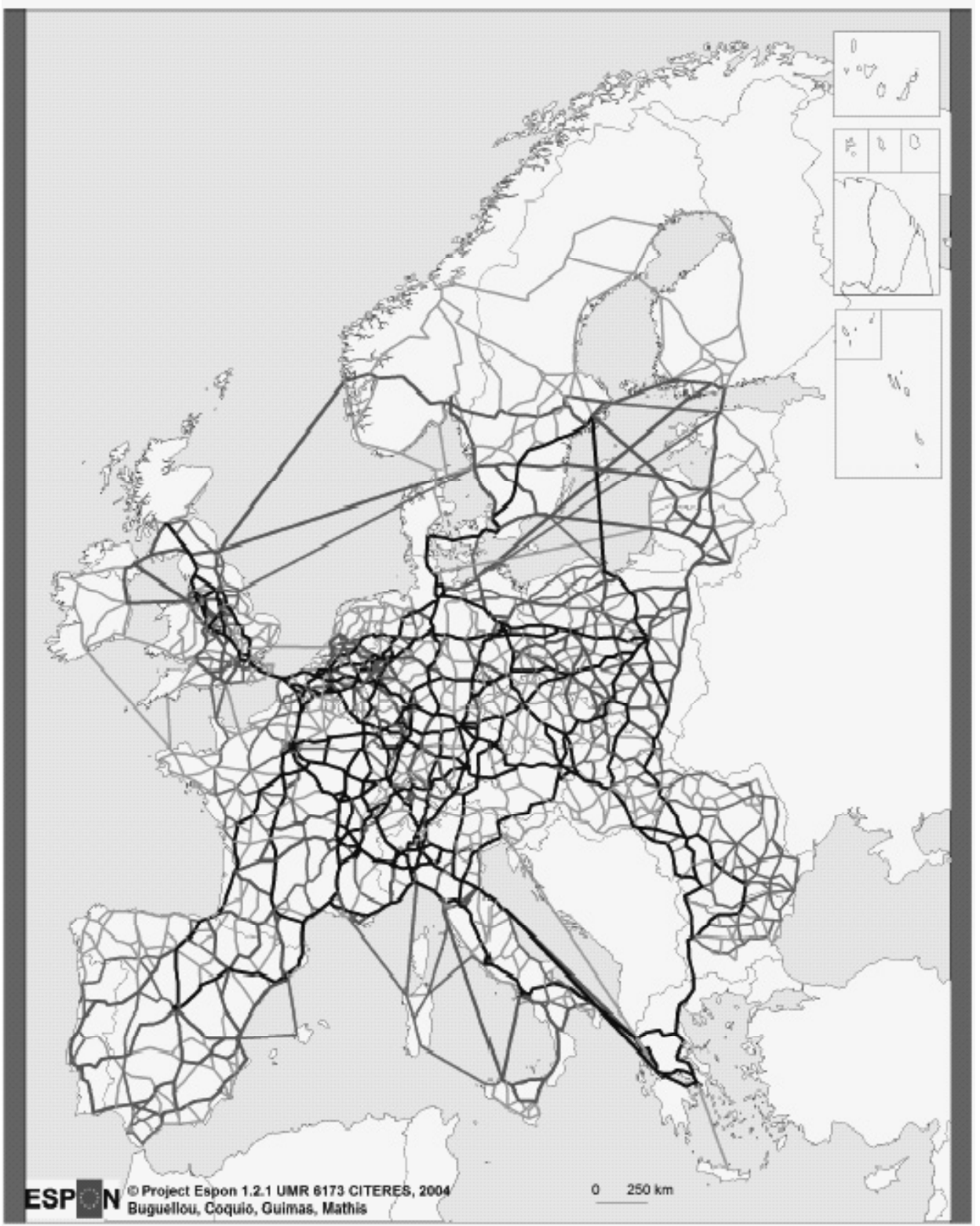

Edges allowing relations of cities of

Source : GISCO GIS, Scene

- more than 1000000 inhabitants

Graph : CESA graph 4172

more than 500000 inhabitants

more than 300000 inhabitants

more than 100000 inhabitants

Figure 1. Hierarchy of the European Road network

Source: ESPON 1.2.1 Final Report, <www.espon.eu> 
the areas, featuring lagging development of the modern transport networks, the pattern of flows is frequently a consequence of the throughput capacity of the elements of infrastructure, and not uniquely of mutual relations and the demographic or economic potential. Even if one assumes that data were estimated, it is still hard to understand the origin of some errors, such as indication of the Polish subregions (NUTS 3) of Łódź and Piotrków-Skierniewice as the areas featuring the biggest tonnage of export from the then candidate countries (year 1995) to the European Union.

The levels of NUTS 2 and NUTS 3 are intermittently referred to in the Report. This has in many cases an impact on the results obtained. On some maps errors are committed for the accession countries concerning the scale of the breakdown. Maps with the NUTS 3 breakdown show for the territory of Poland sometimes the breakdown according to NUTS 2. At the same time, other countries of Central Europe are treated as a whole, without any internal division.

It should be considered that the maps of potential accessibility are best founded on the source material. They were elaborated by the German partner (S\&W) and are based on a different model than the majority of the remaining analyses. In this context it is worthwhile to mention other studies, connected with the influence exerted by the extension of infrastructure on economic development. They were carried out by the same Institution for purposes, in particular, of the parallel ESPON Projects (1.1.1 and 1.1.3). It appears that the image there obtained (analysis of scenarios of transport policy) provides better foundations for the policy-related recommendations concerning the area of the accession countries.

One should also assess positively the analyses concerning accessibility of the transport networks, daily accessibilities and connections between large centres. In general terms, the broadly conceived accessibility, appears to be the strongest basis for formulation of conclusions from the Report. Against this background, the studies concerning the current and forecasted traffic, and the characteristics of the external costs of transport, which are based on them, present a much less convincing image.

\section{POLICY RECOMMENDATIONS OF THE REPORT}

The scientific results (including the rich cartographic material) constitute, potentially, a broad basis for numerous conclusions in the domain of transport policy. Yet, the "policy recommendations", contained in the Report, are neither detailed, nor innovative. Shortcomings with this respect are insofar more important as the results of numerous detailed analyses are sometimes contradictory (e.g. various indicators show different significance of the individual transport corridors). With respect to the basic questions, quoted in the introduction, one should state that the conclusions and recommendations refer primarily to the first of them (influence of infrastructure on the more sustainable and polycentric spatial development). They respond to defi- 
nitely the lowest degree to the third question, linked with the role of enlargement of the European Union.

In general terms the recommendations refer to the objectives contained in the ESDP. They concentrate, however, first of all on the goal: "Effective and sustainable use of infrastructure". To a much lower degree, such goals of the European Perspective are accounted for as promotion of the polycentric development and the equality in the access to the transport networks, and the improvement in the access to knowledge.

The authors justly note that the transport policy in Europe should not be merely an investment-based response to the increasing demand for transport of goods and passengers. In the first case, this results also from the time of implementation of transport-related projects (longer than moving of production to another, more accessible location). That is why recommendations contained in the Report concern, first of all, such objectives as traffic regulation (limiting the congestion) and promotion of the more environmentally friendly forms of transport (alternative to the road transport). It is proposed to attain these goals through:

- Introduction of fees for the use of road network. This recommendation is not described in detail. It is, however, well rooted in numerous research reports dealing with transport policy (prepared, in particular, in the framework of the STELLA Project, <www.stellaproject.org $>$ ). The postulate of introducing common fees for the use of infrastructure becomes increasingly realistic along with the development of the telecomputing services, allowing for cheap servicing of the system. Discussion concentrates, however, still on the prerequisites for the rate policy (coverage of full external costs of road transport, or only of the cost of using the infrastructure?).

- Introduction of speed limits for both trucks and passenger cars. The correctness of this proposal put apart (along with its social acceptability-the speed of $70 \mathrm{~km}$ per hour on the motorways!), this recommendation could be applied in conditions of the already existing extensive railroad and/or road network. It is, though, inappropriate for the conditions of the accession countries, where, in some regions, the corresponding infrastructure does not exist at all.

- Construction of the junction segments at the European, national, regional and local levels. Again, in conditions of the accession countries this, otherwise quite justified, postulate might lead to fragmentation of the limited financial means accumulated for investment projects.

- Construction of rapid freight railways. This recommendation seems to be adequate in the situation of Central Europe. It ought to be tightly connected with the preference for the multi-modal transport (especially in transit traffic).

- Linkage of the system of rapid passenger trains with the extension of the universal system of car hire at the destination locations. This recommendation may find application in the countries with existing systems of very high speed trains (in case of Europe this applies first of all to France). In the countries with lower levels of 
GDP the realisation of this recommendation would also depend upon the support extended to the companies dealing with car hire (in order to achieve the hire rate decrease).

In the summary of the chapter concerning the general European recommendations the authors note that there is, as well, a need for a policy in the domain of development of infrastructure. Except for a sweeping statement, though they do not indicate any priority investment projects, nor do they emphasise the need for evening out the level of development of infrastructure between the "old" and the "new" member states.

In the comments preceding the policy-related recommendations the authors of the Report seem to be inclined to the adoption of the hypothesis that the skeletal (chessboard) pattern of transport network is more advantageous than the centralised pattern (first of all from the point of view of equilibrated and polycentric development). This potential proposition does not find support in the material, collected in the Report. The majority of maps, showing the ranks and the loads of the networks imply the domination of the oblique patterns, based on the centralised nodes in the metropolitan centres, which, consequently, means a reference to the classical hexagonal pattern.

Recommendations are presented separately for the five nominally defined geographical macro-regions:

- Atlantic Arc Area,

- Mediterranean Sea Ara,

- Nordic Area,

- Central Europe Area

- Eastern Europe

Individual chapters of the IIIrd part of the Report (including the cartographic material) illustrate very well the specific features of each of the subregions. This, however, does not find an adequate reflection in the general conclusions and in recommendations. The Project, and especially the recommendations, have been formulated from a distinctly western European, or even "Atlantic", and partly "Mediterranean" perspective (which remains in definite relation to the seats of the institutions being Project partners). The proposals for the accession countries ("Eastern Area") are poor, or outright trivial. To an extent this applies also to Scandinavia ("Nordic Area"), and even to the central region ("Central Area"), encompassing Germany. Thus, while some 15 pages of text are devoted to the Atlantic Region (including the forecast of flows and recommendations concerning concrete investment projects), the territory of the accession countries is treated on just three pages (of which one is taken by a map of doubtful value).

The recommendations for the accession countries are based in their entirety on the confirmation of the correctness of the priority assigned the Pan-European Corridors, designated by the ECMT on Crete in 1992, and contained in the TINA Project. A correction, brought to these priorities, presented on the map, has no counterpart 
description in the text (it is even not certain whether omission of some routes is contained in the recommendation, or is just an effect of a cartographic error). The map, namely, neglects some routes (e.g. the third corridor on the line Berlin-Kiev, through Cracow).

\section{CONSEQUENCES FOR POLAND}

The Report, similarly as many other elaborates of the all-European scale, places Poland in a different spatial context than the national documents to date (including the current Concept for the Spatial Development Policy of the Country). These documents emphasised the keystone location of Poland in Europe. The Report indicates the peripheral location of Poland. This contradiction results only partly from the geographically different point of view. The national documents certainly overestimated the role of the East-West transit (also in the economic aspect-not considering the external costs of transport, associated with it). The Report does not perceive the significance of such a transit almost at all. Besides, it appears to be beyond doubt that significant territories of Poland are peripheral with respect to modern transport infrastructure.

From the point of view of the typologies developed Poland is, in the light of the Report a country:

- with relatively low level of use of the relatively dense transport infrastructure,

- constituting, except for the region of Warsaw, a poorly accessible peripheral territory (Figure 2).

- poorly economically developed in relation to the accessibility it represents,

- an area featuring low influence of cargo traffic (external costs) on the environment.

Taking into account the results contained in numerous domestic reports, such kind of assessment is not fully correct. Moreover, the characterisations listed are partly internally inconsistent (accessibility is low, but it would still entitle Poland to a higher level of economic development).

The material, collected in the Report, made evident the essential differences between the individual regions of Poland in the domain of development of infrastructure and spatial accessibility. Numerous indicators illustrate the relatively good situation of the south-western Poland, and the very poor situation of the north-eastern Poland. This is partly the consequence of the adoption of the "European" point of reference, but to an increasing degree reflects also the actual situation. Yet, in the case of the countries of peripheral location with respect to the core of the European Union, the image of internal accessibility appears to be important as well. This is in agreement with the conclusions of the other Reports from the ESPON Programme (TPG 1.1.1 and 1.1.3), indicating the necessity of supporting the polycentric development within the particular countries. Based on the results, presented in the Report, transport-related investment projects in Poland ought to concentrate 

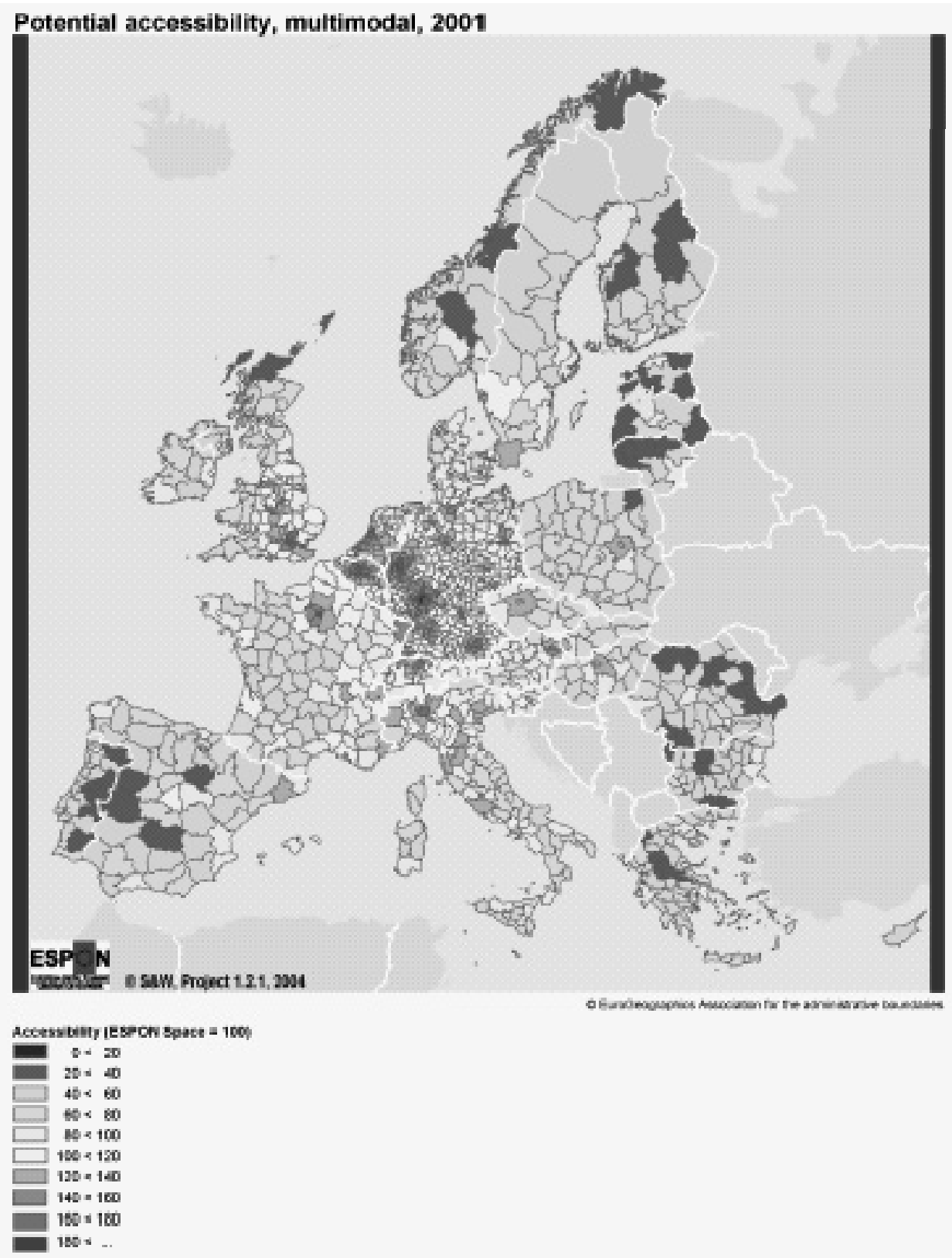

Figure 2. Potential accessibility multimodal, 2001

Source: ESPON 1.2.1 Final Report <www.espon.eu>

on the directions linking it with Western Europe. In practice, domestic demand for transport infrastructure is significant and quickly increases (decentralisation of the economy, mass car ownership). At least for the cases of the larger peripheral countries (Poland, Romania, Spain), the analysis at the national level appears, there- 
fore, to be highly important. It is also necessary to account for the transit from/to the third countries (Russia, Belarus', Ukraine, Turkey). The Report underlines the significance of the seaports and airports as the elements of infrastructure, linking the European Union with the outer world. An analogous spatial role is played by the bigger border crossings (and the associated logistic centres) at the eastern borders of the Union (gateways of the Union, mentioned in the ESDP), which, however, has not been made very pronounced.

The analysis of the Report from the point of view of Poland can be carried out at two levels:

- the potential consequences of the "policy recommendations", under the assumption that they would become the elements of the Union policy,

- conclusions resulting from the entirety of the material presented in the Report, which might be made use of in the construction of the domestic documents (in particular, as the basis for formulation of the investment priorities).

The potential consequences of the recommendations, contained in the Report can be formulated in a couple of essential points:

- The unified treatment of the territory of the entire European Union (EU-27) in the context of the prerequisites for the transport policy may be potentially disadvantageous for Poland and other accession countries. There is a distinct shift of the weight of the forwarded recommendations from planning of investment projects in infrastructure towards the activities aiming at a better use of the already existing infrastructure. This amounts to a threat, over a longer time perspective (starting with the subsequent financing period of 2007-2013), for the support from the European Union for the realisation of the primary and necessary investment projects in our country. The postulate of a better use of infrastructure is certainly justified, but it cannot become the substitute for the evening out of the lack of adequate proportions in the densities of the modern transport networks between the old and new member states of the Union. The problem signalled concerns mainly road extensions. This is demonstrated by the highly telling statement, contained in the Report: “...development of road infrastructure does not need support from the side of spatial planning. It will take place anyway, while other modes of transport necessitate a special attention...".

- There is also a definite threat, linked with the postulate of concentration on adding of the lacking elements of the network at different levels. It is obviously adequate for the situation, existing in Western Europe, where the density of the modern networks is high and it is possible to improve the effectiveness of the entire system through relatively small junction projects. Such situations exist also in Poland (especially on the local scale). Yet, it seems that, given the current state of inadequate investments into transport infrastructure, it is necessary to concentrate the domestic as well as Union means on definite key projects.

- On the other hand, the postulate of developing rapid freight railway connections should be considered to be in agreement with the directions of the Polish transport 
policy. The increase of the role of railways in cargo transport is easier done by administrative means that with respect to the passenger traffic. It is also decidedly more easily accepted, and is even socially desirable. Introduction of rapid railway cargo transport is possible with the use of the existing network (which is not so obvious in the case of passenger traffic).

- In Polish conditions the potential introduction of the fee system for the use of infrastructure (road pricing) cannot take place in abstraction from the income levels of the households and the conditions of functioning of the small and medium enterprises. Such a system ought also to have a universal character. If only some categories of roads are included in the system, the consequence might consist in the transfer of a part of traffic towards the unprepared roads of lower categories and hence (contrary to the assumptions adopted) to the increase of the external costs of the entire system.

Other conclusions, resulting from the whole of the material presented in the Report, may include:

- Proper definition of the position of Warsaw in the European transport system. In the comprehensive considerations the region of Warsaw, side by side with south-western Poland, are the areas featuring the highest level of accessibility on the European scale. The analysis, carried out according to the particular transport modes, shows, however, that for the case of Warsaw this is mainly due to the concentration of air connections. Accessibility of the capital of Poland in terms of road transport is definitely lower than of other central European capitals. The currently valid national concepts of the development of infrastructure leave Warsaw within the periphery of the road network of Europe. This has a bearing not only on the position of the capital itself, but exerts influence, as well, on the transport accessibility of the entire Eastern Poland (Węcławowicz et al. 2006).

- The material analysed indicates the necessity of making a revision of the perception of the spatial distribution of transport accessibility on the territory of Poland (in the general European context). The division into the western (better accessible) and eastern (less accessible) halves of the country ought to be replaced by the division into the south-western and north-eastern halves. Moreover, this situation changes dynamically, and the gap is widening. In practice, all the bigger transport projects, carried out after 1989 (including 100\% of the new motorways length) were implemented in the broadly understood south-western part of Poland. The change of the setting and the widening of the gap were also partly due to the transport-related investment projects in the eastern lands of Germany and in Czech Republic. Thereby, a situation emerges, in which within the south-western part of Poland an area appears that is relatively well transport-wise linked with the core of Europe, and at the same time-separated from the capital and the central part of the country. Simultaneously, the analysis of the actual and potential transport flows indicates clearly the significance of the oblique direction from the South of Germany and Czech Republic towards Warsaw and farther on- towards the Baltic states. 
- Due to the errors in the basic data (or in the models generating them) the Report underestimates the magnitudes of the current and the forecasted cargo traffic on the territory of the accession countries, including Poland. To correct these data is in the interest of Poland, since they constitute the justification for the applications to obtain the investment means.

- The reports from ESPON (including the Report in question, based on the work of the Project 1.1.1) emphasise the role of linkages between the metropolitan centres of the continent, as the poles of growth, especially in the domain of the knowledge-based economy. There are eight so-called MEGAs (Metropolitan European Growth Areas) on the territory of Poland: Warsaw, the Tri-City (Gdańsk-Gdynia-Sopot), Szczecin, Poznań, Łódź (added to the list by the authors of the report analysed), Wrocław, Cracow, and the Upper Silesian Conurbation. The analogous European centres, situated in the direct vicinity of Poland, and exerting influence on Polish space are Berlin, Prague, Vienna, Bratislava, Budapest and Vilnius. Special significance is attributed also to the infrastructure linking (via the shortest routes) the largest agglomerations. In Poland, the elements of the thus constructed network are the routes Warsaw-Berlin, Warsaw-Wrocław, with the branching towards Dresden and Prague, Warsaw-Katowice, with the branching towards Budapest and Vienna, Warsaw-Rzeszów-Kosice (in the direction of Bucharest), and Warsaw-Gdańsk-Stockholm. In this context, in the documents prepared, one should consider the possibility of re-formulating the priorities in the sphere of motorway construction, especially in the eastern half of the country (transition from the chessboard pattern to the hexagonal one; enhancement of the role of Warsaw and Poznan as the international transport nodes). Taking into account the proper interpretation of the keystone location of Poland it is more important to establish logistic centres, linked with the multimodal transport nodes than to build the segments of routes leading up to the very eastern border.

- The maps of accessibility to the road, railway and airport infrastructure demon strate that the areas in Poland with the worst situation in this domain are eastern part of the Lublin region and the Masurian Lake District. Improvement of the transport accessibility of Masuria appears to be a necessity if, in accordance with the currently valid Concept for the Spatial Development of the Country, the opportunities for the regional development there are seen in international tourism. The very same maps prove the need for the development of the regional airports.

- From the point of view of accessibility to markets (expressed in terms of the GDP and analysed on the European scale) the best is the situation existing in the Polish western borderland, including the metropolises of Wrocław and Poznań. This confirms the proposition that in the documents prepared foreign demand should be accounted for in the planned development of service (also non-market service, like health care, and, in a farther perspective, educational service as well) within the border regions. 
- It is emphasised in the report that for the bigger centres, situated at distances bigger than $100 \mathrm{~km}$ from other cities of the same or higher order, it is justified to develop fast transit infrastructure (motorways, high speed railways, or airports). In Polish conditions the sole bigger towns not having (now and in accordance with the valid development projects) access to fast transport and at the same time being located more than $100 \mathrm{~km}$ away from the centres of such transport are Lublin and Białystok. That is why the possibility of including these two cities to the eventual motorway network and/or development of the passenger airports in them should be taken into consideration. This is insofar even more important as both these centres should play the role of the "gateways to Europe".

- An interesting material is constituted by the forecast of the increase of cargo traffic between the "old" and the "new" countries of the European Union for the year 2019. This forecast indicates that on the territory of Poland the main directions of connections will be constituted by the routes Warsaw-Berlin, Warsaw-Wroclaw-Dresden, Cracow-Wrocław-Berlin and Warsaw-Katowice-Vienna. This conclusion remains in close association with the earlier remarks on the underestimated role of the direction Warsaw-Wrocław.

- In the elaborated strategies and other national documents attention should be paid to the possibility of the popularisation in Europe of the new technologies and new organisational solutions in road and railway transport. Their potential spatial consequences should also be accounted for and forecasted. The Report mentions, in particular, such solutions as: (a) combined transport, also in passenger traffic (after the model of the Alpine tunnels and the Eurotunnel); (b) systems of navigation and control of the cargo traffic on the motorways; (c) technology of "single railway car" (the necessity of developing modern logistic centres in railroad transport).

- The Report indicates a high level of external costs expressed through the number of casualties in road accidents in Poland, Czech Republic and Latvia. This might lead to the conclusion that spatial policy ought to attempt to minimise the external costs with this respect. It is commonly held in Poland that the only way to the reduction of the number of victims of road accidents is the legal one (sharpening of the regulations of the Road Code; Komornicki 2005). Yet, this issue has a spatial aspect, expressed through: (a) influence of the quality of infrastructure on the road traffic safety; (b) possibility of a wider differentiation of the regional limitations resulting from the Road Code (e.g. maximum speed limits).

\section{SUMMARY - THE RESULTS OF THE ESPON PROJECT 1.2.1 AND THE CHALLENGES FOR THE POLISH TRANSPORT POLICY}

Taking into consideration the conditioning, defined on the basis of the Final Report of ESPON Project 1.2.1, it should be stated that the Polish space absolutely needs a new long-range vision of development of the modern transport infrastructure for 
the next 25-30 years. It is also necessary to promote this vision on the European arena and to consistently emphasise (both at the scientific and political level) the specific features of the new member countries in terms of infrastructural needs and the principles of transport policy. On the other hand, the vision should take into account the current and the forecasted tendencies in the domain of the European (Union) transport policy. This means, in particular, that the present period of financing (2007-2013-2015) is perhaps the last one, during which such a broad support for the road projects is possible. The preferences for the railway infrastructure may turn out to be dominating in the subsequent periods. This leads to the conclusion that the nearest years ought to be marked by a resolute concentration of investment efforts especially on the road network. In the later years its development (which will still be necessary, in view of the existing delays) will have to be realised from the means of the domestic budget or the private ones.

In the context of the above considerations it can be assumed that the long-term vision mentioned should contain the following basic elements:

- The ultimate pattern of the newly designed high speed railway lines, encompassing the connections between the main metropolises (with the use of the present CMK line-Central Railway Mainline, as the sole that can constitute an element of the future system) and the linkages with the analogous European network;

- A new program of motorway construction, assuming upgrading of the parameters of a part of the expressways (or their segments), as well as construction of some entirely new fragments;

- The sequence of realisation of the primary railway and road investment projects, accounting for the shifts in demand (traffic) towards the successively developed routes on the intermediate stages, and ensuring realisation of the truly most important projects until the year 2013;

- Clear designation of the directions and kinds of transport flows, for which railway transport will be supported (with a tendency towards the limitation of the role of road transport), e.g. such as rapid transit between the metropolises, cargo transit through Poland, passenger transport inside towns. Only on these directions and kinds of flows the means ought to be concentrated (including structural funds), supporting the development of the railroads.

- The comprehensive plans of solving the internal transport solutions for the biggest metropolises, accounting for the priority for the fast rail transport as well as the park and ride systems.

An initial attempt at a new vision of the priority transport projects was presented in the Report on the state of spatial development of 2005 (Węcławowicz et al. 2006). It assumes, in particular:

- construction of the first segment of the high speed railway from Wrockaw and Poznań through Łódź to Warsaw,

- upgrading to the rank of the motorway and priority realisation of significant fragments of the routes S-3 (from Szczecin to the motorway A-2), S-5 (from Grudziądz 
to the boundary with Czechia), S-7 (from Gdańsk to Cracow), S-8 (from Wrocław to Białystok) and S-17 (from Warsaw to Lublin).

From among the essential institutional solutions, which ought to be undertaken in parallel with the work on the long-term vision, one should mention:

- solutions aiming at promotion, or even administrative-fiscal enforcement of the intermodal transport in the cargo transport (especially in transit traffic);

- giving up the present division of the entire long routes into motorways and expressways (in practice, differing to a limited degree as to their ultimate technical parameters); replacing them by the motorways (understood as, at the minimum, the collision-less separate traffic roads), whose individual segments may differ in their parameters (curvature radii, technical velocities, etc.);

- gradual abandonment of taxation of fuel and vehicles to the advantage of introduction of fees for the use of road infrastructure, differentiated in time (hours) and space, and based on the tele-collecting system (road pricing).

\section{REFERENCES}

Banister, D., Stead, D., Steen, P., Akerman, J., Dreborg, K., Nijkamp, P., Schleicher-Teppeser, R. (2000), European transport policy and sustainable mobility, Spon Press, London-New York.

Button, K. (2005), Myths and taboos in transport policy, in: Rietvald, P., Stough, R. (eds.) Barriers to sustainable transport, institutions, regulations and sustainability, Spon Press, London-New York.

ESPON 1.1.1 Final Report <www.espon.eu>

ESPON 1.1.3 Final Report <www.espon.eu $>$

ESPON 1.2.1 Final Report <www.espon.eu>

Forecasting car ownership and use, 1982, Road Research, Raport OECD, Paris.

Komornicki, T. (2005), Specific institutional barriers in transport development in the case of Poland and other Central European transition countries, IATSS Research, 29, 2, 50-58.

Lijewski, T. (2000), 100 lat rywalizacji samochodu z koleją [100 year competition between car and railway], Prace Komisji Geografii Komunikacji PTG, VI, p. 131145, Warszawa-Rzeszów.

Menes, E. (2001), Społeczno-ekonomiczne aspekty rozwoju motoryzacji indywidualnej w Polsce [Socio-economic aspects of development of individual motorization in Poland], Przeglad Komunikacyjny, 1, Warszawa, 1-6,

Nijkamp, P., Rienstra, S.A., Vleugel, J. (1998), Transportation planning and the future, John Wiley, Chichester.

STELLA Project, <www.stellaproject.org>

Suchorzewski, W. (2000), Peripherality and pan-European integration: Experience and prospects, in: Key issues for transport beyond 2000, 15. Symposium of CEMT, 
Aristotle University of Thessaloniki.

Taylor, Z. (2002), Zmiany w polskiej polityce transportowej ostatnich lat [Changes in Poland's transport policy over the recent years], in: Wybrane zagadnienia geografii transportu, Uniwersytet Szczeciński, Szczecin.

Węcławowicz, G., Bański, J., Degórski, M., Komornicki, T., Korcelli, P., Śleszyński P., 2006, Przestrzenne Zagospodarowanie Polski na początku XXI wieku [Spatial organization of Poland at the beginning of the 21st. century], Monografie, 6, IGiPZ PAN, Warszawa. 
BCl@PAN http://bibliotekacyfrowa.pan.pl 


\title{
ETHNICAL DIVERSITY AND REGIONAL DEVELOPMENT OF EASTERN BORDERLAND REGIONS IN POLAND, LITHUANIA AND LATVIA
}

\author{
MARIUSZ KOWALSKI and JERZY SOLON \\ Institute of Geography and Spatial Organisation \\ Polish Academy of Sciences \\ Twarda 51/55, 00-818 Warszawa \\ e-mail: mar.kow@twarda.pan.pl j.solon@twarda.pan.pl
}

\begin{abstract}
The paper deals with the problems of ethnic diversity of the regions (NUTS 3) belonging to Poland, Lithuania and Latvia, situated along the eastern borderland of the European Union. The ethnic factor, namely, influences in an important manner the shape of public life in all three regions. It impacts, as well, on mutual relations between the three countries, and on the relations between them, on the one hand, and their eastern neighbours, not being the members of the European Union, on the other (Belarus', Russian Federation). The complex ethnic landscape may turn out to be a negative, as well as positive factor of the regional development.

Key words: Poland, Lithuania, Latvia, EU Eastern Borderland regions, ethnic diversity
\end{abstract}

\section{INTRODUCTION}

The present study was prepared within the framework of the research project ESPON 1.3.3 The Role and Spatial Effects of Cultural Heritage and Identity (2004-2006). This project was carried out by an international research group, established by twelve organizations, representing twelve European countries. Poland was represented in this consortium by the Institute of Geography and Spatial Organization of the Polish Academy of Sciences.

The tasks of the project included:

- collecting a database of indicators, concerning cultural heritage and cultural identity, for the NUTS 3 regions of the 25 member countries of the EU-25, and Norway, Switzerland, Romania and Bulgaria; 
- creation of the tools serving the purpose of analyzing the role and spatial influence of the cultural heritage and identity of the European regions;

- indication of the methods for inclusion of such elements as cultural heritage and identity into the European system of planning;

- preparation of twelve case studies, presenting selected problems, associated with the subject matter of the study.

One of the issues, taken up in the framework of realization of the project, was ethnic diversity of the European regions. It also became the subject of the case study, elaborated by the Polish participants of the project. Analysis was carried out of the ethnic problems in three regions: of Białystok in Poland, Vilnius in Lithuania, and Daugavpils (Latgalia) in Latvia (Figure 1). All three regions are situated within the eastern borderland of the European Union, and all three border upon Belarus'. The Latvian region borders also upon the territory of Russian Federation, while the Polish and Lithuanian regions are located in a close vicinity of this territory. The selected areas belong nowadays to separate countries, but they have been in the past subject to similar conditions. For centuries, the areas in question have been crossed by the boundary between the eastern and western Christianity, while the border between the Baltic and the Slavonic peoples has been functioning on these areas for an even longer period. For two centuries (1569-1772) the entire area in question was a part of the Polish-Lithuanian Commonwealth, and thereafter, until 1917, it be-

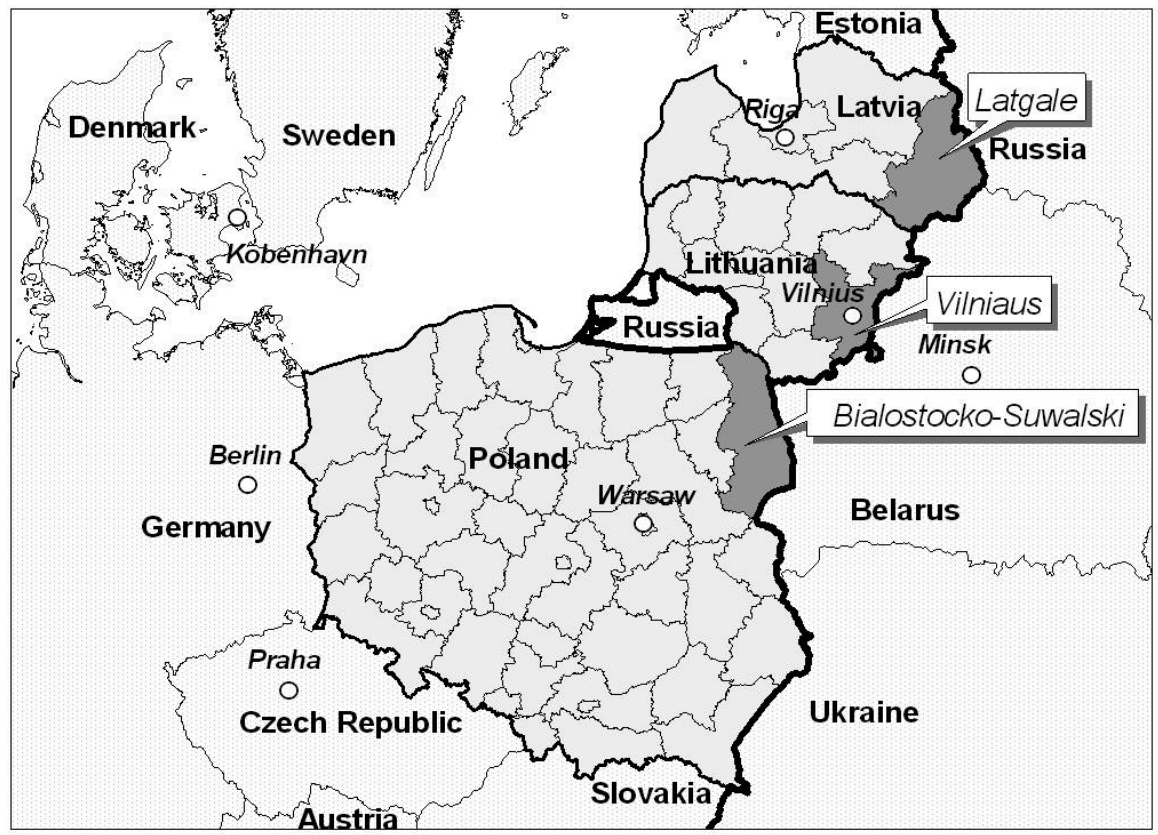

200

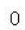

200

400

600 Kilometers

Figure 1. Location of study regions 
longed to Russia. Due to the political changes, having resulted from the World War I and the Bolshevik revolution, the regions in question became the parts of the newly established three separate countries. The region of Białystok and the major part of the region of Vilnius were incorporated into Poland. A small western fragment of the region of Vilnius belonged to the Republic of Lithuania. The region of Daugavpils was a part of the Republic of Latvia. The political order established then persisted for only two decades. The World War II brought new changes. In its effect the entire contemporary region of Vilnius became a part of Lithuania. The boundaries, established in 1945, function until today. Initially, they separated Poland, subordinated to the Soviet Union, and the two republics, belonging to the Soviet Union. Owing to the collapse of the communist system all three countries gained full sovereignty. In 2004, they became the members of the European Union.

In parallel with nationalism, the idea of European community started to develop in Europe in early 50-ties of the XX century. It was based not so much on the ethnic specificities across the continent as on the common identity of all the inhabitants of Europe. This postulate became also one of the objectives of the idea of the European Union. The question arises of the chances of realising these objectives in the situation, in which the nationalisms still occupy a significant position in creation of the socio-political attitudes, and where multi-cultural regions still exist, having been in the past many times over the igniting points of the political conflicts, negating the unity of the Europeans.

What is the shape of the ethnic structure of the traditional borderland regions? What is the present-day development of relations between the ethnic groups and nations, do differences get smoothed out, or, to the contrary, get deeper? Is ethnic diversity only a barrier to the development of a regional community, or can it become a factor conducive to such development? In the "old" member countries of the EU-15 the situation is with this respect quite differentiated. There are several conflict-prone regions (the Basque Country, Flanders). There are, however, also such ones, where it turned out possible to solve the basic problems (South Tirol, Alsace, Aland Islands). Something that has been named "banal nationalism" (Billing 1995) is still functioning.

What is the situation in the countries having recently joined the European community? How the multi-ethnic regions influence the relations between the countries and the societies, how ethnic diversity influences their own development? What scenario (model) of the development of the multi-ethnic societies is currently being realised and what such scenario can be realised in the perspective of the decades to come?

All these questions should be addressed and answered for understanding the current state of the border regions.

In the opinion of Gellner (1983) in order to fulfil the basic assumption of the nationalism that is - that each one should belong to a nation, and all the representatives of a nation should find the best way to their development in a nation-state, means that 
all the territories identified with a given national culture ought to be gathered in one country, and the remaining groups, living there, must undergo assimilation, emigrate or consent to live within the social margin. According to Berry (1997) there are four possible ways of development of an individual (ethnic group) in the framework of the multi-cultural societies: assimilation, separation, integration and marginalisation.

For purposes of describing the processes of acculturation other models have also been proposed. The alternation model assumes that an individual may participate in two cultures, adapting his/her behaviour to the current social context (La Framboise et al. 1993). Another model, referred to as the fusion model, assumes that cultures, functioning within the same economic, political and geographic space, mix together, forming an entirely new culture. One of the most recent concepts speaks of the linear or bipolar model (Phinney and Devich-Navarro 1997). It assumes that the conflict between the minority and the majority cultures is unavoidable. An individual, choosing a new culture, automatically loses attachment to the traditional culture. Conform to the model an individual is on the way from the culture of its ethnic group towards the dominating culture (see Valk 2002).

The aim of this study is fourfold:

a) to characterize the present ethnic differentiation of the three regions as well as the expressions of the differentiated cultural heritage;

b) to evaluate the impact of the complex historical conditioning on the ethnic structure of the selected regions, and on the mutual relations between these ethnic groups;

c) to identify the main economic, social and political problems of the three regions and their influence on political issues within and between bordering countries;

d) to evaluate what model describes in the best way the present trends in development of different ethnic groups in the framework of the multi-cultural societies of the three analyzed countries.

The study is based on data collected within the frames of ESPON 1.3.3 project (mainly statistical data on demography and cultural assets and events) as well as on previous studies focused on history and differentiation of the regions (Eberhardt 1997 a, 1997 b, 1997 c, 1997 d; Kowalski 1997, 1998).

The report takes up the problem of ethnicity, as an important element of the socio-political life, influencing the relations between the states, nations and ethnic groups. Europe was the continent, where the ethnic factor and the nationalism impacted in a particular manner upon the relations between nations, being, for instance, a significant component of the origins of the World Wars I and II, as well as the exterminations, having taken place during the wars, and the subordination of some nations to the other ones.

The starting point to the analysis was determination of regions diversified in ethnic terms in the countries, which fell under our competence in the framework of the ESPON project. The subsequent step was presentation of the ethnic differentiation on the basis of the statistical materials collected. Then, assessment was made as 
to how the ethnic diversity influences the relations between the ethnic groups and the national countries, representing them: is the ethnic diversity the obstacle or the asset for the development in contemporary Europe, with respect to the three selected countries and regions?

\section{REGION OF BIAtYSTOK}

\section{ETHNIC DIFFERENTIATION}

The region of the city of Białystok is among the most differentiated NUTS 3 units on the territory of Poland. Bigger differentiation is observed only in the three regions of the Silesian province and the region of Opole province. This latter area is inhabited side by side with Poles, by Germans, and persons declaring Silesian nationality.

In the region of Białystok an important population group, besides Poles, is constituted by the Belarusians (Table 1). There are also smaller, but still perceptible clusters of Lithuanians and Ukrainians. Belarusians are significantly concentrated in two counties (NUTS 4): Hajnówka (39.3\%) and Bielsk Podlaski (19.9\%). They form important minorities yet in three counties: the city of Białystok $(2.6 \%)$, the surroundings of Białystok (3.3\%) and Siemiatycze $(3.5 \%)$. There are some municipalities (NUTS 5) on the area of the counties of Hajnówka and Bielsk Podlaski where Belarusians are the majority of the population. The highest share was noted in

Table 1. Population by nationality in powiats of bialostocko-suwalski region (PL341)—percents

\begin{tabular}{|c|c|c|c|c|c|c|c|c|c|}
\hline Powiat (NUTS 4) & $\begin{array}{c}\text { total } \\
\text { numbers }\end{array}$ & $\frac{\sqrt{n}}{0}$ & 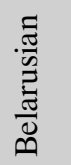 & 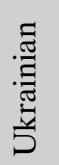 & 总 & 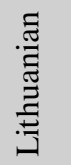 & 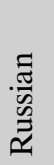 & 志 & $\begin{array}{l}\frac{n}{0} \\
\frac{\vec{E}}{0}\end{array}$ \\
\hline augustowski & 58007 & 99.6 & 0.1 & 0.0 & 0.1 & 0.0 & 0.2 & 0.0 & 0.1 \\
\hline białostocki & 136653 & 96.6 & 3.3 & 0.0 & 0.0 & 0.0 & 0.0 & 0.0 & 0.1 \\
\hline bielski & 61267 & 78.9 & 20.0 & 0.7 & 0.0 & 0.0 & 0.1 & 0.0 & 0.2 \\
\hline hajnowski & 50052 & 59.5 & 39.4 & 0.7 & 0.0 & 0.0 & 0.1 & 0.0 & 0.3 \\
\hline moniecki & 43615 & 100.0 & 0.0 & 0.0 & 0.0 & 0.0 & 0.0 & 0.0 & 0.0 \\
\hline sejneński & 21522 & 78.2 & 0.0 & 0.0 & 0.0 & 21.5 & 0.2 & 0.0 & 0.1 \\
\hline siemiatycki & 50084 & 96.1 & 3.5 & 0.2 & 0.1 & 0.0 & 0.0 & 0.0 & 0.1 \\
\hline sokólski & 73871 & 98.9 & 0.8 & 0.0 & 0.0 & 0.0 & 0.0 & 0.2 & 0.1 \\
\hline suwalski & 35199 & 99.5 & 0.0 & 0.0 & 0.0 & 0.4 & 0.0 & 0.0 & 0.0 \\
\hline Białystok city & 280938 & 96.9 & 2.6 & 0.1 & 0.0 & 0.0 & 0.1 & 0.1 & 0.1 \\
\hline Suwałki city & 68123 & 99.2 & 0.0 & 0.0 & 0.2 & 0.5 & 0.1 & 0.0 & 0.1 \\
\hline total & 879331 & 93.8 & 5.3 & 0.2 & 0.0 & 0.6 & 0.1 & 0.0 & 0.1 \\
\hline
\end{tabular}

Source: Results of National Census 2002, Central Statistical Office of Poland, Warsaw. 
the municipality of Czyże (81.8\%). This area directly borders with the territory of the Republic Belarus'. The boundary between the two countries runs along the present line since 1945.

Ukrainians concentrate in the same locations as the Belarusians do, but their shares in total population numbers are much lower. In the county of Hajnówka it is $0.7 \%$, and in Bielsk Podlaski-0.7\%. At the municipality level the highest share, of about $3.1 \%$, is noted in the commune of Czeremcha.

The third ethnic group of Eastern Slavonic origin is the one of Russians. There are about 600 of them in the region. A part of them belong to the denominational group of the Old Russian Orthodox faith, who found refuge in Poland in the face of persecutions in Russia. A small fraction of the local Orthodox faithful is also considered to be the Russians.

Cultural identity is not unequivocally associated with the declaration of nationality. Only roughly $50 \%$ of the representatives of the communities of Eastern Slavonic origin (with a kinship to the Belarusians or Ukrainians) declared the Belarusian or Ukrainian nationality. The remaining part of the representatives of this population declared Polish nationality. Despite this national identification, they differ significantly from the typical ethnically Polish population. They are namely, tied with the Christian Orthodox Church, while their traditional cultural customs refer to the culture of the neighbouring Belarusian and Ukrainian populations.

The ethnic and denominational differences have a clear influence on political attitudes, including electoral preferences. The orthodox inhabitants of the region were much more positive towards the Russian domination of the past and towards the introduction of the communist system in 1945. The catholic population was much more strongly opposed with respect to these forces, which brought about the antagonisms. This kind of situation persists to a degree until today and finds its reflection in the electoral behaviour. The orthodox population votes first of all for the candidates of the left, who are being associated with the former communist system. The catholic population of the region supports mainly the candidates of the right, associated with the former anti-communist opposition. The organisations representing the Belarusian ethnic interests gain marginal electoral support.

The Lithuanian population is much less numerous than the Belarusians. In distinction from the latter they are, like most Poles, Roman Catholics. Their primary distinguishing factor is the language, strongly differing from Polish, and belonging to the Baltic group of languages. In one of counties (NUTS 4) Lithuanians account for $21.4 \%$ of the population, in one commune (NUTS 5) of the same county-in Puńsk-for around $75 \%$ of the total population number, and in another one-the town of Sejny-for roughly $15 \%$. This region neighbours directly upon the Republic of Lithuania. The boundary between the two countries was demarcated in 1919. In 1945 it became the boundary between Poland and the Soviet Union. Until the downfall of the communist system it was tightly closed and did not allow for the contacts between the inhabitants of the two countries. Local Lithuanians, des- 
pite their inimical attitude towards the communist system, support in the elections the candidates of the left, similarly as the orthodox Belarusians. They perceive in these candidates the counterbalance to the Polish nationalist forces, perceived as associated with the rightist option.

The remaining minorities are very small. Jews, constituting before the World War II the third ethnic group on this area, and in some towns even the dominating one, are represented nowadays by just a couple of persons. There are a bit more Poles of Jewish extraction, but they are entirely integrated with the Polish society. Such a drastic drop of the number of Jewish population is first of all due to the Holocaust, perpetrated by the Nazis during the World War II. Only some $10 \%$ of Polish Jews survived this extermination. The survivors emigrated in their majority to Israel, the western European countries and the overseas (mainly North America). The traces of the high numbers of Jews and of their culture are the numerous remnants of the material culture (synagogues, cemeteries, residential houses). In the recent years a kind of revival of interest in the Jewish culture and the history of Polish Jews, including the complex and oftentimes conflicting Polish-Jewish relations, can be observed. This concerns also tourism, and in particular the tourists coming from abroad. They are first of all the representatives of the Jewish communities, who come in order to learn the history of their ancestors.

There is an interesting group of Tartars, settled on these areas by the Lithuanian rulers (until 1569 the entire region in question belonged to the Grand Duchy of Lithuania, and then, between 1569 and 1795 - a part of it did), who were, starting with 1383, at the same time also the kings of Poland. Tartars differ from the local population first of all by their Muslim (Sunni) religion. They never constituted a large group and gradually, owing to intermarriages and the influence of the dominating cultural patterns, assimilated with the local population. Nowadays, this group amounts to just roughly 300 persons. Numerous monuments of material history remained, like the old wooden mosques, functioning until today. Locations linked with Tartar culture are connected through a specially designated tourist route.

Germans constituted in older days a visible group. They had been coming since the Middle Ages, and in higher numbers mainly after 1795. In the years 1795-1807 they were to a large extent the representatives of the Prussian administration (officers), while later on-craftsmen, industrialists and farmers. They underwent a significant assimilation in the Polish environment. An important part of them distinguished themselves by their membership in the Evangelical denomination. If they did not leave Poland due to the World War II, they underwent complete assimilation. The evidence of the process is constituted by the frequent names of German origin (Schmidt, Miller, Schulz).

\section{THE EXPRESSIONS OF THE DIFFERENTIATED CULTURAL HERITAGE}

Polish culture plays the dominating role. In this region it appears in its borderland, eastern variety. The language of the local Poles reminded a bit the Belarusian 
language. In comparison with the other regions of the country local population is much more strongly attached to the traditional system of values, which is expressed, in particular, through the intensity of religious life. Until quite recently a large portion of the local Poles emphasised their gentry status. In this region, in many villages, the representatives of petty nobility-akin in terms of their wealth and social status to the Spanish hidalgo-accounted for a majority of inhabitants. This created a specific cultural climate, reflected in the economic life and in social relations. The gentlefolk villages are distinct as to their architecture and the pattern of buildings. Their inhabitants display some specific features of culture and social attitudes.

Among the minority groups, the most visible in the sphere of cultural heritage are Belarusians and Lithuanians.

The Belarusian population distinguishes itself through their language, denomination and folk culture, inherited from the ancestors. Maintenance of the Belarusian tradition is made possible owing to the numerous public schools with Belarusian as teaching language, and the chair of Belarusian culture at the University in Białystok. There are many organisations promoting Belarusian culture and taking care of preservation of the Belarusian identity. The Belarusian cultural life finds its expression in the activity of the artistic and literary community, existence of numerous artistic groups and ensembles, as well as publication undertakings. According to many opinions the conditions for the development of the Belarusian culture are here better than in the Republic Belarus', ruled by Alexander Lukashenko, where Russian culture is preferred.

The separate character of the Belarusian culture and the Orthodox faith finds its reflection in the material culture. The monuments of the Orthodox church architecture attract tourists from the entire country, and even from abroad. There is a special interest in old wooden Orthodox churches. The monastery compound in Grabarka is an important pilgrimage centre for the orthodox faithful. The monuments of the wooden village architecture have been grouped in a number of open-air museums.

There are numerous cultural events that are associated with Belarusian culture and Orthodox religion. These are, for instance, the Festival of Orthodox Church Music in Hajnówka, Midsummer Eve in Białowieża, Festival of Belarusian Rock Music "Basowiszcza", etc.

The Lithuanian cultural heritage, given the smaller number of the Lithuanians, is represented in a much more modest manner. Lithuanian public schools function. Cultural events are, however, of a more local significance. Lithuanian cuisine enjoys popularity with tourists. The situation of the Lithuanian population has a very high importance for the Polish-Lithuanian relations. Polish authorities, having granted essential rights the Lithuanian minority in Poland, count on the reciprocity, from the side of the Lithuanian authorities, with respect to the much bigger Polish minority in Lithuania.

A Polish law allow for the use of family names in native transcription (Lithuanian, Belarusian, etc.) in official documents and grants the language of a minority 
the status of an official language in the municipalities where a given minority accounts for more than $20 \%$ of inhabitants. Organisations of ethnic minorities and their undertakings of cultural character are financially supported from the state budget. The same applies to education associated with ethnic minorities, which is fully financed from public means, just like all the public education.

The expressions of cultural differentiation, both spiritual and material, play an increasing role in promotion of tourist traffic, forming a synergy in the region with numerous landscape attractions (forests, lakes, rivers, moraine hills), natural assets (national parks, rich animal world), as well as sports and recreation opportunities (sailing, kayaking, hunting).

\section{THE REGION OF VILNA}

\section{ETHNIC DIFFERENTIATION}

The NUTS of Vilnius (Vilna) is the most differentiated one in ethnic terms in Lithuania. This fact remains in close association with the complex history of the region and with its borderland location. The largest ethnic group is constituted by the Lithuanians, concentrated first of all in Vilna (in Lithuanian: Vilnius). The areas surrounding Vilna are, on the other hand, inhabited mostly by Poles. In two administrative districts, Vilna (without the city itself) and Soleczniki, Polish population accounts for a clear majority of the inhabitants (Table 2). There are many municipalities, in which the share of Poles reaches $90 \%$ of the respective totals.

Until the World War II Poles were the majority of inhabitants of Vilna. The region belonged to Poland. After the war Vilna was incorporated in the Lithuanian Republic, being a part of the Soviet Union. Almost all Poles, inhabiting Vilna, moved to Poland in her new boundaries. Those Poles, who inhabited the countryside around Vilna, stayed. In the abandoned city first of all Lithuanians, Russians and Poles settled. The domination of the Lithuanian population became increasingly distinct with the course of time. Nowadays, Vilna is a Lithuanian island surrounded by the areas inhabited in their majority by Poles. This reminds of the situation of the French speaking Brussels, surrounded by the areas dominated by the Flemish populations, which is the source of serious socio-political problems.

Russians are a significant ethnic group in Vilna. The city belonged to Russia in the years 1795-1916, but the massive inflow of Russians to the town started only after the city has been incorporated in the USSR. Until the 1980s they were the group that set the tone for the city. The language of everyday contacts between people was Russian. It was the spoken language not only for Russians, but also for the Belarusians and Ukrainians, inhabiting the city. This phenomenon was largely due to the similarity between the Belarusian and Ukrainian languages and the Russian language. Likewise, for the local Poles, moving to Vilna from the sub-urban areas, Russian was a closer language than the Lithuanian. The exodus 
Table 2. Population by nationality in municipalities of Vilnius region (LT00A) - percents

\begin{tabular}{|c|c|c|c|c|c|c|c|c|c|}
\hline $\begin{array}{l}\text { Municipality } \\
\text { (NUTS 4) }\end{array}$ & $\begin{array}{c}\text { total } \\
\text { numbers }\end{array}$ & 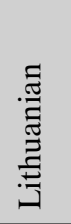 & $\frac{.5}{0}$ & 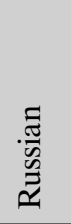 & 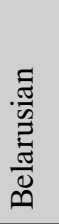 & 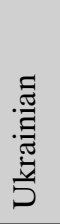 & $\sum_{0}^{\infty}$ & 䔍 & $\begin{array}{l}\frac{n}{0} \\
\frac{\Xi}{0}\end{array}$ \\
\hline Vilnius city & 553904 & 57.5 & 18.9 & 14.0 & 4.1 & 1.3 & 0.5 & 0.2 & 3.6 \\
\hline Elektrenai & 28923 & 82.1 & 7.5 & 6.6 & 1.3 & 1.0 & 0.0 & 0.2 & 1.4 \\
\hline Salcininkai & 39282 & 10.4 & 79.5 & 5.0 & 2.9 & 0.6 & 0.0 & 0.1 & 1.5 \\
\hline Sirvintos & 20207 & 86.6 & 10.0 & 1.9 & 0.5 & 0.4 & 0.0 & 0.0 & 0.6 \\
\hline Svencionys & 33135 & 51.0 & 27.4 & 13.3 & 4.4 & 0.7 & 0.1 & 0.3 & 2.9 \\
\hline Trakai & 37376 & 53.0 & 33.2 & 8.5 & 2.4 & 0.7 & 0.0 & 0.2 & 2.1 \\
\hline Ukmerge & 48651 & 94.3 & 0.7 & 3.8 & 0.3 & 0.4 & 0.0 & 0.0 & 0.5 \\
\hline Vilnius & 88586 & 22.4 & 61.3 & 8.4 & 4.4 & 0.7 & 0.0 & 0.4 & 2.4 \\
\hline Total & 850064 & 54.9 & 25.4 & 11.6 & 3.6 & 1.1 & 0.3 & 0.2 & 2.9 \\
\hline
\end{tabular}

Source: Results of National Census 2001, Central Statistical Office of Poland, Warsaw.

of the Polish elite to Poland caused that the local Poles became more susceptible than Lithuanians to the influence of the Soviet variety of Russian culture. Yet, in the initial period, the Lithuanian population, flowing to Vilna, was dominated by the Russian language, as well. Even though they constituted the relative majority, but the joint share of the Slavonic population, first of all Russians and Poles, was bigger. It was only at the end of the 1980s that Lithuanians gained the absolute majority in Vilna (51\%), and the regaining of independence by the country entailed the language-wise Lithuanisation of the city. The Russian language terminated its role as the means of everyday communication between the inhabitants of Vilna.

Belarusians are a visible population group in the region of Vilna. The relatively small distance to the areas inhabited by Belarusians caused that in the period of existence of the Russian Empire and the USSR Vilna was the main regional centre for the areas of western Belarus'. This brought about a natural inflow of the Belarusian population to the city. The role of the Belarusian culture is strengthened also by the fact that a large part of Poles inhabiting the region of Vilna speak Belarusian at home. In the period of the Russian Empire (i.e. until 1916) they were considered, by the authorities, in the official statistics as the Belarusians.

There are also such distinct population groups, traditionally inhabiting the region of Vilna, as Jews, Tartars and Karaims.

The Jewish population came to the region of Vilna from Poland in the period of the Polish-Lithuanian union (1569-1795). In view of their occupational specialisation, this population group concentrated first of all in towns. They were the majority in many towns. Vilna, where they accounted for roughly $1 / 3$ of the population, was 
an important centre of spiritual life of Jews, of international significance. For this reason, in particular, it was called the "Jerusalem of the North". During the World War II the Jewish population suffered enormous biological losses, due to the extermination policy carried out by the German Nazi authorities. These losses were only partly compensated for by the inflow of Jews from the farther-off areas of the Soviet Union after the World War II. Closing of the boundaries made it impossible for them to emigrate to Israel and the western countries. The "perestroika" and the disintegration of the Soviet Union opened the boundaries, which entailed a radical decrease of the number of Jews.

Tartars started to settle in the region considered in the 14th century, encouraged by the rulers of Lithuania. A number of Tartar villages were established. Their inhabitants distinguished themselves by their denomination (Muslims) and customs. Mosques became the characteristic elements of many localities. With time, a part of Tartars underwent assimilation, adopting the language and the religion of the local native population. Those, who retained their identity, are distinct first of all for their religion. In terms of language they adopted the local Slavonic languages (Polish, Belarusian, and Russian).

A small, but extremely interesting group are the Karaims. The Lithuanian Grand Duke Vytautas the Great settled them in the township of Trakai in the 15th century. They live there until today, although they account for a small part of the inhabitants only. They underwent in the past an intensive Polonisation, and so an important part of them emigrated after the World War II to Poland. They spoke in the past their own language, which is nowadays used only rarely. The language belongs to the Turkish group (similarly as the Tartar language). They do also stand out because of their religion, which took shape under the influence of Judaism.

The fact that Lithuania made a part of the Soviet Union was conducive to the inflow of people belonging to the numerous nationalities, inhabiting the Empire. For this reason one can encounter in the region, and first of all in Vilna, the representatives of almost all the nationalities inhabiting the former Soviet Union (like, in particular, the Volga Tartars, Armenians, Azeris, Latvians, Georgians). In the past, these ethnic groups were subject to strong Russification. Nowadays, they adopt the Lithuanian language. Despite their gradual assimilation they still constitute an important element in the cultural diversity of the city.

The strong cultural diversification of Vilna makes out of its population a particularly open society. Three main languages are used in mutual contacts: Lithuanian, Russian and Polish. There are numerous inhabitants, who can freely pass during a conversation from one language to another.

The inhabitants of other regions of Lithuania are in these terms much more conservative, and the distrust with respect to strangers is considered to be the national quality of Lithuanians. The multicultural character of Vilna makes the Lithuanians living there differ much from this stereotype. 


\section{THE EXPRESSION OF DIVERSITY OF THE CULTURAL HERITAGE}

Until the year 1939 the social life of the region was dominated by Polish culture. Even today many Lithuanians - in some rural areas to the West of Vilna-use more often Polish language than the Lithuanian. This domination ended with the exodus of almost all Poles from Vilna to Poland.

In the period of the Soviet rule the entire social life was subordinated to the communist ideology. In the Soviet Union this was associated with the domination of the Russian language. The culture and language of the non-Russian nationalities were tolerated and could be cultivated within the framework of the ideology in force. In Soviet Lithuania the Lithuanian language had a formal status equal with the Russian. In many spheres and places, though, it ceded to the domination of the Russian language. In the region here considered Russian culture dominated.

Polish language had much less rights than the Russian or Lithuanian. There was just one Polish-language newspaper and there were some schools teaching in Polish. The few Polish cultural associations could only deal in folk art. Under these circumstances Polish population underwent strong Russification. Half of the Polish children learned in the Russian-language schools.

The disintegration of the Soviet Union and the gaining of independence by Lithuania changed the situation diametrically. Lithuanian culture acquired the dominating position and started to be essentially supported by the state. The immigrant population gained full citizen rights, although for performing of some professions knowledge of Lithuanian language is required. This brought about strong assimilation tendencies among the representatives of the minorities.

With this respect, though, Poles were more conservative than Russians. Feeling to be the co-hosts of the region, they emphasise much more strongly their separate identity than Russians. The majority of the Russian schools in the region were turned into Polish-language schools. Numerous organisations appeared, supporting Polish culture, including organisations of political character. The idea arose of establishing a Polish autonomous district on the areas, where Poles constitute the majority of inhabitants. This idea was supported by the Russian authorities, counting on the acquiring by the region of the status similar to that of the "Dnester Republic" in Moldavia or of Abkhasia in Georgia, and becoming a Russian protectorate. The resolute moves of the Lithuanian authorities thwarted the realisation of this scenario. This conflict revived the Lithuanian-Polish antagonism, which lasted over the first half of the 20th century. The conflict concerned the status of the region of Vilna. Until 1795 Vilna was the capital of the ancient Lithuania, but the Lithuanian state of that time included the present-day territory of Belarus', and the city, as well as the region, was dominated by the Polish population. In Vilna itself Lithuanians accounted for only $2 \%$ of the population (currently $60 \%$ ). Thus, Vilna was claimed by Lithuanians, Poles and Belarusians. These three nations consider Vilna until today to be a part of their proper tradition. 
The conflicts of the past, strengthened by the recent events, impact upon the present-day relations between the Lithuanian state and the Polish minority. Numerous Lithuanian ideologues consider local Poles to be the immigrant population or the Polonised Lithuanians. Their primary postulate is to Lithuanise the region. The Lithuanian authorities to some extent give way to such ideologies. The state supports the development of the Lithuanian-language education in this region, devoting special funds to this purpose. Polish schools are neglected. Some $50 \%$ children from the Polish families frequent Lithuanian schools, which are better equipped and secure a better comfort of learning. The authorities do not agree to grant the Polish language the status of official language on the areas with Polish majority. The authorities are also against the use of the original Polish transcription of the family names of Polish population, which results in their deformation.

The political relations between Poland and Lithuania are correct, if not friendly, but the situation as described above causes sometimes a worsening of these relations.

The situation of the Belarusian population appears as much better. This population has no ambitions similar to those of the Polish society, and is satisfied with the possibility of developing Belarusian education and culture in the degree much fuller than this is the case in Belarus.

Quite particular is the situation of the Russian population. In the communist period, the presence of this population was perceived by the Lithuanians as linked with the Soviet occupation. The conflict preceding the regaining of independence by Lithuania disproved very much the relations between the two communities. In spite of this, Russians acquired full citizen rights, that is-much more than the authorities of the neighbouring Latvia and Estonia offered the Russians. This was possible also in view of the relatively limited-in comparison with these two other Baltic states-number of Russians. Such a course of events resulted in the soothing of the conflict and accelerated assimilation of Russians in the Lithuanian society. It facilitates also the maintenance of the correct relations between Lithuania and Russia.

Cultural differentiation is expressed, as well, through the diversity of cultural events. Many of them take on an ethnic character. The Lithuanian events dominate, of course, in this respect. The second place is occupied by the events organised by the Polish community. Polish radio broadcasting and a couple of Polish press titles exist. Russian culture, though, still plays an important role. Its range of influence encompasses not just Russians, but also the immigrants belonging to other nationalities of the former Soviet Union. A significant part of the Polish population-especially the representatives of the older generation-continues to be the audience of the Russian culture. There are numerous Lithuanian magazines that are still published in two versions - the Lithuanian and the Russian ones.

Cultural diversification is an attraction for many tourists. Tourist traffic is dominated by the visitors from Poland, for whom the travel to Lithuania has to a large extent a sentimental meaning. Tourist traffic concentrates in Vilna and in the nearby town of Trakai. 
The biggest attraction of Vilna is the Old Town, reaching back with its origins to the Middle Ages. The mutual penetration of cultures causes that side by side with Roman Catholic churches there are also Orthodox churches, and side by side with the instances of the western art, one encounters also those of the Byzantine art. The faithful may participate in the liturgy in Lithuanian, Polish or Russian languages.

In some villages near Vilna one can see the monuments of the Muslim art, and first of all the historical, wooden mosques.

In Trakai, next to the reconstructed castle of the Grand Dukes of Lithuania, tourists can visit the Karaim quarter, with wooden living houses and the Karaim temple. The township and the surrounding areas form the Historical National Park. It is composed of various kinds of reserves, devoted to town planning, archaeology, and two architectural ones. There are also several nature reserves.

The monuments of Jewish culture, first of all the buildings of former synagogues (one of them still functioning in Vilna), as well as numerous Jewish cemeteries, can be seen in the entire region.

\section{THE REGION OF LATGALIA}

\section{ETHNIC DIFFERENTIATION}

The respective NUTS 3 consists mainly of the historical region of Latgalia (in Latvian: Latgale). This region was also called in the past Polish Inflants (Latvian: Polu Vidzeme). The NUTS 3 encompasses, as well, the eastern part of the historical region of Semigalia (Latvian Zemgale). The region is situated in the south-eastern part of Latvia and borders upon Russia, Belarus' and Lithuania. Its administrative centre is located in Daugavpils, called in Lithuanian Daugpilis, in Polish-Dyneburg, in German-Düneburg, while in Belarusian and Russian-D'vin'sk. This diversity of names illustrates well the cultural differentiation of the region. Its fate was indeed quite varied. Inhabited since the Middle Ages by the Baltic tribe of Latgales, it was in the 13th century conquered by the German Order of the Knights of the Sword, and incorporated into their state in Livland (Inflants). This entailed a long period of strong influence from the German culture. In 1561 Livland joined the Polish-Lithuanian Commonwealth. Latgalia was this part of Livland, which was most tightly associated with the Commonwealth. Polish culture gained strong influence over the area of the region. German nobility was the first to undergo Polonisation. So, such known Polish landowner families of far-off German extraction originate from this region as Zyberk-Plater, Denhoff, Manteuffel, Ropp, Romer, Kelles-Krauz, etc. Polonisation affected also a part of the peasant population, mainly in the southern part of the region (the neighbourhood of Dyneburg).

In the 18th century a large group of the Russian Old Orthodox faithful settled in Latgalia, which brought additional aspect to the diversity of the cultural landscape of the region. After the region had been incorporated in the Russian Empire, which 
took place in 1772, new groups of Russians came, first of all linked to the administration and the military. Belarusians and Lithuanians flowed in from the neighbouring areas. Jews, inhabiting mainly towns, were quite numerous. Similarly as in the other regions of the Polish-Lithuanian Commonwealth, they frequently constituted majority in towns.

Long-lasting association with Poland and Lithuania was conducive to the increased influence of the Roman Catholic Church, whose faithful include in the region both Latvians and Poles. In the remaining regions of Latvia the Protestants dominate. The Latgales differ from the other Latvians by their separate dialect, which is considered by some to be a self-standing language. It reminds a bit the Lithuanian language. Because of this, some Lithuanian politicians forwarded at the beginning of the 20th century the postulate of incorporation of Latgalia to the new Lithuanian state. In the same period Polish state also claimed the rights to Dyneburg and its surroundings. Ultimately, entire Latgalia was included in the Republic of Latvia.

The presence of the Slavonic population (Russians, Poles and Belarusians) allowed for consideration of this region by the pre-revolutionary authorities of Russia as a part of the Great Russia. After incorporation of Latvia into the USSR (ultimately in 1945), Latgalia remained within the confines of Latvia, but the inflow the Russian population underwent intensification. This population took largely the place of the Jewish population, exterminated by the Nazis. Side by side with Russians, Belarusians and Ukrainians flowed in as well. The percentage share of the Russian population was in Latvia among the highest in the non-Russian republics of the former Soviet Union. At the end of existence of the USSR, in 1989, Latvians accounted only for $52 \%$ of the inhabitants of Latvia. Russian population dominated decidedly in Latgalia. After Latvia had regained independence a slow increase of the share of Latvians in total population took place. Russian population, however, still dominates in Latgalia.

Due to historical conditioning the region constitutes a true cultural mosaic. It is inhabited by Russians, Latvians, Poles, Belarusians and Lithuanians (Table 3). Side by side with Roman Catholics there are Old Orthodox, Orthodox and Lutheran faithful. Of the numerous Jewish community only single persons remained. Almost all Jews were killed during the World War II. The remaining ones emigrated to Israel and to the countries of the West after the collapse of the USSR. Similarly as in Lithuania, the representatives of many nationalities inhabiting the territory of the former USSR live in Latgalia, and first of all in Dyneburg.

An instance of the intermixing of population on the rural areas can be provided by the municipality of Kaplavas, situated in the southern part of the region, at the border with Lithuania. In 1989 Latvians constituted there $22 \%$ of the population, Russians-23\%, Poles-24\%, and Belarusians-28\%.

The large share of the Russian population became a serious problem at the instant Latvia regained independence in 1990. The authorities of the collapsing USSR, and then of the Russian Federation tried to use the Russian minority in order to keep 
Table 3. Population by nationality in municipalities of Latgale region (LV005)—percents

\begin{tabular}{|c|c|c|c|c|c|c|c|c|c|c|c|c|}
\hline $\begin{array}{l}\text { District } \\
\text { (NUTS 4) }\end{array}$ & 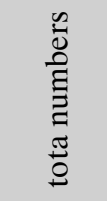 & 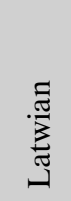 & 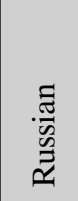 & 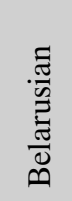 & 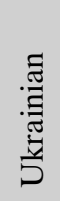 & $\begin{array}{l}\frac{1}{5} \\
\frac{\pi}{0}\end{array}$ & 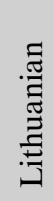 & $\stackrel{\infty}{3}$ & $\sum_{0}^{2}$ & Ð્త్ & 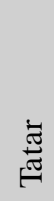 & 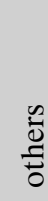 \\
\hline $\begin{array}{l}\text { Daugavpils } \\
\text { city }\end{array}$ & 115265 & 16.0 & 55.2 & 8.8 & 2.4 & 14.9 & 1.0 & 0.6 & 0.3 & 0.1 & 0.2 & 0.6 \\
\hline Rezekne city & 39233 & 42.6 & 50.7 & 1.7 & 1.3 & 2.7 & 0.2 & 0.3 & 0.0 & 0.1 & 0.1 & 0.4 \\
\hline Balvu & 30624 & 76.6 & 19.5 & 0.7 & 0.8 & 0.3 & 0.1 & 0.0 & 0.4 & 0.1 & 0.0 & 1.3 \\
\hline Daugavpils & 42758 & 39.5 & 38.0 & 6.7 & 1.3 & 11.9 & 1.6 & 0.1 & 0.5 & 0.1 & 0.1 & 0.4 \\
\hline Kraslavas & 36836 & 48.2 & 24.4 & 18.1 & 1.2 & 6.6 & 0.4 & 0.1 & 0.5 & 0.1 & 0.0 & 0.4 \\
\hline Ludzas & 35125 & 56.3 & 36.1 & 4.1 & 1.4 & 1.1 & 0.3 & 0.1 & 0.1 & 0.0 & 0.0 & 0.5 \\
\hline Preilu & 41735 & 24.4 & 9.8 & 0.6 & 0.3 & 0.7 & 0.1 & 0.0 & 0.2 & 0.0 & 0.0 & 0.1 \\
\hline Rezeknes & 43090 & 56.9 & 39.0 & 1.3 & 0.8 & 1.2 & 0.2 & 0.0 & 0.3 & 0.1 & 0.0 & 0.3 \\
\hline Total & 384666 & 43.1 & 40.4 & 6.0 & 1.5 & 7.2 & 0.6 & 0.2 & 0.3 & 0.1 & 0.1 & 0.5 \\
\hline
\end{tabular}

Source: Population and Housing Census results 2000, Central Statistical Office of Poland, Warsaw.

Latvia in the framework of the USSR, and when this failed - to secure the subordination of Latvia to Moscow. Territorial claims were also formulated, concerning first of all the area of Latgalia. On the other hand, the authorities of sovereign Latvia, tending to make the state more Latvian, refused granting Latvian citizenship the population that had flown into the country during the period of existence of the USSR. This regulation affected a large part of inhabitants of Latgalia. In such a situation certain part of the population emigrated from Latvia. This brought a worsening of relations between Latvia and Russia.

Despite this situation, the majority of the immigrant population welcomed the establishment of the sovereign Latvia, hoping that severing the ties with the Soviet Union would improve their standard of living and bring liberalisation of the sociopolitical life. The pro-Latvian attitudes were the weakest exactly in Latgalia, which underwent the most dramatic economic regress after the downfall of the USSR. The pro-Soviet sentiments are the strongest here.

In view of the existing situation, Latvian authorities conducted a differentiated ethnic policy. It was especially advantageous for the Polish population, who were perceived as an ally in the face of the Russian separatist tendencies. Support was extended for the development of Polish culture and education in Latgalia, in the attempt of attracting Polish community away from the Russian influence. This serves the maintenance of the traditionally good relations between Poland and Latvia. Yet, it has not changed the fact that also a large proportion of Poles, who came to Latvia during its Soviet era, have not obtained Latvian citizenship. Poles, however, were granted significant facilitation possibilities when trying to obtain the citizenship. 


\section{THE EXPRESSIONS OF CULTURAL DIVERSITY}

The cultural diversity of the region shows up through numerous institutional undertakings. There are numerous organisations maintaining the tradition of cultural identity of Latgalia and of the Latgales within the framework of the Latvian society. There are, as well, organisations and institutions acting on behalf of ethnic minorities (mainly Russian, Polish and Belarusian). Education for these ethnic groups functions. The activity of these institutions results in numerous events aiming at the promotion and maintenance of traditions of various ethnic and national cultures.

Numerous historical monuments constitute a part of tradition of many national, ethnic and denominational groups. We can mention here the monuments of sacred art of many denominations and religions (Roman Catholic, Lutheran, Old Orthodox, Orthodox, Jewish), the urban patterns reaching back to medieval times, gothic castles and the later period rural manor and palace compounds. High importance is attached in Latvia to cultivation of folk culture, including the monuments of folk architecture. This is connected with the peasant origins of the contemporary Latvian nation.

Despite the cultural richness and numerous historical monuments associated with it, Latgalia still awaits its discovery as a region featuring tourist attractiveness. From this point of view, side by side with the cultural heritage, the natural assets of the Latgalian Upland (rivers, lakes, moraine hills) should be considered as strong points.

\section{SUMMARY}

All the regions here considered are differentiated in ethnic and denominational terms. The region of Białystok is, however, definitely the least differentiated of the three, since the population of nationalities other than the Polish one accounts for only roughly $6 \%$ of the respective total. More important here is the denominational differentiation, because the share of the Orthodox population amounts most probably (there are no official data on the subject) for more than $10 \%$. The limited shares of the minority populations cause that the conflicts of ethnic or religious character do not represent a serious problem. The presence of the minority groups and the monuments of their culture enrich, on the other hand, the cultural image of the region, and constitute an important element in attracting tourist traffic.

The presence of the Lithuanian group and the privileges, it was granted form a significant factor in the shaping of the good neighbourhood relations with the Republic of Lithuania, and have an indirect impact on the situation of Polish population in Lithuania.

The presence of the Belarusian minority should also constitute a tangible element in shaping the relations with the Belarusian state. The attitude of the current Belarusian authorities, though, makes mutual collaboration in this domain difficult. The Belarusian population living in Poland has much better conditions for developing their culture than the Belarusians living in Belarus' itself. Hence, the situation 
of the Belarusians in Poland does not have any influence on the situation of Poles in Belarus', where the self-organisation activity of the local Poles is treated with high degree of distrust from the side of the authorities.

The ethnic question has a much higher significance in the region of Vilna in Lithuania and in the Latvian Latgalia. Ethnic differentiation is much higher there, and the conflicts arising therefrom are much more serious. The social and economic advantages resulting from the cultural diversity are to a much bigger extent overshadowed by the negative phenomena resulting from the ethnically based tensions.

In the case of the region of Vilna the tensions associated with the presence of the important Polish minority not only negatively impact on internal relations, but also on relations between Poland and Lithuania. Many Lithuanians perceive the liveliness of the Polish culture not only as a threat to the territorial integrity of Lithuania, but also as a danger for the Lithuanian cultural heritage. In this situation the presence of numerous tourists from Poland is not always seen as an element serving the development of the region and the good neighbourhood relations between the two countries.

The presence of the Russian and Belarusian minorities, highly controversial at the beginning of the 1990s, does not give rise nowadays to the so negative emotions. This is a positive element in the shaping of the relatively correct relations with the Russian Federation. One can see it especially well against the background of the not quite correct relations between Russia and the remaining Baltic states (Latvia, Estonia).

In the case of Latgalia it is the Latvian-Russian conflict that comes to the forefront. The peripheral location of the region and its economic collapse are additional negative factors shaping the socio-economic situation. The region features the highest unemployment rate in the country. These circumstances are highly disadvantageous for the development capacities associated with cultural wealth and the natural assets of the region, which could otherwise be the backbone of economic growth. The tense relations between the Latvian and the Russian populations impact negatively on the Latvian-Russian relations, this fact being also reflected in a negative manner in the Latvian-Belarusian relations. All this exerts a disadvantageous influence on the possibilities of the socio-economic development of the regions located on both sides of the border. The Latvian-Russian conflict, though, echoes in the improvement of the situation of Latvian Poles. Polish population is treated by the Latvian authorities as an ally in the struggle with the Russian domination in the region. The cultural and educational undertakings of the Polish community find support from the Latvian authorities. Friendly relations between Poland and Latvia are partly a reflection of this fact.

Referring to the models, presented by J.W. Berry (1997), one can notice in the regions analysed both the realisation of the assimilation and the integration processes, which could be nominally considered as "constructive", and of the separation and marginalisation processes, which can be considered as "destructive". 
The former ones are the expressions of the integration of the regional society and serve the normalisation of relations between the neighbouring countries. The latter ones are symptoms of the persisting disintegration and are conducive to the increased conflicts between neighbours. Assimilation is characteristic for a large part of the population of Eastern Slavonic origin, inhabiting the region of Białystok. This applies also to an important part of the Polish- and Russian-speaking inhabitants of Lithuania. Integration dominates among the Latvian Poles, as well as among the Polish Lithuanians and Belarusians. The situation is different with a large part of Poles in Lithuania or of Russians in Latvia. A part of the Lithuanian Poles displayed the separatist (autonomist) tendencies, and similarly with the Russians in Latvia. In the case of Russians, both in Lithuania and in Latvia, one can also notice the phenomenon of marginalisation, associated with the difficulties in acquiring citizenship (Latvia) and/or lack of participation in public life (Latvia, Lithuania).

It is also possible to note connections with other models. The model of alternation is, for instance, characteristic for the community of the Eastern Slavonic origins, living in the region of Białystok. The majority of representatives of this community developed a double identity_of an Eastern Orthodox Pole or of a Polish Belarusian. Definitely, the feeling of identity of the Poles inhabiting the area of Dyneburg (Daugavpils) in Latvia (a Latvian Pole) develops in a similar direction. The elements of cultural fusion can also be found in the same examples. The Eastern Orthodox Pole or the Latvian Pole are doubtlessly new cultural qualities. On the same basis the behaviour according to the linear-bipolar model can be observed, as well. It dominates first of all in the communities, undergoing gradual assimilation, of which the most striking example is definitely provided by the Belarusians in Poland.

The studies showed a very diversified and ambiguous image. One can notice both positive and negative elements, associated with the existence of regions that are diversified in ethnic terms. The tensions persisting may indicate, though, that construction of a single European society may turn out to be a very difficult task. Not just in view of the regions differentiated as to their ethnic composition, but, first of all, because of the persisting high popularity of the national ideologies, strengthening the separatist tendencies, as well as the lack of acceptance for the separate characteristics of the ethnic minority groups (assimilation policies and xenophobic attitudes).

\section{REFERENCES}

Arroyabe, E. (1999) Europe as a mosaic of identities: some reflections, in: Turton, D., González, J. (eds.) Cultural Identities and Ethnic Minorities in Europe, 23-34.

Berry, J. W. (1997), Immigration, Acculturation and Adaptation, in: Applied Psychology: An International Review, 46, 1, 5-68.

Billing, M. (1995), Banal Nationalism, Sage Publishers, London.

Eberhardt, P. (1997 a), Demographic issues concerning the Polish-Lithuanian bor- 
derland, in: Geopolitical Studies, 2, IGiPZ PAN, Warsaw, 101-114.

Eberhardt, P. (1997 b), Problematyka narodowościowa Wileńszczyzny, Czasopismo Geograficzne, LXVII, 1, Wrocław, 39-69.

Eberhardt, P. (1997 c), Przemiany narodowościowe na Litwie, Warszawa.

Eberhardt, P. (1997 d), Problematyka narodowościowa Łotwy, Warszawa.

Gellner, E., 1983, Nationals and Nationalism, Cornell University Press, Ithaca.

Kowalski, M. (1997), Ethnic Character of the North-Eastern Borderland of Lithuania, Geopolitical Studies, 2, Warsaw, IGiPZ PAN, 115-131.

Kowalski, M. (1998), Wyznanie a preferencje wyborcze mieszkańców Białostocczyzny (1990-1997), Przeglad Geograficzny, LXX, 3/4, 269-282.

LaFromboise, T., Coleman, H. L. K., \& Gerton, J. (1993), Psychological impact of biculturalism: Evidence and theory, Psychological Bulletin, 114, 395-412.

Phinney, J. S. \& Devich-Navarro, M. (1997), Variations in bicultural identification among African American and Mexican American adolescents, Journal of Research on Adolescence, 7, 1, 3-32.

Valk, A. (2002), Questions to answer thinking about relations between ethnic or national and European identity, in: Euro Conference: "Political Priorities between East and West: Europe's rediscovered wealth. What the accession-candidates in Eastern and Central Europe have to offer", March 18th-19th, 2002, Institut für den Donauraum und Mitteleuropa, Vienna.

Population and Housing Census results 2000, Central Statistical Bureau of Latvia, Riga. Results of National Census 2002, Central Statistical Office of Poland, Warsaw. Results of National Census 2001, Lithuanian Department of Statistics, Vilnius. 


\title{
REGIONAL INEQUALITIES IN A TRANSITIONING COUNTRY (HUNGARY) - DOES HDI ${ }^{1}$ A USEFUL TOOL FOR MEASURING?
}

\author{
GÁBOR NAGY \\ Centre for Regional Studies, Alfold Institute \\ Hungarian Academy of Sciences \\ 5600 Békéscsaba, Szabó D.U. 42, Hungary \\ e-mail: nagy@rkk.hu
}

\begin{abstract}
In this paper, the author try to show, an alternative regional structure of a New EU-Member Country (Hungary) and its change in the period of transition (1990-2004). Described the theories of regional development (economical and geographical studies), the globalisation theories and the transition studies, and try to answer, if Human Development Index (HDI) is a useful tool for measuring inequalities in European country in transition.
\end{abstract}

Key words: Hungary, HDI, regional inequalities, regional development

\section{PRELIMINARIES OF INVESTIGATION}

The post-fordist phase of economic thinking overstepped the view of mass production, the level of added value and focused on the people as human resource of development. In this point of view the most important factor of competitiveness became the level of well-being, the flexibility of employees, the level (and quality) of education, the possibilities of recreation. The changing point of view prefer the different dimensions of quality of life, instead of economic success, central position in decision making etc., the 'traditional' elements of competitiveness, in the mainstream of regional studies. In this paper we try to show an alternative regional structure of a New EU-Member Country (Hungary) and its change in the period of transition.

\section{THEORIES OF REGIONAL DEVELOPMENT}

In this special context the theories based on internal resources seemed the most important ones. Back to Stöhr's original thought (1990) the local well-being based mainly on local resources, their special combinations, new paths of local and regional development. The novel combination of resource utilisation and enhanced exploitation of them combined with local (even hidden components) knowledge became

1 HDI - Human Development Index 
crucial in increasing the level of quality of life (Romer 1994). However, Romer's interpretation suggest, the spatial distribution of knowledge (particularly the certain part of knowledge, which might be converted into well-being) is uneven and the channels of dispersion are limited, because of the limited possibilities of personnel connections.

The theories of development stages (Rostow 1960; Friedmann 1973; Richardson 1980) suggested a moderate level of regional differences in economy and society, through the spatial diffusion of economic activities. Krugman (1991) has a different point of view, his model showed a constantly differing regional structure and diverging level in quality of life, through the casual chains, accumulating processes, with the favourable position of large metropolitan areas. Porter's opinion is between the two arguing theories, the Porter-diamond (Porter 1996) suggest a well-structured model for regional development, with an ultimate goal, the increasing quality of life through some clear economic bases.

The problem of the models concentrated around the spatial distribution of power, formulating strict centre-periphery structures in different administrative levels, as Ash Amin (Amin 1976; Amin-Thrift, 1994), David Harvey (Harvey 1982; Harvey 2005), or Neil Smith (1984) mentioned. This type of inequality, involve regional differences in a longer term, with clearly mapped centres, semi-peripheries and peripheries (in some cases regions without marking the World economy and society). The control over the technological innovation, the core competencies of production chain, the decision-making process and lobbying activities (particularly in international level, formulating the frame of economic development, dispersing the values etc.), hybernate the favourable position of existing highly developed areas against the economic peripheries.

\section{GLOBALISATION STUDIES}

The globalisation theories help us to see the processes of East-Central Europe 1990-2004 in a wider context: transformation from state owned centrally planned economies into market led model, changing the legal and institutional background, answering the challenges of globalisation trends, completing the accession period to NATO, OECD, EU, WTO etc.. In Scott's theory (1998) the dichotomy between the engines of 'modernisation' and their 'hinterland' seemed very useful in the context of EU-15 and the New Member Countries (enlargement in 2004, 2007). Dicken (1992), who discussed the new priorities of corporate building and corporate governance made clear the moderate stimulating and diffusion effects of 'green-field' FDI projects into these countries and the limited connection between the local well-being and the economic success, particularly the industrial restructuring in the countryside of transitioning regions. According to Knox and Agnew (1998) the competition for investment funds (competing locations and regions, as well) resulted a competition in offered advantages and resources to developers, to stabilise the economic position in a wider economic area. This process lead to an unwaited result, the newly made 
funds must be spent partly on economic infrastructure, on developing human resources suitable for large companies, instead of increasing the quality of life. Artner (2006) made a special point of view of globalisation from the losers and bottom-up organised social movements against globalisation practise.

\section{TRANSITION STUDIES}

The Czech, Polish, Slovakian, Romanian and Hungarian case studies (Bradshaw and Stenning 2004; Turnock 2001; Hampl 1999; Domański 1999; Mládek 1996; Horváth and Rechnitzer 2000; Barta, G. Fekete, Kukorelli and Timár 2005) pointed out the macro-level success of economic convergence up to the EU-15 level in a wide range of indexes. However, there were large social groups, areas, which became the losers of the transition period. In this group of New Member Countries the quality of life in 2007, in general, is similar to the peak of the former Socialist regime, after almost a decade of fast economic development. The regional inequalities seems much sharper than before the transition, particularly in economy. The results of regional and social policies were limited, in spite of the growing transfers from the EU. The capital cities and the regions around them are competing each other (even the similar cities in the EU-27, as well), while the development way of them and the countryside diverged. The gateway city position of these metropolitan areas are moderate, the diffusion of innovations (coming from the global actors and from EU) hardly spread in rural areas. The structure of settlement-stock is highly important in regional and local scale convergence to the more developed areas of Europe, where the large cities are missing (see Hungary for example), the dichotomy between the capital city and the 'rest' became sharper, the development potential of regions is more moderate.

\section{CONCEPT OF THE PAPER}

The Williamson hypothesis $(1965 ; 1991)$ described the increase and moderation of regional differences, in developing countries in a quite simple way. After the structural reforms (period of transformation in 1989-1990 in East-Central-Europe) and wider connections into the global frame of economic and social development, the regional imbalance will emerge. The innovations concentrate in larger centres, the restructuring of local economies and societies will deeper and wider at that places, while there will be large zones of lacking adaptivity and flexibility. After a certain period, the new frame and forms of modern market economies and capitalist society will be root deeply in the whole area of the transitioning country as a result of diffusion effects from the large competitive centres. The increasing homogeneity in the frame of development and the diffusion of innovations results a more balanced spatial structure, with decreasing differences among administrative units, capital and countryside, urban and rural areas.

In the economy we could model (Nagy G. 2005) a continuous divergence among administrative units in the period of transition (1990-2004), however the rate of 
split slowed down after 2000. Budapest had a unique position in Hungarian space structure, even the economically well-developed regions (NUTS 2, NUTS 3, LAU 1) were unable such scale of development. The model showed a dualistic structure in the countryside, too, the lagging behind regions (South and East Hungary) had slight development potential, while the regions with favourable geographical location (along the Hungarian-Austrian border, along the Budapest-Vienna axis, laying in the wider agglomeration zone of the capital city) can transform their advantages into attracting FDI, economic restructuring, high rate of growth. The Williamson-hypothesis did work in the first phase of transition (1990-1999), but the turn in spatial processes had not seen after almost one decade of the new millennium (2000-2007). The regional differences increasing constantly, particularly the capital-countryside dichotomy seems very strong. The group of winner and loser regions became stable. The gap between the two groups was increased after 2000 as well. It is possible, that in a longer term the Williamson hypothesis will work and EU Structural and Cohesion Funds, the rural development sources of Common Agrarian Policy may result a more balanced spatial structure, but it will take decades, in the Hungarian case.

The major question is: if we concentrate not only economic transformation, what will be the spatial consequence of the transition? Is it possible, that indexes of quality of life paint a different picture of the country? Are the large-scaled development actions e.g. in infrastructure result a more balanced regional structure?

There were, some investigation in social dimensions, which showed partly different results comparing the economic models. In the case of personal incomes the research (TÁRKI 1997-2006) announced fast growing differences among the social groups (particularly 1. and 10. decades) and stagnation after 1999. The difference between the rich and poorest groups was 8.2 fold in the peak (2002-2003 ) and 7.2-7.5 at the end of the period (2004-2006). This moderating process was the goal of the social policy of the Social-Liberal coalition in 2002-2006 term and resulted a high rate imbalance in fiscal budget of Hungary.

If we see the level of durable goods in households (KSH 1992-2007) among regions or social groups, there are no clear tendencies: the conventional goods showed moderate level of differences, even convergence, while the new ones showed hard divergence. The diffusion of durable goods is hardly connected to wages, but after 2002 Hungarian households bought these kind of goods (partly blank) credit.

\section{USING HDI AS INDEX OF QUALITY OF LIFE}

In the following sections of the paper we will investigate a new aspect of regional inequalities in a transitioning country, the change of quality of life in NUTS 3 level. There are several ways to point out the way of changes and measure some dimensions of the problem. In this paper, following the previous (Nagy G. 2005) research, we try to model the changes, using a complex index in this area, HDI. There are methodological problems to create HDI in NUTS 3 level, because this index was 
constructed for national level, to help the international comparison among countries, macro-regions, continents.

The first result of the paper, that we were able to built-up the index, using official statistical data, following the original content of national-level HDI. The second result was, that this NUTS 3-level HDI was useful to show the regional differences in quality of life. The third important result was that we could calculate this index in the whole period of transition (1990-2004) and describe the changes among NUTS 3 units.

The index, which internationally being used, in the last decades became the HDI (Nemes Nagy and Jakobi 2003; Rechnitzer and Smahó 2005). HDI is a complex index concentrate the meaning of 14 simple variables in 5 main areas:

1. Demography: estimated life-expectancy by sex;

2. Education, skills: uneducated children under 10 years, finished secondary school over 18 years population, average completed years in education;

3. Activity, unemployment: activity rate, rate of unemployment, rate of long-term unemployment;

4. Housing conditions: rate of houses/flats without any comfort, rate of houses with 4 or more rooms, number of newly built houses;

5. Income conditions: number of taxpayers, PIT/person, level of net income, purchasing power level.

The method of calculation was simple, the best unit (county in this case) counts 1,000 point, and the other NUTS 3 units got points in the share of the best one. The primary indices were aggregated firstly in the 5 main areas (without weighting them) and than in the complex index level (simple average). The overall index was HDI in a special date for one county.

Our hypotheses were:

- As HDI concentrate special indexes, the changes in quality of life, has no direct connections with economic changes. The changes in regional structure will be differ from the results of economic transformation.

- The level of incomes and the durable equipment of households suggest a more moderate level of regional inequalities, than in the case of economy. We think, that differences in quality of life (practically the differences in HDI indexes in NUTS 3 level) will moderate, than in economic ones (e.g. GDP per capita).

- After 2000, the divergence in social and economic transformation seemed slowing down and stagnating. We think, that regional differences in HDI will stagnate, as well, in the 2000-2004 period.

- The differences among social groups wider than in West-European countries, is it imply, that Hungary is closer to the Latin-American, or South-European (Italian, Spanish, Portuguese) models? 


\section{LIMITS OF MEASURING}

We used the database of Hungarian Central Statistic Office ( $\mathrm{KSH})$. We had to trust the method of collection, the level of representation, as well. Some data collection of KSH showed large level uncertainty in longer term (e.g. durable goods in households by region, or social groups).

In 1990 and 2001 there were National Census, covering the whole population of the country. In 1996 and 2005 there were so called Microcensus, contained only the data of $2 \%$ of total population. This means not just the limited circle of data available, but even differing results.

We had data missing in some cases:

1. the rate of long-term unemployment by counties in 1990-definitely there were no such groups at that time ${ }^{2}$;

2. the rate of non-comfortable flats in 1990-the National Census had no such category. So we had to create a special index on this area ${ }^{3}$;

3. the level of purchasing power index by counties in 1990 , in that case we used the net income level ${ }^{4}$.

\section{THE RESULTS}

The level of national average (HDI) showed a non-clear path (Table 1). The level of change between 1990 and 2001, such as 1996 and 2004, the differences were moderate. The rate of standard deviation slowly decreased, while the regional level (NUTS 2) differences became more characteristic.

HDI strengthen the formerly well known fact: Budapest had a favoured position in Hungary. The wider agglomeration zone of the capital city (Pest county) showed a fast rate of increasing its HDI.

Northwest-Hungary is the core area of the successful economic transformation. It had better HDI at the beginning of the transition period (1990) in the countryside and these counties (Fejér, Komárom-Esztergom, Veszprém, Győr-Moson-Sopron, Vas, Zala) were able to stabilize it. The advantage in 1990 concentrated in the quality of living conditions, the level of wages and education, similarly in 2004, however the rate of activity (employees, tax-payers) was higher than in the other regions.

In Southern and Eastern regions the change of HDI went back into different causes, the larger groups of indexes moved in different ways. There were significant changes in education (increase) and wages, just like purchasing power index (decreasing). One of the major problems of these regions concentrated on activity

2 The mass unemployment came only in the Autumn of 1990 in Hungary and the date of National Census was February 1st. in 1991.

3 The complex index contains the rate of flats without water supply, electricity and sewage system. The index was the rate of houses and flats without any kind of three index.

4 In 1996 HDI index we used the very first purchasing power index for 1998 year. 
Table 1 . HDI by counties, 1990, 1996, 2000, 2004

\begin{tabular}{|l|c|c|c|c|}
\hline County & 1990 & 1996 & 2000 & 2004 \\
\hline Budapest & 0.953 & 0.983 & 0.921 & 0.952 \\
\hline Pest & 0.721 & 0.713 & 0.768 & 0.764 \\
\hline Fejér & 0.760 & 0.752 & 0.761 & 0.743 \\
\hline Komárom-Esztergom & 0.780 & 0.755 & 0.767 & 0.763 \\
\hline Veszprém & 0.760 & 0.790 & 0.806 & 0.738 \\
\hline Győr-Moson-Sopron & 0.831 & 0.849 & 0.846 & 0.783 \\
\hline Vas & 0.797 & 0.782 & 0.819 & 0.747 \\
\hline Zala & 0.712 & 0.745 & 0.737 & 0.741 \\
\hline Baranya & 0.712 & 0.688 & 0.706 & 0.676 \\
\hline Somogy & 0.691 & 0.668 & 0.683 & 0.643 \\
\hline Tolna & 0.690 & 0.649 & 0.698 & 0.688 \\
\hline Borsod-Abaúj-Zemplén & 0.696 & 0.615 & 0.630 & 0.600 \\
\hline Heves & 0.701 & 0.676 & 0.697 & 0.689 \\
\hline Nógrád & 0.684 & 0.648 & 0.651 & 0.674 \\
\hline Hajdú-Bihar & 0.659 & 0.636 & 0.648 & 0.651 \\
\hline Jász-Nagykun-Szolnok & 0.661 & 0.645 & 0.643 & 0.630 \\
\hline Szabolcs-Szatmár-Bereg & 0.608 & 0.564 & 0.595 & 0.590 \\
\hline Bács-Kiskun & 0.667 & 0.653 & 0.671 & 0.652 \\
\hline Békés & 0.687 & 0.682 & 0.671 & 0.648 \\
\hline Csongrád & 0.718 & 0.719 & 0.754 & 0.715 \\
\hline HUNGARY (average) & 0.766 & 0.698 & 0.726 & 0.708 \\
\hline Source: The author & & & & \\
\hline
\end{tabular}

Source: The author's own calculation.

area, the level of unemployment and long term unemployment was constantly higher, the rate of active workers significantly lower that in the North-western regions.

The level of life expectancy increased significantly instead of a short term decrease after 1990. Between 1990 and 2004 it rose $+3,5$ years for males and $+3,2$ years for females. However, the direction of change is positive, the level of life expectancy is far from the Western standards 5 ! There are well defined differences among counties and regions, but in a moderate level, comparing the economy. Budapest has no significant advantage in this area, however the capital city not far from the best index.

The level of education increased in general (Figure 1 and 2). The rate of uneducated children decreased significantly between 1990 and 20046, while the rate of well-educated ones were increased 50\%, in Budapest only $40 \%$, but the dichotomy of the capital and the countryside hardly changed. The level of education pointed out

5 For female about 8 years gap can be measured, for male more than 10 years.

6 From $1.2 \%$ to $0.6 \%$, in general. 
the favourable position of large university centres and their counties (Csongrád, Baranya, Hajdú-Bihar).

The activity rate had a dramatic decrease between 1990 and 1996, about 1.5 million workplaces ceased, mainly in agriculture (0.5-0.6 million) and industry (0.8 million). However, there was a moderate and constant increase after 1993, the level of active earners was 5\% lower in 2005 comparing 19907. There are significant differences among counties and regions in the level of employment, with a strong connection of the success of economic transformation.

The rate of unemployment had a wave with a peak in November 1993 (over 13\%), and after a slow decrease with the lowest rate in 20048 (Figure 3 and 4). The regional differences were constantly existing in a very high level at the whole period of transition and the spatial structure of unemployment was quite stable. The level of migration inside the country is low, in spite of the differing living conditions, the regional imbalances in workplaces and unemployment ${ }^{9}$ !

The rate of semi and non-comfortable units decreased dramatically in the transition period, but the large diversity of counties does exist (Figure 5 and 6). The high rate of people living in scattered farmsteads the major cause of the differences, because the costs of building common infrastructure is very high at that areas. The number of people living in those flats or houses decreased $10 \%$ in general, however the highest level can be measured in the agglomeration zone of Budapest. Between 1990 and 2004 at least 300,000 people (15\% of the whole population of the capital city) moved out and find a place in the outskirts to build a new semi-detached or family house!

The change of purchasing power index divided the transition period into two parts: from 1998 to 2002, we can see a divergence among NUTS 3. administrative units (counties), with a clear dominance of Budapest and the stable advantage of Northwest-Hungary (Figure 7 and 8). After 2002, the index showed a moderate convergence in the countryside (excluding Budapest) but a stronger dichotomy between the capital city and the rest of the country.

It is interesting, that the rate of tax-payers is significantly higher than the share of employees, but the change of the index and the regional differences among counties were quite similar to the other.

The changing level of paid Personal Income Tax (PIT/person) has strong connection with the level local economy (GDP, net sale, export capacity, added value etc.), in general the success of economic transformation through the level of wages and rate of employment.

7 The number of active earners was 4.6 million in 1990, 3.5 million in 1996, 3.7 million in 2001 and 3.9 million in 2005. The $5 \%$ decrease in activity rate was the result not just the decrease of active workers, but the whole population, too. In 1990 the total population was 10.4 million, in 200510.1 million.

8 After 2004, in parallel with the economic and fiscal crisis the rate of unemployment became increase.

9 One cause of the process belongs to the real-estate market inequalities among the different areas of Hungary, which restrain the level of long-distance migration. 


\section{THE CONSEQUENCES}

HDI is a conservative index, the level of changes in a short period can hardly be measured. However, HDI shows a more stable regional structure of the country rooted in the spatial structure of the former regime, and only partly influenced by the transition period, there are some interesting consequences after the research. The HDI of Hungarian counties showed similar regional differences as economic potential (Rechnitzer 1993), or GDP did in the former investigations (Figure 9 and 10), but a significantly more moderate level. The dichotomy between Budapest and the countryside is clear and stable (Figure 11 and 12). The Northwest regions has a consequent advantage in HDI comparing to Southern and Eastern regions. The regional structure of quality of life strengthen the favourable position of economically more developed regions, increasing their potential in attraction new FDI plants. The low level of long distance internal (even the international) migration potential of Hungarian people suggest the stability of the existing spatial structure. The national regional policy with, or without EU funds has no influence on this process, they are able to slow down the trend, but not to change it.

\section{TESTING THE HYPOTHESES}

HDI, as a complex index in measuring the differences in quality of life spatially became a useful tool. The model - with limits - gave us the content of national level index in the level of NUTS 3 units, and we were able to calculate the indexes in different years, covering the whole transition period of Hungary.

Answering the major question, we can say, that the spatial structure of Hungary in quality of life is differ from the regional inequalities, as result of economic transformation process. The overall diversity of NUTS 3 units is more moderate, the distance between capital city and countryside is tighter, the divergence of counties (NUTS 3 units) is limited. In spite of this, the major components of the spatial picture of quality of life is similar to the economic one:

- The capital city offers the highest level of quality;

- There are well defined winner and loser regions. The first group, concentrate in the 'success' regions of economic restructuring, the other lays in 'problem-regions'.

The level of HDI in counties, have medium-level relationship with economic processes, through the number of workplaces, the level of wages. In this context the similarities between economic and social regional structure can be understand. The differences among regional units are more moderate, than in the case of GDP per capita index. The levels of HDI had higher level relations with the level of family incomes and durable equipment of household. The differences among counties in HDI-comparing with GDP per capita-are moderate.

In the period of 2000-2004, the difference between Budapest and the countryside emerged. The counties with higher HDI index in 2000 lost their position comparing the capital city. The distance between higher and lower level group in HDI had not 
changed in that period, the two counties (Baranya and Csongrád), which had better position in 2000, became the members of the loser group. The Williamson-hypothesis (Williamson 1996) in the case of HDI in the transition period did not work. In Hungary, after 1990, the regional (NUTS 3 level) differences had not emerged dramatically and after the first decade of transition these differences did not decreased, at all. We could see a stabile spatial structure with small-scale movements in the field of quality of life with moderate disperse among units in the whole period of transition. In this context, the Hungarian spatial structure in HDI moved from West-European model to South-European, but it has no similarities with Latin-American one in the period of transition (1990-2004).

\section{REFERENCES}

Amin, A. (1976), Unequal development, Monthly Review Press, New York, London. Amin, A., Thrift, N.J. (1994), Living in the global, (Chapter 1), in: Amin, A. and Thrift, N.J. (eds.) Globalisation, institutions and regional development in Europe, Oxford University Press, Oxford.

Artner, A. (2006), Globalizáció alulnézetben. Elnyomott csoportok—lázadómozgalmak [Globalization from worm's eye view. Oppressed social groups-Rebel movements], Napvilág Kiadó, Budapest.

Barta, Gy., G. Fekete É., Sz-né Kukorelli I., Timár J. (eds.) (2005), Hungarian spaces and places: patterns of transition, Centre for Regional Studies, Pécs.

Bradshaw, M., Stenning, A. (eds.) (2004), East-Central Europe and the former Sowiet Union. The post-socialist states, DARG Regional Development Series, 5, Pearson-Prentice Hall, Harlow.

Dicken, P. (1992), Global shift. The internationalisation of economic activity, Paul Chapman, London.

Domański, R. (1999), The competitiveness of regions in the Polish and European perspective, Studia Regionalia, 9. Wydawnictwo Naukowe PWN, Warszawa.

Friedmann, J. (1973), Urbanisation, planning and regional development, Beverly Hills Cal., London.

Hampl, M. et al. (1999), Geography of societal transformation in the Czech Republic, Charles University Press, Prague.

Harvey, D. (1982), The limits to capital, University of Chicago Press, Chicago.

Harvey, D. (2005), A brief history of neoliberalism, Oxford University Press, Oxford.

Horváth, Gy., Rechnitzer, J. (eds.) (2000), Magyarország területi szerkezete és folyamatai az ezredfordulón [Spatial structure and regional processes in the Millenium in Hungary], MTA RKK, Pécs.

KSH (Központi Statisztikai Hivatal [Hungarian Central Statistic Office]) (database 1992-2007), Budapest, Hungary.

Knox, P., Agnew, J. (1998), The geography of the world economy, 3rd edition, Arnold, 
London, Routledge, Chapman\&Hall, New York.

Krugman, P. (1991), Geography and trade, MIT Press Cambridge, MA.

Mládek, J.(ed.)(1996), Transformation processes of regional systems in Slovak Republic and Czech Republic, Geographica, 37. Univerzita Komenského, Bratislava.

Nagy, G. (2005), Changes in the position of Hungarian regions in the country's economic field of gravity, in: Barta et al. (eds.) Hungarian spaces and places: patterns of transition, Centre for Regional Studies, Pécs, 124-142.

Nemes Nagy, J. - Jakobi, Á. (2003), Modelling Human Development Index in Hungary. UNCTAD Report, Budapest. Manuscript.

Porter, M. (1996), Competitive advantage. Agglomeration economies and regional policy. International Regional Science Review, 1/2, 85-94.

Rechnitzer, J. (1993), Szétszakadás vagy felzárkózás. A térszerkezetet alakitó innovációk [Divergence or convergence. Innovations shaping spatial structure], MTA RKK, Györ.

Rechnitzer, J., Smahó, M. (2006), Regional characteristics of human resources in Hungary during the transition, Discussion Paper Series, 50. Centre for Regional Studies, Pécs.

Richardson, H. W. (1980), Polarisation reversal in developing countries, Papers of the RSA, 12, 67-85.

Romer, P. (1994), The origins of endogenous growth, Journal of Economic Perspectives, 8,3-22.

Rostow, W.W. (1960), The stages of economic growth. A non-communist manifesto, Harvard University Press, Cambridge MA.

Scott, A. J. (1988), New industrial spaces, Pion, London.

Smith, N. (1984), Uneven development, Basil Blackwell, Oxford, New York.

TÁRKI, Jelentések a társadalom szerkezetéröl [Reports on social structure of Hungary], (1997-2006), TÁRKI, Budapest.

Turnock, D. (ed.) (2001), East Central Europe and the former Soviet Union. Environment and society, Arnold Publisher, London.

Stöhr, W.B. (1990) (ed.), Global challenge and local response. Initiatives for economic regeneration in contemporary Europe, Mansell Publisher, London.

Williamson, J.G. (1965), Regional inequality and the process of national development: a descripition of the patterns, Economic and Cultural Change, 13, 1-84.

Williamson, J.G. (1991), Inequality, poverty and history, Basil Blackwell, Oxford.

Williamson, J.G. (1996), Globalisation and Inequality. Then and now: The late 19th and the late 20th Centuries Compared, NBER Working Paper, 5491. 


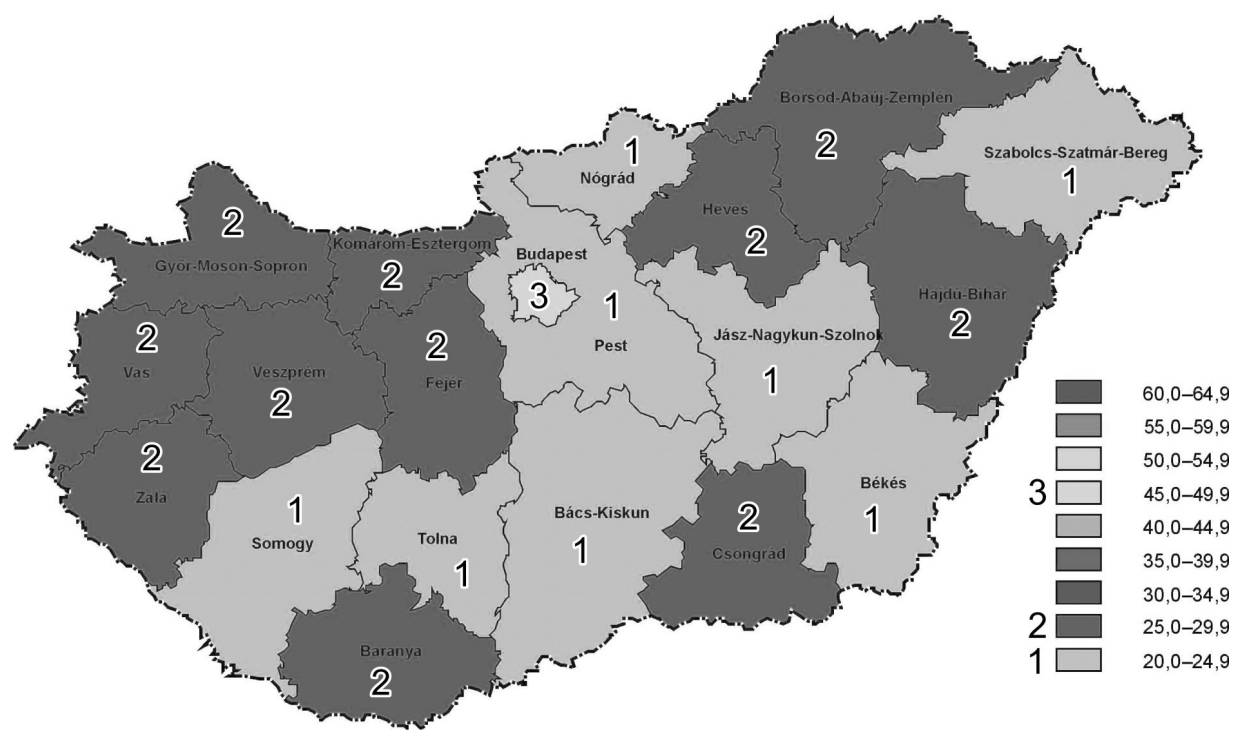

Figure 1 . The share of finished secondary school over in 18 years population in 1990 Source: National Census, 1991.

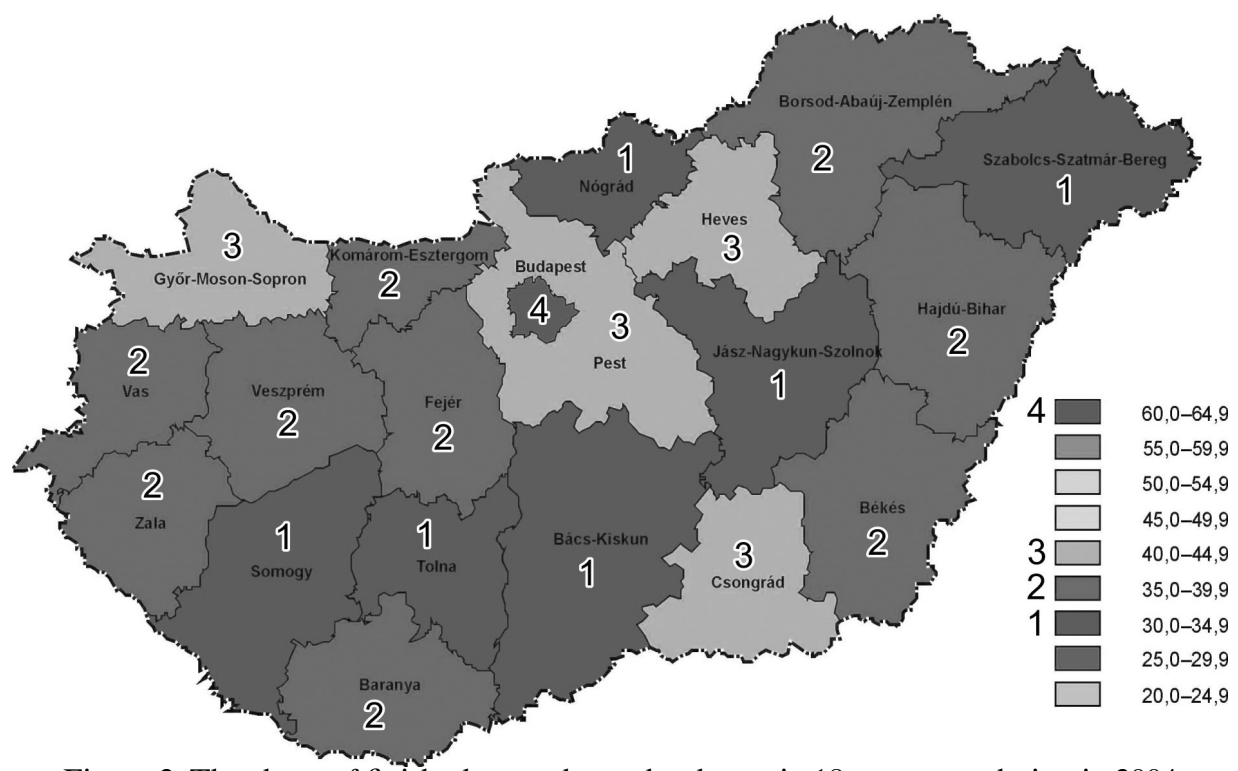

Figure 2. The share of finished secondary school over in 18 years population in 2004 Source: National Micro-Census, 2005.. 


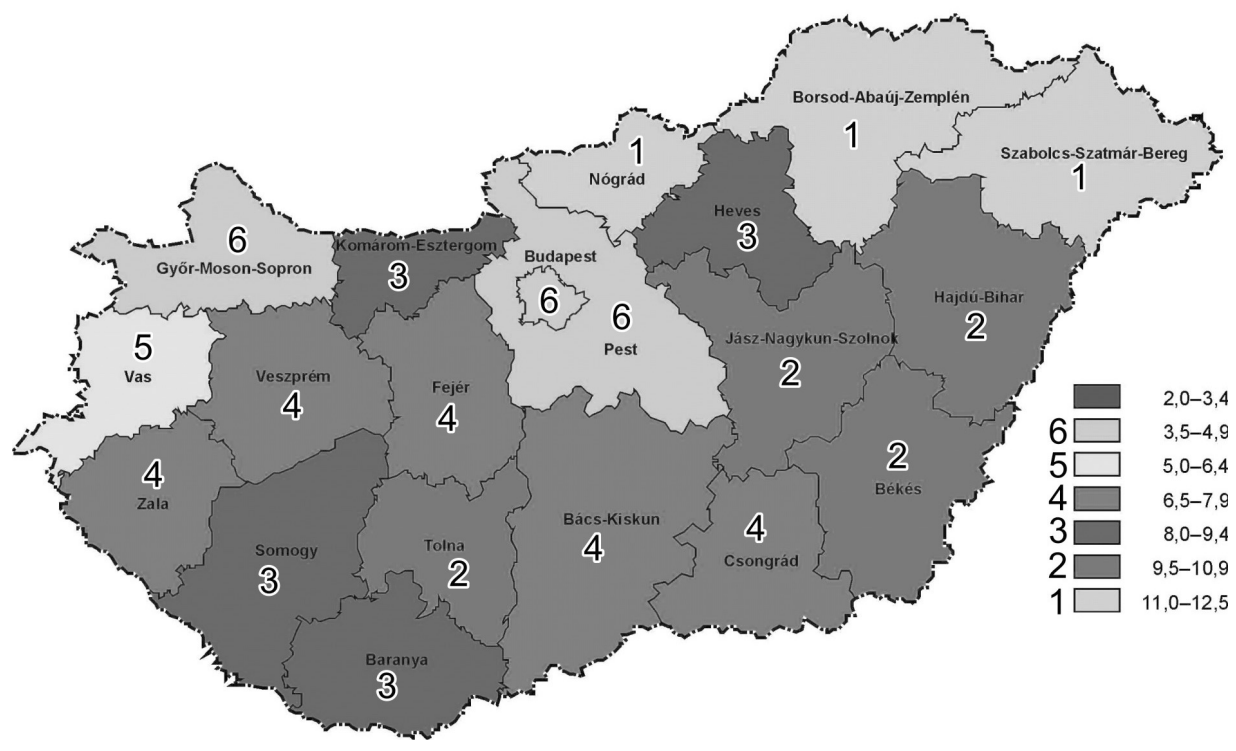

Figure 3. Share of unemployment in 1996

Source: National Micro-Census, 1996.

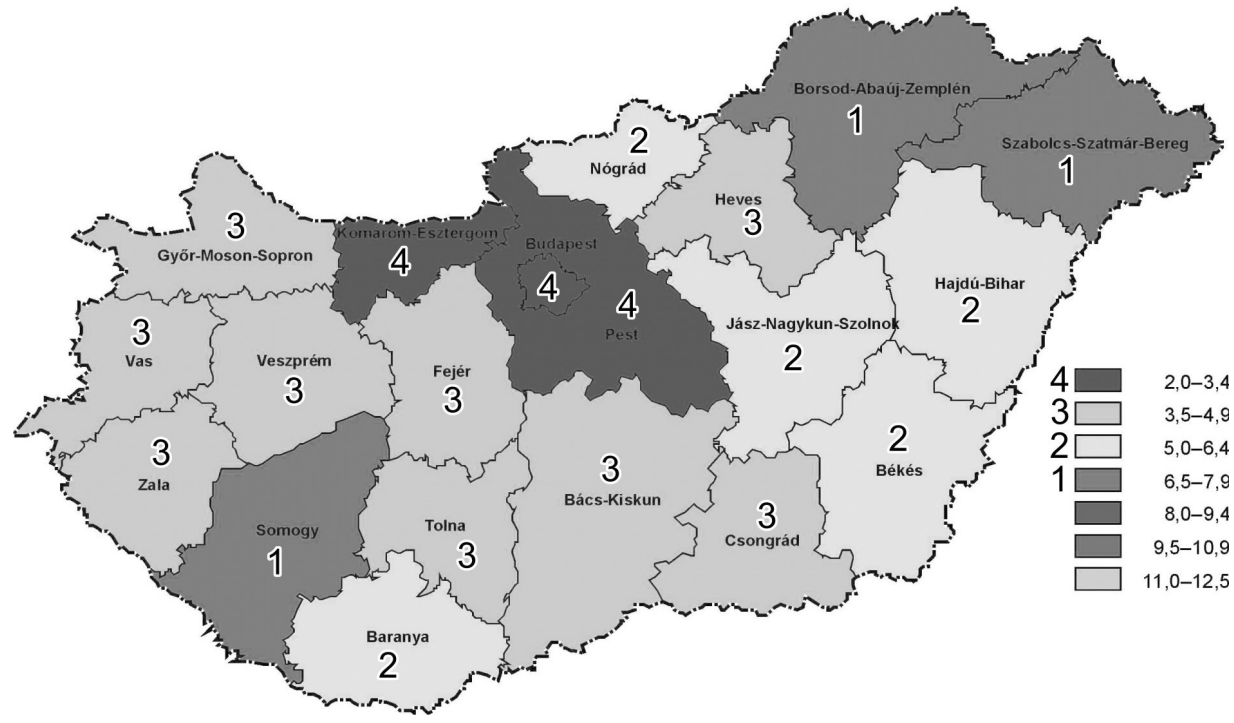

Figure 4. Share of unemployment in 2005

Source: National Micro-Census, 2005. 


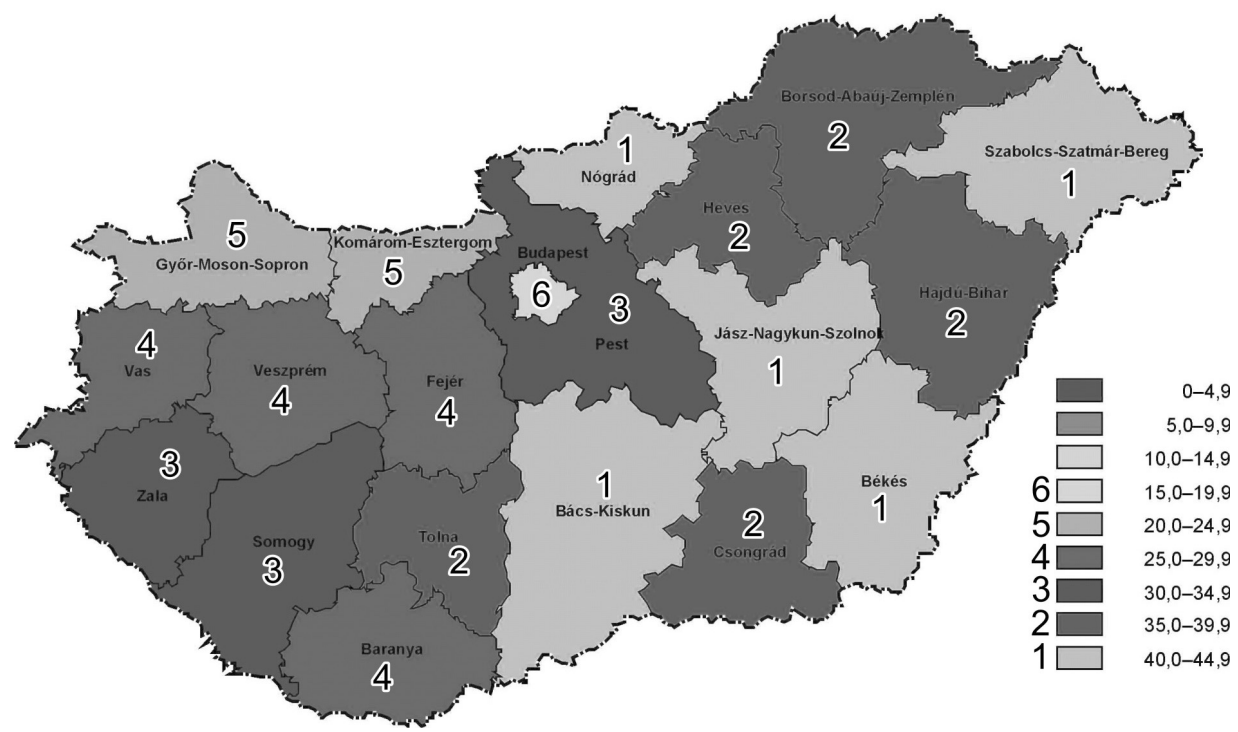

Figure 5. Rate of non-comfortable housing units in 1990

Source: The author's own calculation based by the data of National Census, 1991

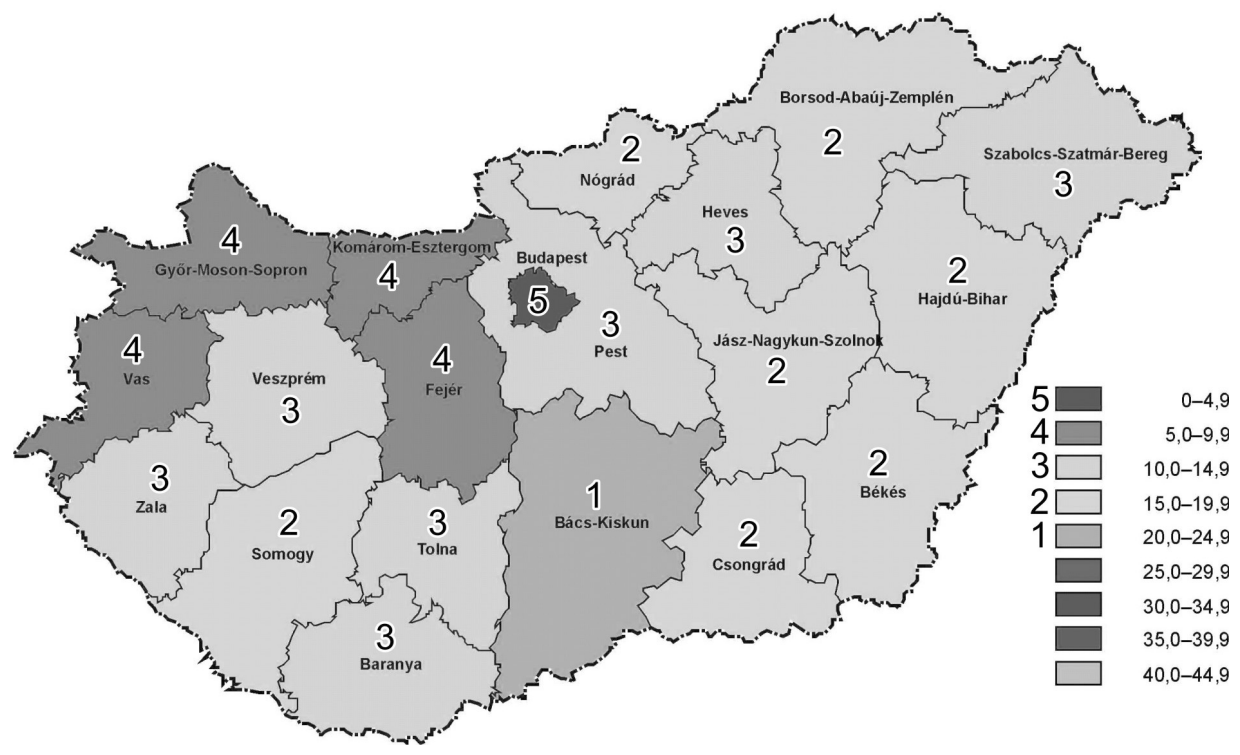

Figure 6. Rate of non-comfortable housing units in 1990 Source: National Micro-Census, 2005. 


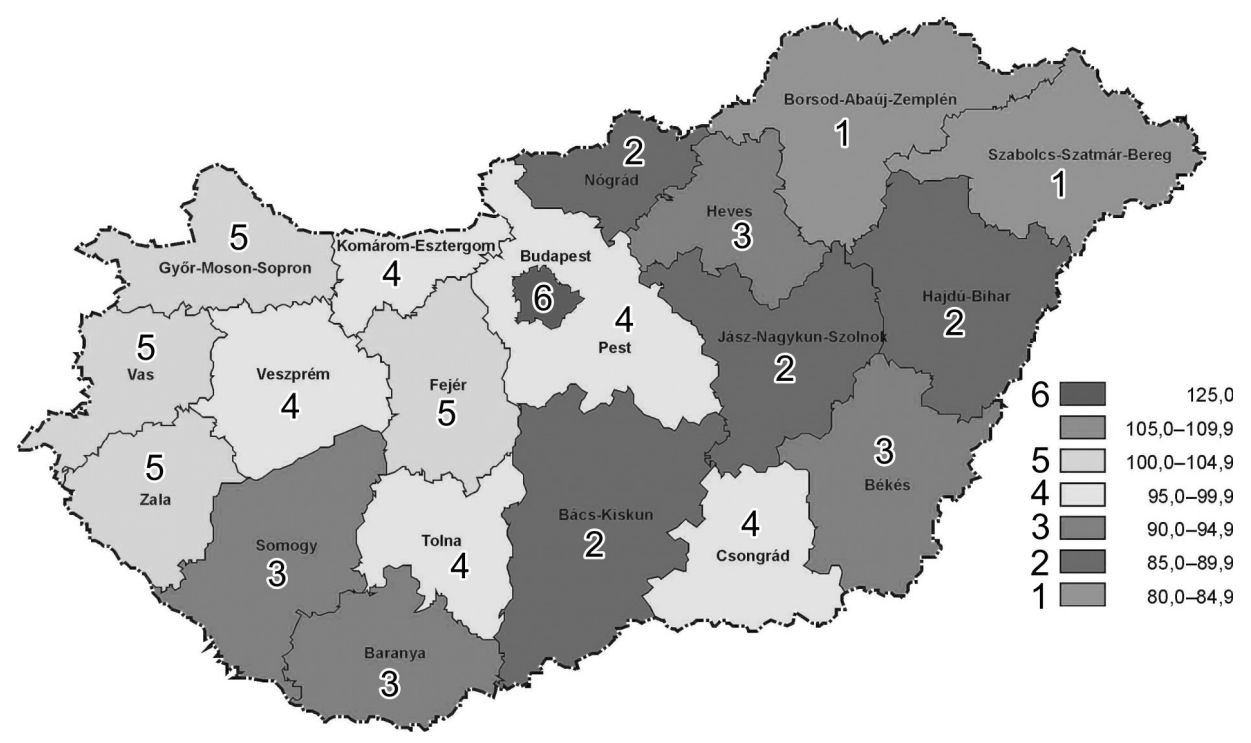

Figure 7. Purchasing power by counties in percent of national average, 1998 Source: GfK, Hungária, 2000.

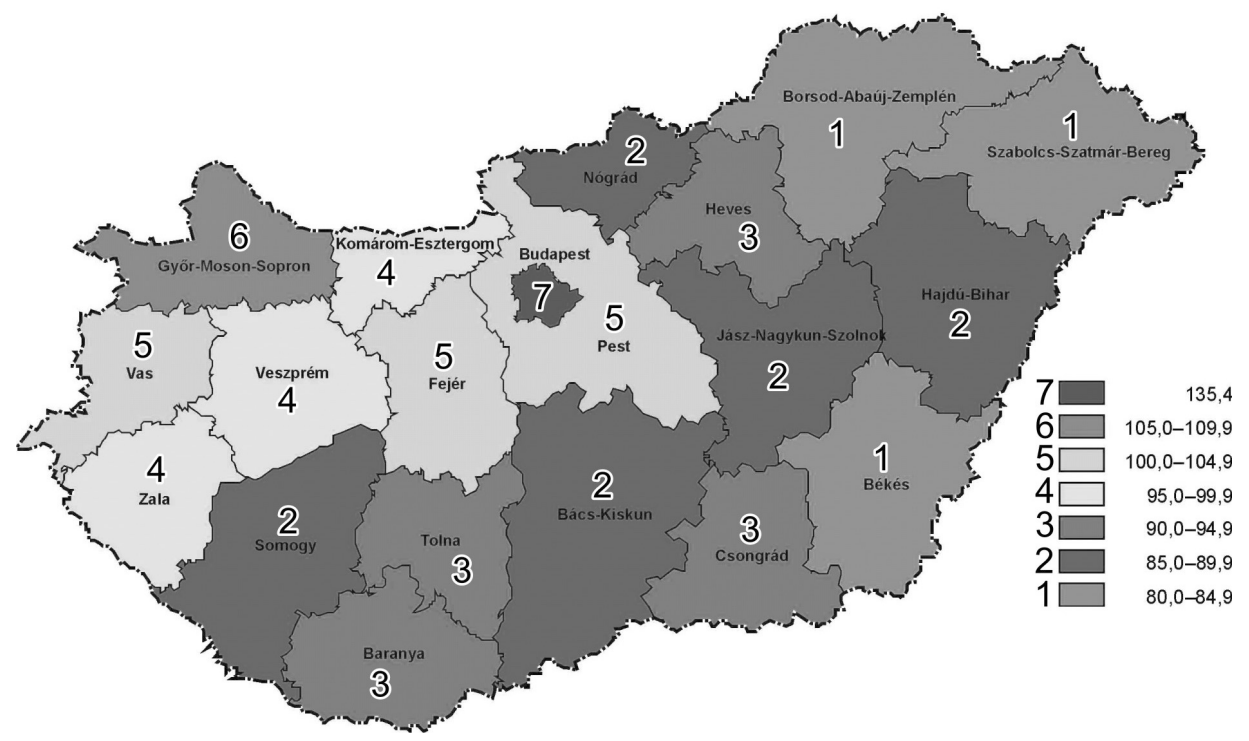

Figure 8. Purchasing power by counties in percent of national average, 1998 Source: GfK, Hungária, 2007 


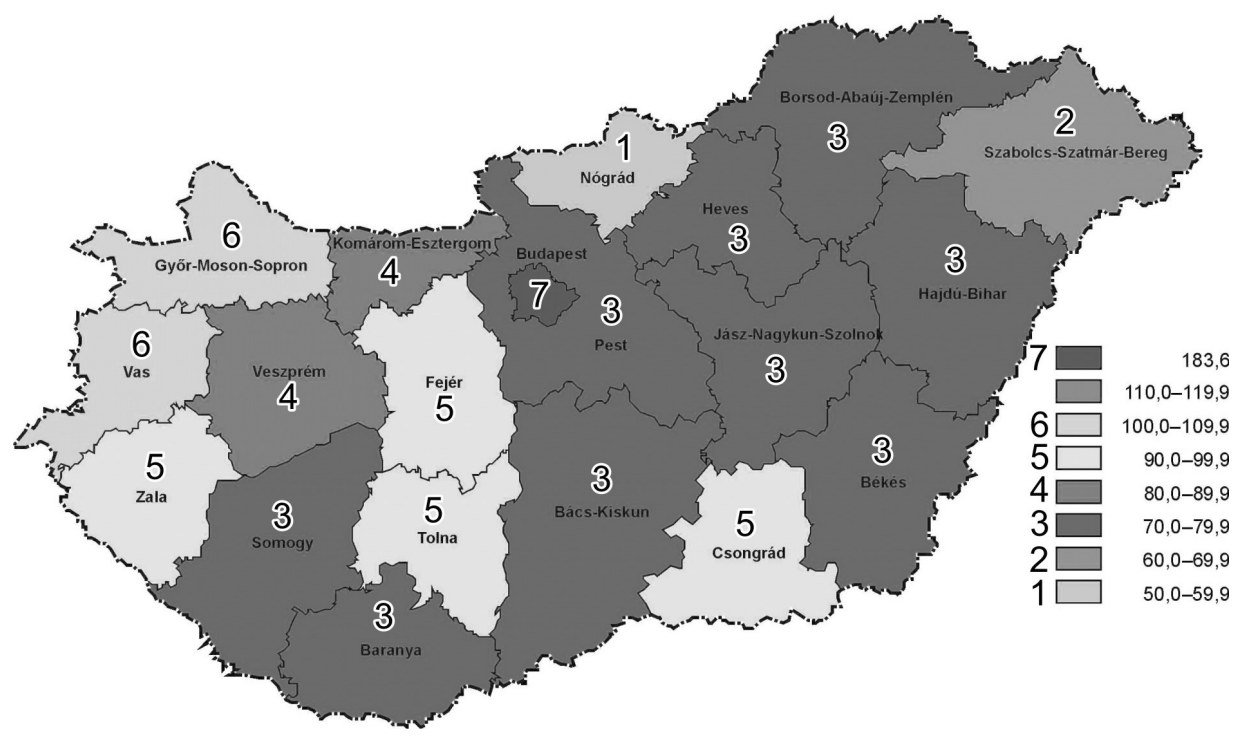

Figure 9. GDP per capita by counties in 1995

Source: KSH, 1997.

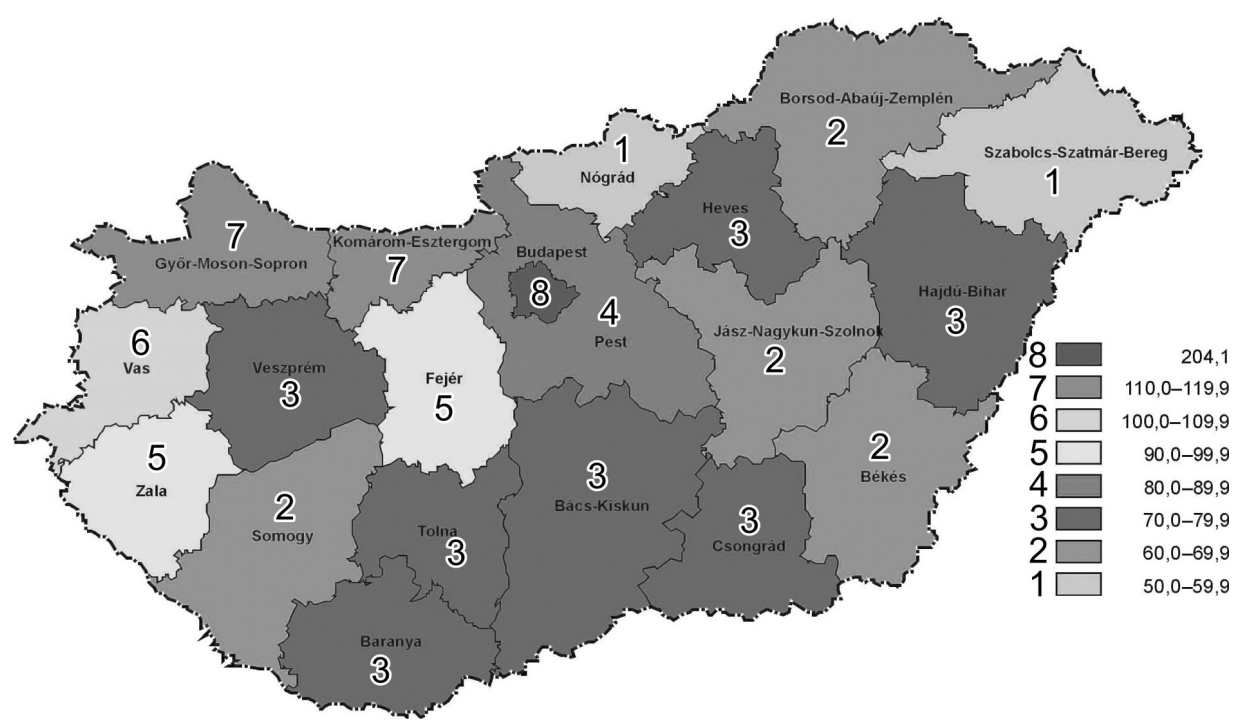

Figure 10. GDP per capita by counties in 2004

Source: KSH, 2006. 


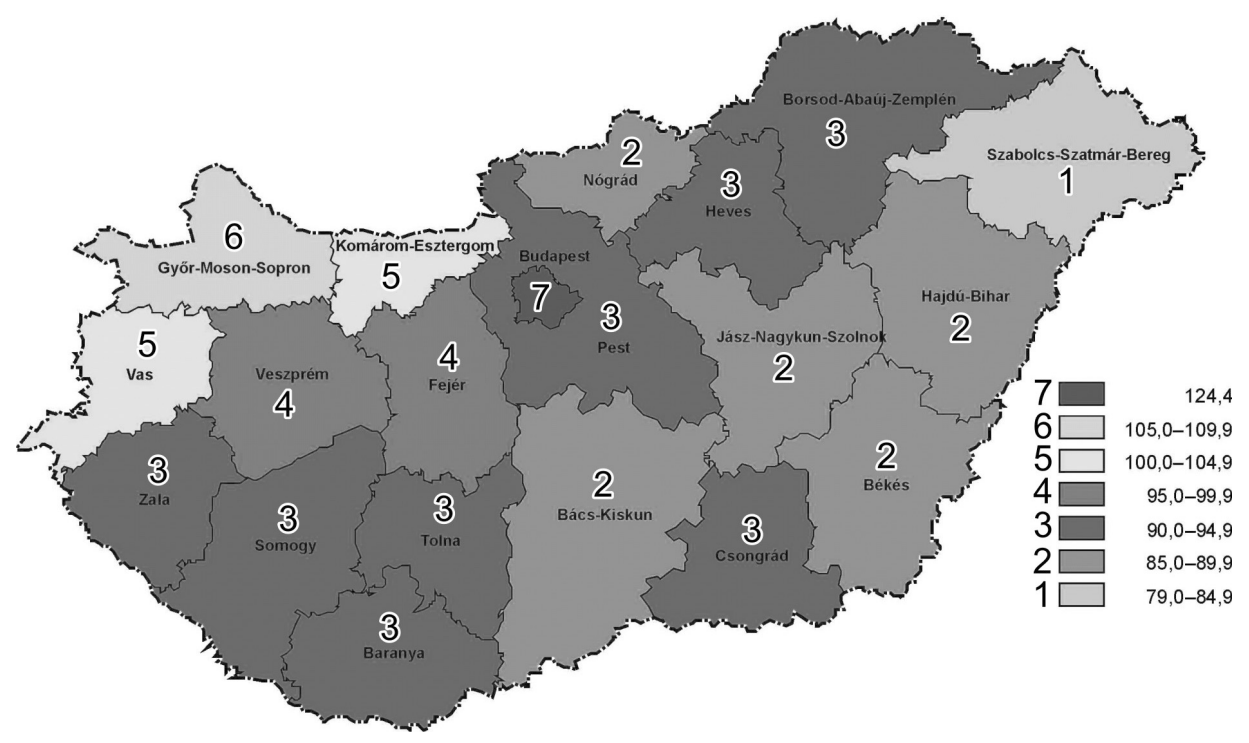

Figure 11. Human Development Index (HDI) by counties in 1990

Source: The author's own calculation.

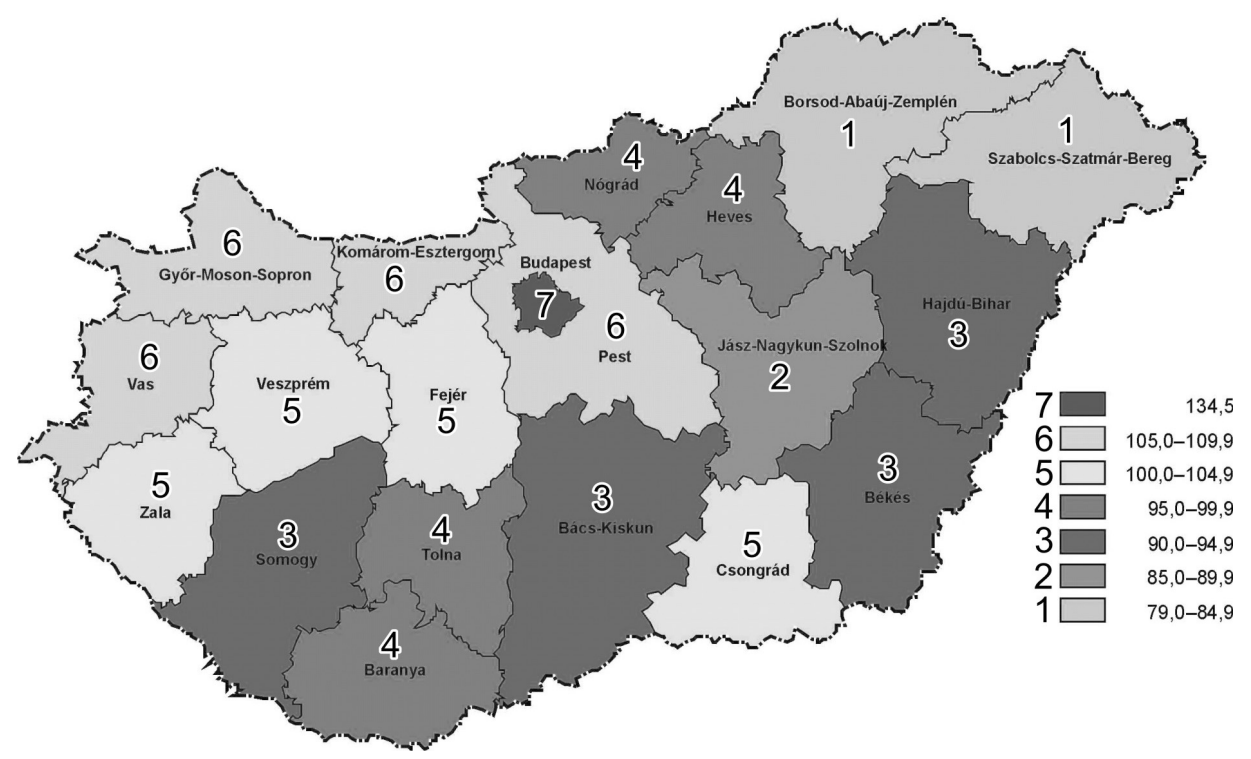

Figure 12. Human Development Index (HDI) by counties in 2004 Source: The author's own calculation. 
BCl@PAN http://bibliotekacyfrowa.pan.pl 


\title{
REPORT ON UKRAINIAN REGIONAL POLICY. THE MAIN TRENDS OF REGIONAL POLICY FORMATION IN CONDITIONS OF REALIZATION UKRAINIAN EURO-INTEGRATION STRATEGY
}

\author{
SVITLANA PYSARENKO \\ Institute of Regional Researches \\ National Academy of Sciences of Ukraine \\ Kozelnytska 4 29026, Lviv, Ukraine \\ e-mail: prosvetka@mail.ru
}

\begin{abstract}
This paper presents shortly the common regional policy of EU, which now is based on theory of "new regionalism" and on three principles: the subsidiary, the decentralization and the partnership. The regulation of EU regional policy provides for a wide variety of form and methods for the organizational and economic stimulation of region development. The author aim is presented the Ukrainian policy and strategy to integration into EU.

Key words: regional and national policy, development, European Union, Ukraine
\end{abstract}

The regional policy is of great importance for the strategy of Ukrainian integration into EU. The efficiency of Ukrainian integration into EU depends greatly upon the correspondence of the main principles of Ukrainian regional policy with European standards. There is a great diversity of means, which used to solve regional problems relating to the territorial distribution of labour and interregional cooperation, the restructuring of industrial regions and the modernization of infrastructure, the improvement of ecological situation and the betterment of competitive abilities.

The common regional policy of EU is based on theory of "new regionalism". Its impact had strengthened in the middle of 1980's. According to this theory, the regional development, depend on the use of endogen regional potential. This approach shifts the emphasis from direct government regulation to "self-reacting mechanisms" formed 
in the regions. Now the regional policy of EU is based on three principles: the subsidiary, the decentralization and the partnership. In the connection with European integration, the regional policy of EU purposes following objects:

- strengthening the economic and social unity;

- long-run developing;

- searching the optimal balance between competition and cooperation and improving competitiveness of EU;

- essening the gap in economic developments at public and European levels;

- coordinating actions at EU, transnational and national levels.

One of the necessary conditions for EU activities is a high level of social-economic convergence. The unification of criteria, which let national governments determine problem regions, is of high importance. In EU there have been implemented Common Classifications (NUTS 1, NUTS 2, etc.) of all territorial entities, which now is based on following criteria: unemployment rate, the trends of migratory streams, income per capita, the specific weight of agricultural production and collapsing industries in GDP. That is why one of the necessary conditions for EU activities is a high level of social-economic convergence. Central regions of northern EU members are considered to be the most developed. The remote regions of southern members-Italy, Spain, Portugal, and Greece-pass for agrarian and agrarian-industrial. At present, the belt of central regions in Western Europe includes the area between two main thoroughfares: Glasgow-Manchester-London-Paris-Lyons-Marseilles and Randstad-Ruhr-Zurich-Rome-Naples (Albrechts 1991, p. 22). These regions are notable for high income per capita, polyfunctional and dynamic development and increasing investment activity.

The remote regions are characterized by relatively low income per capita, big share of people engaged in agriculture. There is a number of prerequisites determining the regional policy in EU members. First, the policy should have effective legislative base. The regional policy suggests a number of region development ways. The selection should be made according to legislative in force in order to provide the consistency and transparency of the policy, the proclamation of its results. Second, the regional policy should be carried out in long run. Third, the regional policy should be market-oriented. Its aim is to create conditions that ensure the most effective development of market economies. Forth, the regional policy has to be territorially specified. Fifth, the regional policy demands to coordinate political approaches.

The economic mechanism of EU region development provides for:

- direct financing;

- budget equalization;

- invest stimulation (invest grants, subsidies)

- tax stimulation (tax credits, transfers, the redistribution of tax authorities)

The organizational mechanism of EU regional policy stipulates for the system of territorial development planning, which includes two sub-systems-spatial planning 
and region development planning (comprehensive approach to the forming of region concept). The sub-system of region development planning (programming) makes provisions for region development programs, elaborated by common government procedure. The institutions, which are directly engaged in region development (besides public authorities and local governments) are following: the municipality associations, the national and local agencies of region development; the Chambers of Commerce and Industry; technopolises, innovation and business centres; regional financial companies; business incubators; venture enterprises; guarantee funds (Lendiel 2001, p. 82-83). The activity of region development agencies notices the special attention. Their main tasks are:

- to provide information and consultations on enterprise management, investment attraction, new technologies transfer;

- to deliver financial resources (credits, loan guarantees, grants, subventions mainly for small and medium-sized enterprises);

- to create the enterprise infrastructures (technological bases and business incubators, premises for lease) (Local economic development...1995).

The regulation of EU regional policy provides for a wide variety of form and methods for the organizational and economic stimulation of region development. The general trends of the regulation of regional policy are following:

- the perfection of administrative-territorial system;

- the clear definition of regional policy object on the base of specific administrativeterritorial systems and historical features of development;

- the strengthening of government stimulating to advantage the regional initiatives and the economic potential of regions;

- fostering the structures which ensure the harmonization of different interests;

- providing the legislative base to realize regional policy;

- the functioning of long-run planning for region accomplishment.

Taking EU experience into consideration, the governmental support of Ukrainian regions should be aimed at the stimulating their economic development, the strengthening of their competitiveness, and, to a certain extent, at the compliance of budget needs and financial assistance. Such orientation of social-economic policy has to improve the budget self-sufficiency of regions by the change of the tax levels and structure, the distribution of government costs among budget levels etc). The direct address government regulation of region development-in forms of investment, subsidies, subventions for specific economic units-and the social sphere of regions should be made on the common base (state-region) in combination with state guarantees, specific-purpose crediting, etc. The efficiency of government programs should be improved while concentrating the resources mainly on interregional programs. Thus, the macroeconomic regulators (preferential tax treatment, crediting, etc) differentiable on regions should be used more extensively to strengthen the operative control of economic preferences utilization. 
Ukraine is on the way of European integration and it is necessary to take into consideration the experience of EU Common Regional Policy, and regional policies of EU members. First of all it applies to the problem of the social-economic differentiation of Ukrainian regions. Over past decade, there has been a trend of the aggravation of differentiation in the levels of social-economic development of Ukrainian regions. Now in some regions the difference in incomes per capita amounts to $35-45 \%$, while according to international norms it should not exceed $20 \%$.

In accordance with European Commission findings, one of the main reasons of the erratic regional development of EU members is the difference in region competitiveness. In Ukraine the region competitiveness may be represented by four groups of regions. They were picked out on the base of cluster analysis. First group is formed by Kyivs'ka, Zakarpats'ka, Poltavs'ka, Zaporiz'ka, Odes'ka regions and Crimea autonomy. Second group consists of industrial regions, which lead the policy of insufficient industry diversification (Donets'ka and Dnipropetrovs'ka); regions, which have outlet to the frontiers (Volyns'ka, Lvivs'ka, Rivnens'ka) and Cherkas'ka region. Third group includes Ivano-Frankivs'ka, Mykolayivs'ka, Khersons'ka, Zhytomyrs'ka, Sums'ka, Ternopil's'ka regions. These regions specialize on industries, which productions are not in requisition on world and national markets. Forth group is formed by highly industrialized regions (Kharkivs'ka and Lugans'ka) as well as traditionally agricultural ones (Kirovograds'ka, Vinnyts'ka, Chernivets'ka, Khmelnyts'ka). The analysis of intraregional changes in this group of regions allows concluding that trans-Ukrainian depressive area has been formed on the line Chernivets'ka—Khmelnits'ka-Vinnyts'ka-Kirovograds'ka regions.

The region competitiveness appertains not only to central authorities but to local authorities as well. Thus, both macroeconomic and intraregional policies should be aimed at the forming of region competitiveness. The government measures of the support and improvement of region competitiveness provide for:

- strengthening the governmental regulation of structural transformations and forming the industry structure which is in line with competitive advantages;

- reinforcing the government impact an order to create the effective conditions for infrastructure development, skilled labour, modern scientific and technical achievements, the favourable tax and monetary policies of market regulation;

- stimulating the domestic competition;

- creating the system of technical and technological standards in order to exclude low-quality products;

- stimulating the leasing mechanisms and other forms of indirect crediting;

- improving the legislative positions on competition in Ukraine and partial converging the Ukrainian and EU legislations in the sphere of competition policy;

- controlling the state commercial monopoly and improving the current legislation in order to ban the discriminatory practice of state commercial monopoly while buying or selling goods;

- reforming the sector of natural monopolies; 
- forming the institutional foundation-non-governmental organizations which engage with competition development and the protection from unfair competition by means of the informational system of Ukrainian Antimonopoly Committee bodies;

- creating the clusters (according to Porter, cluster is a vertically integrated structure which combines different parts of processing chain from raw material suppliers to final producer) which are going to enforce the regional management on the base of interindustry and regional cooperations.

Thus, the question is the forming of regional regulative mechanism, which would help to improve the region competitiveness. The competitiveness strategy should be developed for every region. This strategy should stipulate for:

- the estimation of region competitiveness along with the determination of conditions and factors favourable for effective competition;

- the substantiation of priority industries, productions and products which can obtain short-run competitive advantages on regional, national or world market; the defining of methods and measures for development contribution;

- the considering of the experience of EU members during administrative and territorial reform.

\section{REFERENCES}

Albrechts, L. (1991), Shifts in Europe and their impact on the European spatial structure, An Enlarged European Region in Competition.

Lendiel, M. (2001), Special'ni istituti rozvitku teritorij: yevropejs'kij dosvid ta instrumenti rozvitku teritorij na shliakhu yevropejs'kikh principiv, K. Millenium.

Local economic development incentives and international trends (1995), Westwiew Press. Ballassa, B. (1989), Comparative advantage trade policy and economic development, Harvester Wheat sheaf, New York, 41-79.

Hueglin, T. O., Regionalism in western Europe: conceptual problems of a new political perspective (1986), Comparative Politics, 18, 4, 439-458.

Szell, G. (1999), Democracy and sustainable development, in: Environment in the 21st century-environment, long-term governance and democracy, Harmattan, Paris.

Europe at the service of regional development, European Commission, Brussels. 
BCl@PAN http://bibliotekacyfrowa.pan.pl 